\title{
MODULAR, HIGH-VOLUME FUEL CELL LEAK-TEST SUITE AND PROCESS (PHASE I)
}

\section{FINAL TECHNICAL REPORT}

CONTRACT PERIOD: $\quad$ SEPTEMBER 2008 - JUNE 2011

PRIMARY CONTRACTOR: ULTRACELL CORPORATION

SUBCONTRACTORS: PACIFIC NORTHWEST NATIONAL LABORATORY

CINCINNATI TEST SYSTEMS

PRINCIPAL INVESTIGATORS: RU CHEN, PH.D.

IAN KAYE

ULTRACELL LLC

399 LINDBERGH AVENUE

LIVERMORE, CA 94551

JANUARY 2012

Disclaimer: On August 1, 2011 the assets of UltraCell Corporation, including IP, technical know-how, inventory, equipment, etc. were purchased by Bren-Tronics Inc (Commack NY) and assigned to a new company called UltraCell LLC, a wholly owned subsidiary of Bren-Tronics Inc. The core technical team from UltraCell Corporation also transitioned to UltraCell LLC. This report was voluntarily prepared by UltraCell LLC; however UltraCell LLC is not contractually bound to prepare this report and is not liable for any content. UltraCell LLC is not contractually bound by any of the contractual terms (CDRL, data rights, etc.) that UltraCell Corporation agreed to when UltraCell Corporation accepted the contract for which this report was written. The contract for which this report was written remains the sole responsibility of UltraCell Corporation, and this contract was not novated to UltraCell LLC. UltraCell LLC cannot guarantee the accuracy of this report. 


\section{EXECUTIVE SUMMARY}

Fuel cell stacks are typically hand-assembled and tested. As a result the manufacturing process is labor-intensive and time-consuming. The fluid leakage in fuel cell stacks may reduce fuel cell performance, damage fuel cell stack, or even cause fire and become a safety hazard. Leak check is a critical step in the fuel cell stack manufacturing. The fuel cell industry is in need of fuel cell leak-test processes and equipment that is automatic, robust, and high throughput. The equipment should reduce fuel cell manufacturing cost.

For UltraCell fuel cell stacks, all manufacturing steps are carried out manually, and the process is labor-intensive and time-consuming. The throughput time (the elapsed time between parts entering and stack exiting the manufacturing process) is about seven hours. Stack break-in process is a dominant factor determining the throughput time. The yield of the stack built is not stable, and it highly depends on the quality of incoming parts, especially MEA, and skills and experience of stack builders. Several failure modes have been identified: external leak, crossover leak, low open circuit voltage (OCV), low fuel cell voltage, and negative cell voltage. To increase the stack yield, these failures must be significantly reduced.

The stack build history was reviewed and analyzed in an effort to better understand the various failure modes, their root causes, and the component and process parameters which contribute. The inspection data of bipolar plate (thickness, socket depth, flow channel depth, and flatness) were collected. The dimensional variation of stack components was analyzed to determine whether it is a major source of stack failure. Pin-hole and machining defects were found on bipolar plates. An incoming part inspection procedure was created to screen bipolar plates for these defects.

Individual fuel cell stack components were characterized using conventional mechanical analysis techniques. Compressive Young's modulus of individual component can be obtained from the static stress scan test. The creep of stack components under constant load can be obtained from the creep and recovery test. The frequency scan and dynamic temperature scan are not very informative for some gaskets due to the small thickness. The static stress and creep and recovery 
tests are very important for the selection of materials with better sealing properties. The test results also help us better understand the stack behavior during manufacturing and operation, identify the root causes of fuel cell stack leakage, and reduce the stack failures.

A finite element model capable of modeling the dynamic mechanical properties of fuel cell stacks was developed. This effort is critical in understanding how complex assemblies such as fuel cells actually respond to the applied dynamic forces.

Several leak-test methods were investigated. Crossover current test, current interrupt test, and open circuit voltage decay test can be used to detect crossover leak in fuel cell stacks. All three methods are capable of pinpointing the location of crossover leak. However, current interrupt test is not very sensitive, and it does not meet the detection limit required for fuel cell stacks. Crossover current test and voltage decay test have good sensitivity and are easy to implement. These two methods and pressure decay test were selected for fuel cell stack leak test.

The fuel cell stack quality metrics were created based on typical measurement values obtained from production of stacks. A specification for the Stack Quality Characterization System (SQCS) prototype was developed. The specification includes required functions, detail procedures to perform these functions, hardware, software, graphical user interface, gas interface, electrical interface, heating system, and compression stand. The prototype was designed with functions and features for research and development as well as manufacturing uses. The SQCS prototype was then fabricated. The leak-test suite prototype was installed at UltraCell facility at Vandalia, $\mathrm{OH}$. The prototype was then tested and evaluated. The prototype can performs all manufacturing processes which include inline leak-test, compression, bolting, break-in, and performance test. All these processes except bolting are carried out automatically. The prototype monitors all processes, quickly identifies failures, and provides diagnostic information. Safety features were implemented in the prototype to protect operator.

The results obtained on the new automated test protocols on the new instrument were directly compare with old existing manual test protocols. It was demonstrated that the new instrument can reliably detect individual cell failures. Leak-test capability was greater than 5 stacks/hour. 
UltraCell personnel and PNNL were trained to use the prototype. The fuel cell stack and system tests demonstrated that the SQCS process do not introduce new failure mode to fuel cell stacks. 


\section{INTRODUCTION}

The portable personal electronic devices are widely used in our daily lives. These devices include cell phones, digital cameras, music players, DVD players, game players, e-readers, notebook computers, tablets, and many other devices. The demand for power for these devices increases dramatically. In 1990, the average American consumed 500 watt-hours for his/her portable electronic devices. Today, each person needs more than 100,000 watt-hours. The power for these portable electronic devices is exclusively provided by batteries. The world battery market is projected to be over $\$ 100$ billion by 2016. Portable fuel cells offer some competitive advantages over batteries. Fuel cells are lighter and have longer run time. Portable fuel cells can be a replacement of batteries. They can be used to charge batteries. Portable fuel cells can be used in areas that the reliable power grid does not exist. They can be used as power sources for boating, recreational vehicles, and camping. They can be used to power electronic devices in emergency response, law enforcement, and surveillance. Portable fuel cells have many potential applications in the military. These applications include individual service member's power needs, field electronics such as computers and phones, forward operating base (FOB), squad power, and unmanned autonomous systems (UAS). Pike Research believes the current period of product development will lead to commercialization for portable fuel cell at a larger scale starting in the 2015 timeframe. The firm forecasts that annual unit shipments of portable fuel cells will reach 7 million per year by 2017. The global market for portable fuel cell will reach $\$ 2.3$ billion by 2016 , up from $\$ 185$ million in 2009 .

UltraCell develops and commercializes an advanced Reformed Methanol Fuel Cell (RMFC) technology originally invented at the U. S. Department of Energy's Lawrence Livermore National Laboratory (LLNL) and Case Western Reserve University. This technology, based on reforming methanol into hydrogen using proprietary technology, enabled a breakthrough in micro fuel cell performance (Figure 1.1). UltraCell was the first company to commercialize ultra-compact RMFC technology to provide clean, renewable energy to power portable electronics. The XX25 and XX55 were the first in their classes to have undergone extensive Military Specification qualification testing and field trials (Figure 1.2, 1.3, 1.4, and 1.5). 


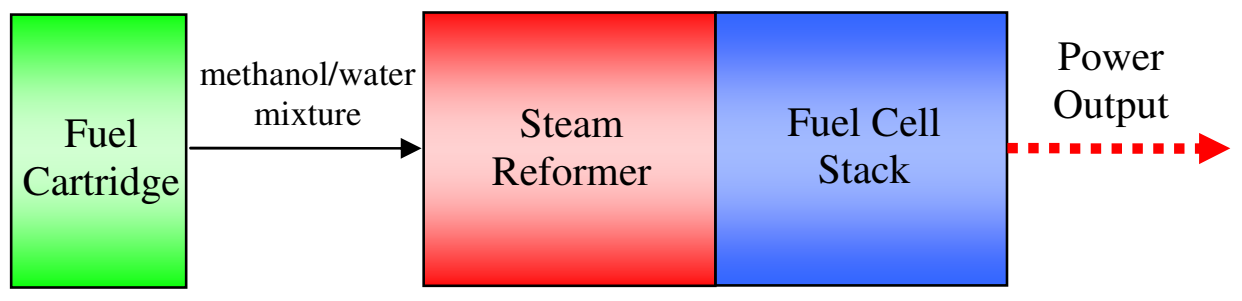

Figure 1.1 Concept of reform methanol fuel cell
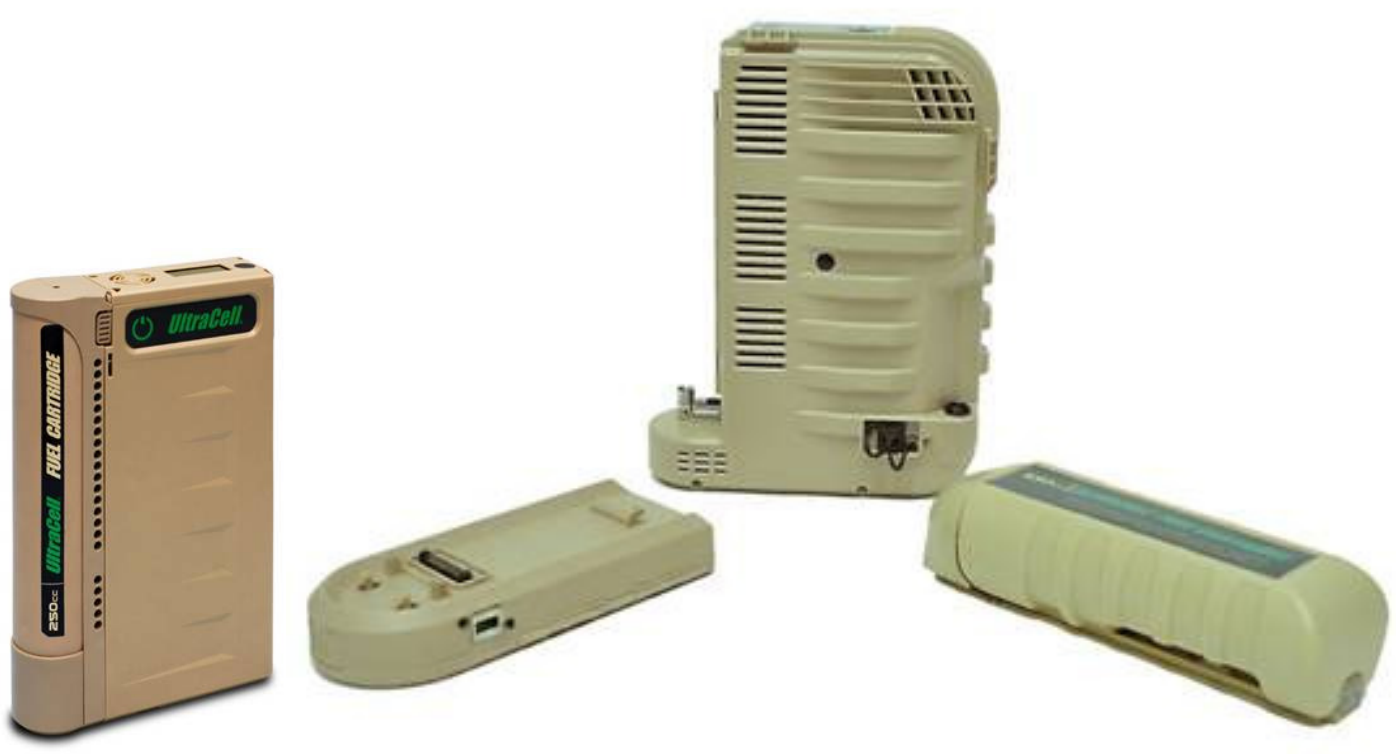

Figure 1.2 UltraCell products XX25 and XX55 


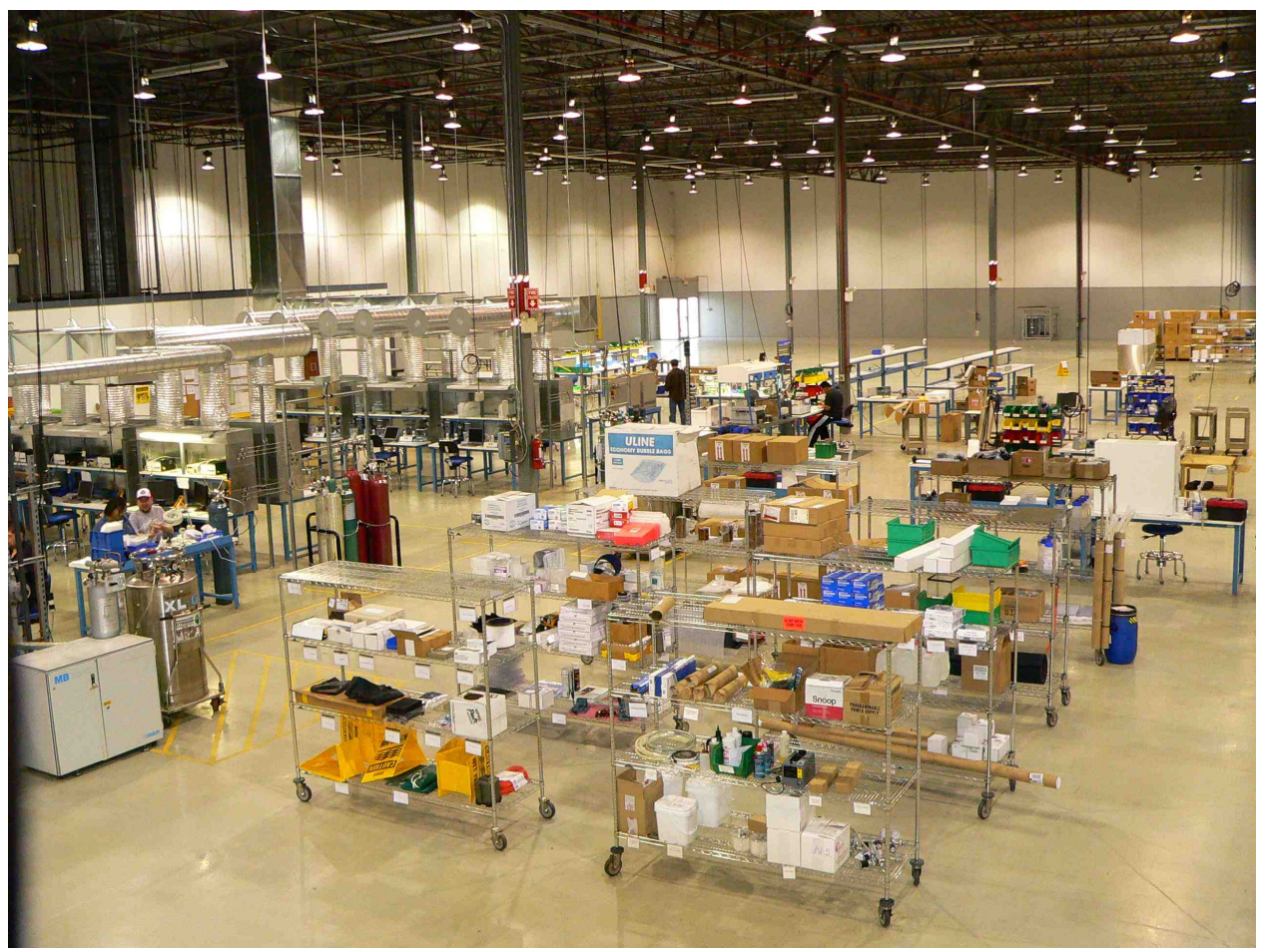

Figure 1.3 UltraCell fuel cell manufacturing facility

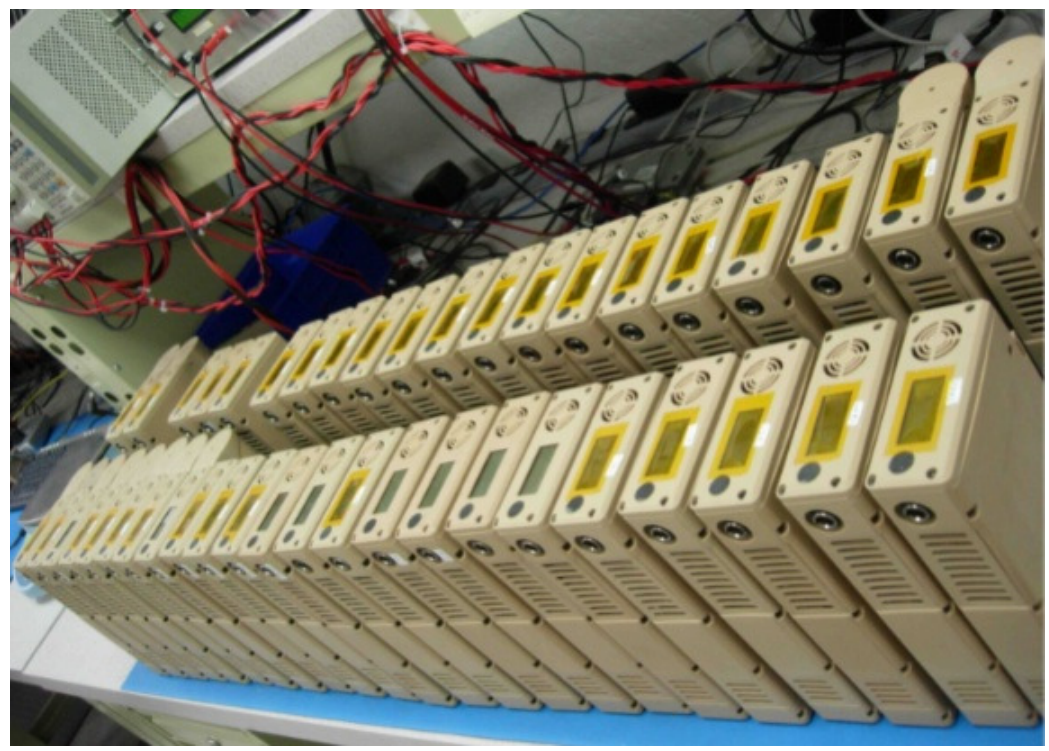

Figure 1.4 UltraCell XX25 systems 


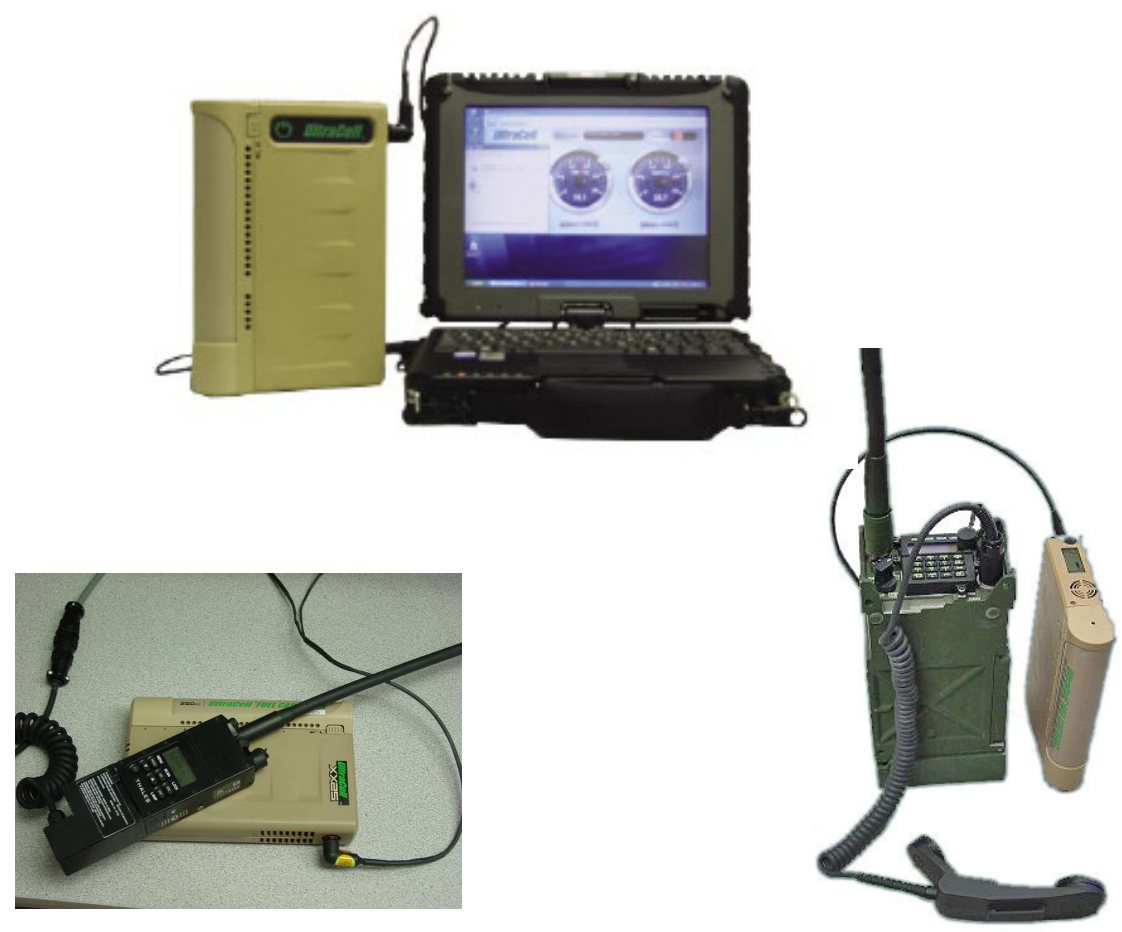

Figure 1.5 Applications of XX25

\section{FUEL CELL STACK MANUFACTURING}

\subsection{Manufacturing Process}

Fuel cell stacks are the most critical parts of fuel cells. They convert chemical energy into electricity. A fuel cell stack mainly consists of membrane electrolyte assemblies (MEA) and bipolar plates (BPP). Other components such as end plates, current collectors, gaskets, gas manifolds, and fasteners are also needed. Stacks for XX25 and XX55 are shown in Figure 2.1. The XX25 stack contains 12 cells while the XX55 stack contains 22 cells.

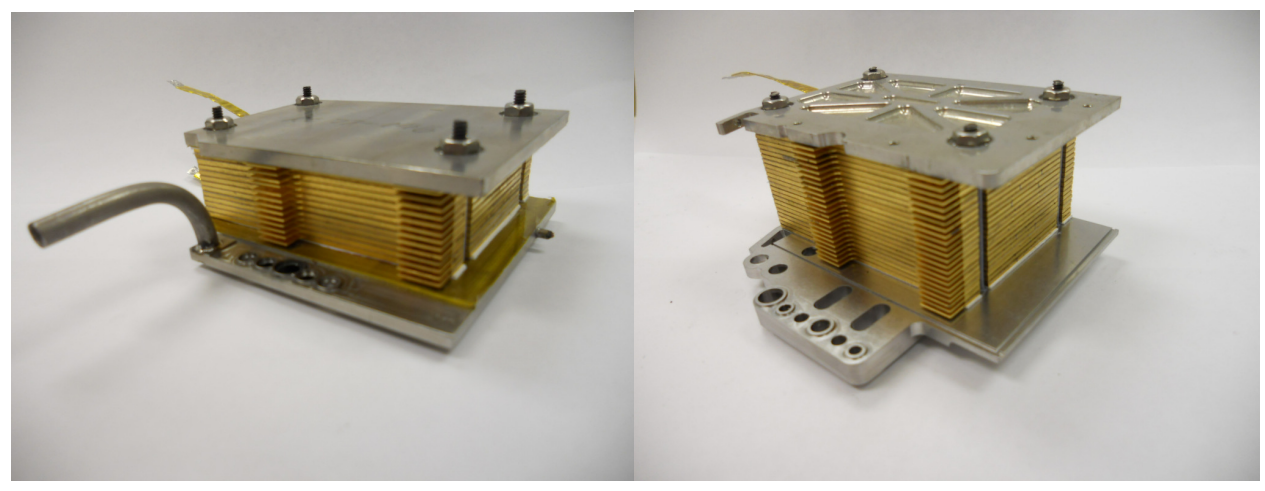

Figure 2.1 XX25 and XX55 stacks 
The manufacturing process of the stack is shown in Figure 2.2. All incoming parts for fuel cell stacks are inspected. Parts that pass the inspection are assembled into stacks. Stacks are compressed and bolted. Leak tests are performed on stacks. Leak-free stacks are conditioned using a break-in process. The performances of the stacks are evaluated at the operating temperature. Stacks are cooled down to the room temperature. The compression and leak of stacks are measured to ensure there is no change before and after the performance test. Qualified stacks are then integrated into fuel cell systems.

All the steps in the stack manufacturing process are carried out manually, and the process is labor-intensive and time-consuming. The throughput time (the elapsed time between parts entering and stack exiting the manufacturing process) is about 7 hours. The dominant factor is the break-in process, and reduction of break-in time has a huge impact on the final design of leak test suite, especially Flexo-Tiltometer. Typical break-in time for phosphoric acid/polybenzimidazole membrane electrode assembly (MEA) is $16-24$ hours. By MEA pretreatment and conditions optimization, UltraCell is able to reduce the break-in time to several hours. The cell voltage reaches more than $95 \%$ of the maximum performance in a short period of time after the beginning of break-in process. The yield of the stack built is not stable, and it highly depends on the quality of incoming parts, especially MEA, fuel cell stack design, and skills and experience of stack builders (Figure 2.3). There is great opportunity to improve the stack yield. Several failure modes have been identified, and they are: (1) external leak, (2) crossover leak, (3) low open circuit voltage, (4) low cell voltage, (5) negative cell voltage, (6) post-break-in external leak, and (7) post-break-in crossover leak. As can be seen in Figure 2.4, the majority of stack failures can be attributed to leakage in stacks. 


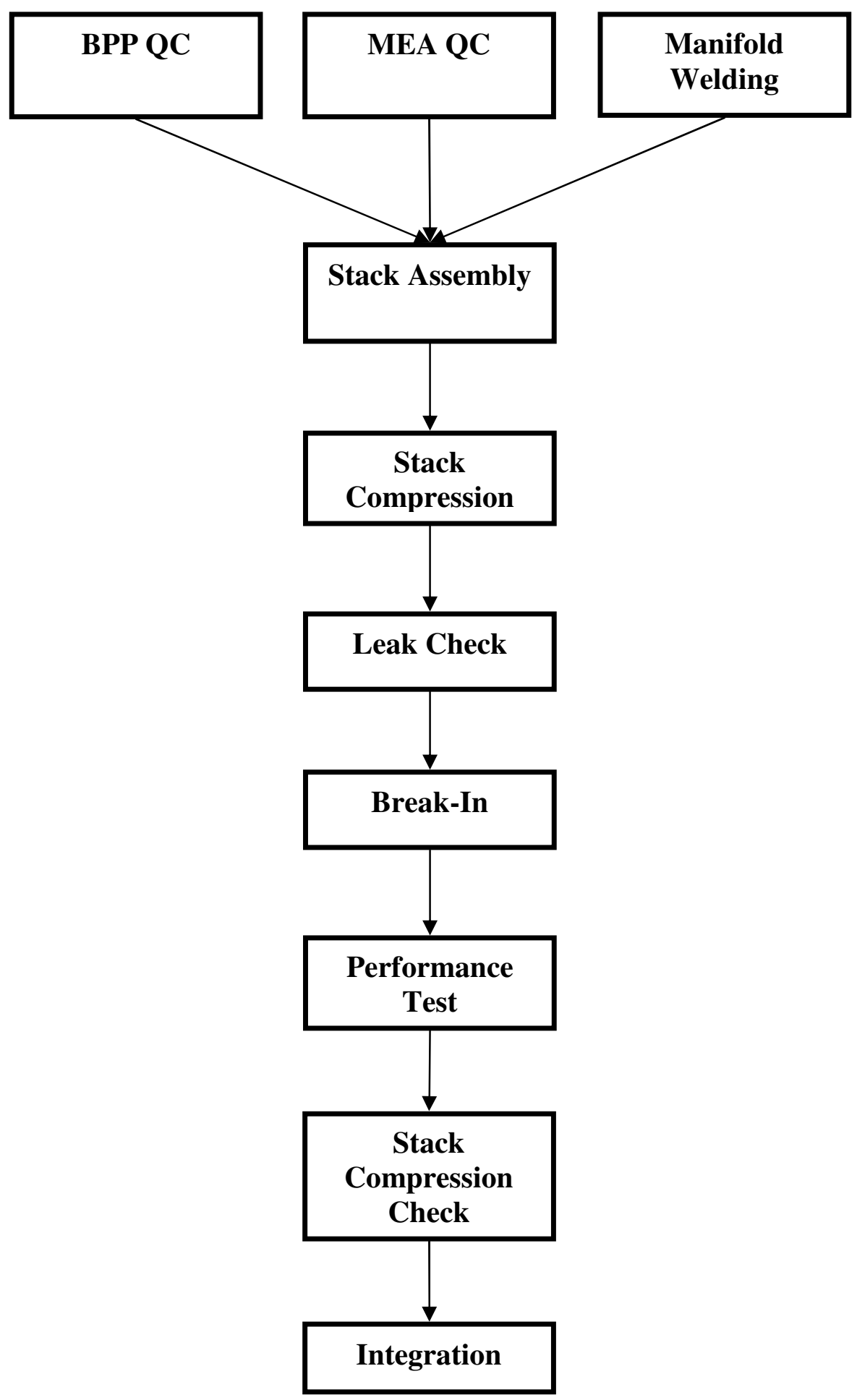

Figure 2.2 Fuel cell stack manufacturing process 


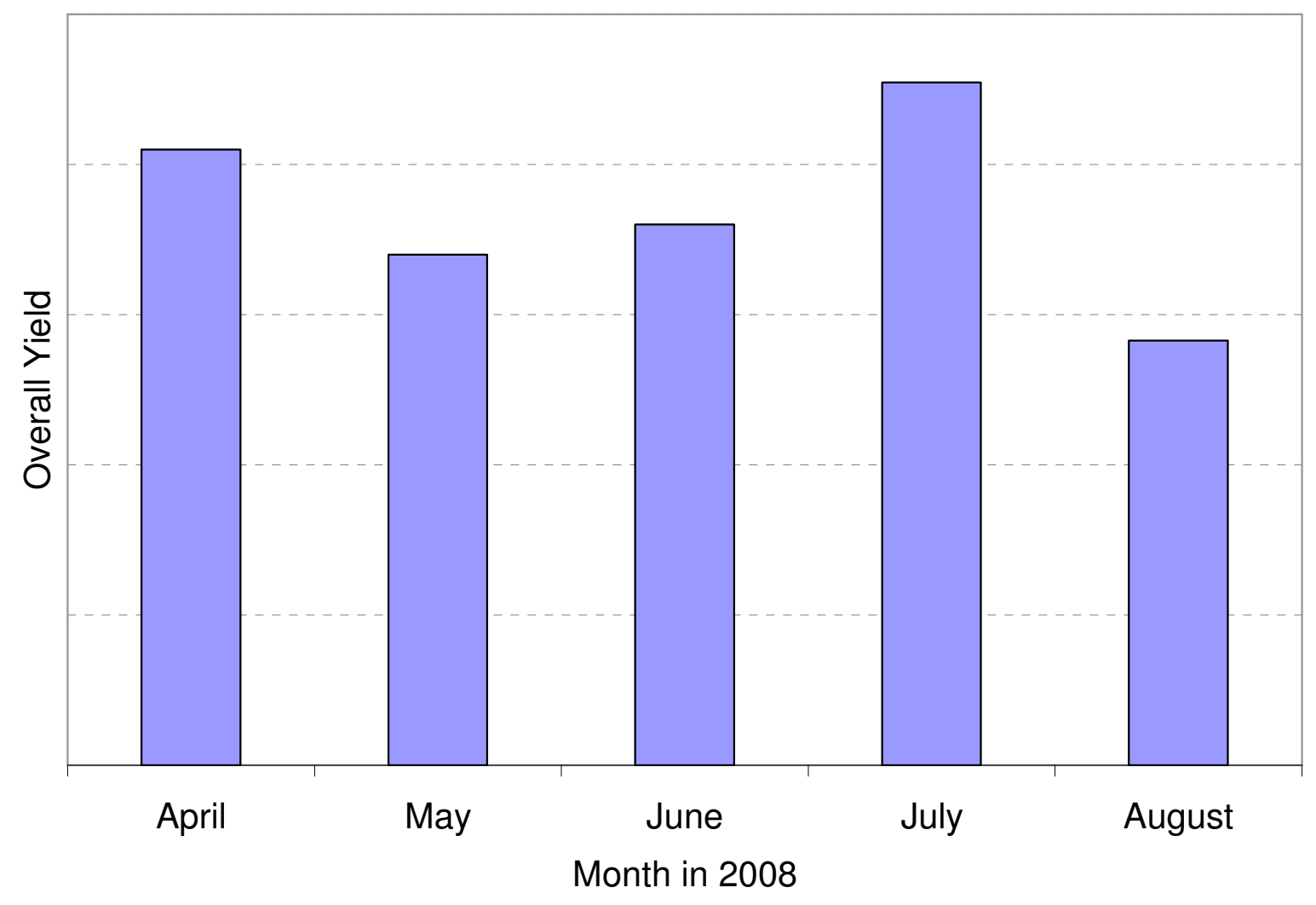

Figure 2.3 XX25 stack production yield 


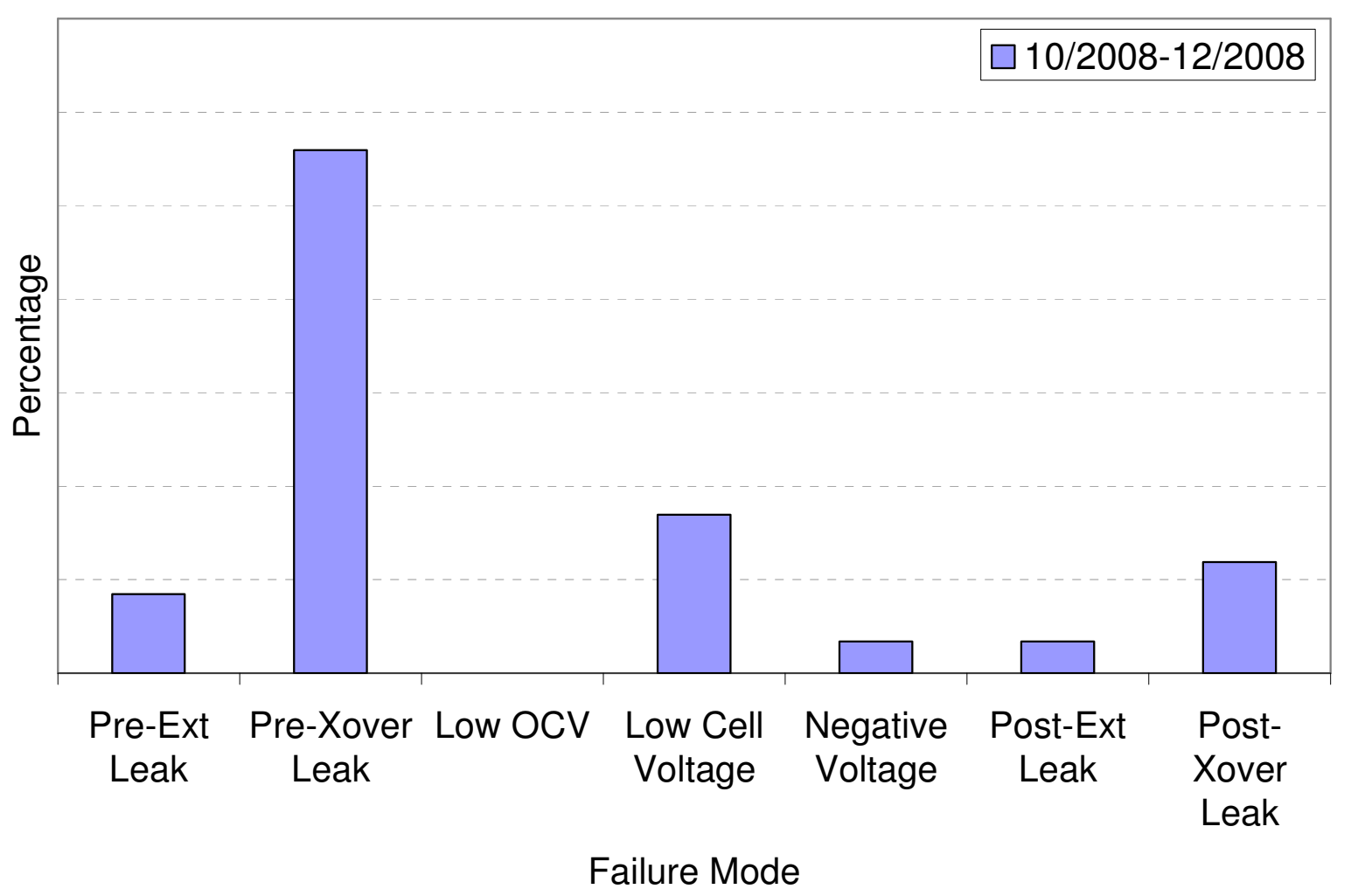

Figure 2.4 XX25 stack failure modes

\subsection{Bipolar Plate Defects}

Initial work was focused on developing linkages between common stack failure modes and the underlying root causes. To this end, UltraCell and PNNL reviewed and analyzed stack build history in an effort to better understand the various failure modes, their root causes, and the component and process parameters which contribute to failures.

All incoming bipolar plates were inspected. The dimension data such as thickness, socket depth, flow channel depth, and flatness were collected (Figure 2.5). The dimensional variation of stack components was analyzed to determine whether it is a major source of stack failure. Pin-holes were found on some bipolar plates. These pin-holes can cause crossover leak in stacks. Some 
manufacturing defects were found on some BPPs (Figure 2.6). These defects change gas flow distribution on an individual fuel cell, resulting in fuel/air starvation.

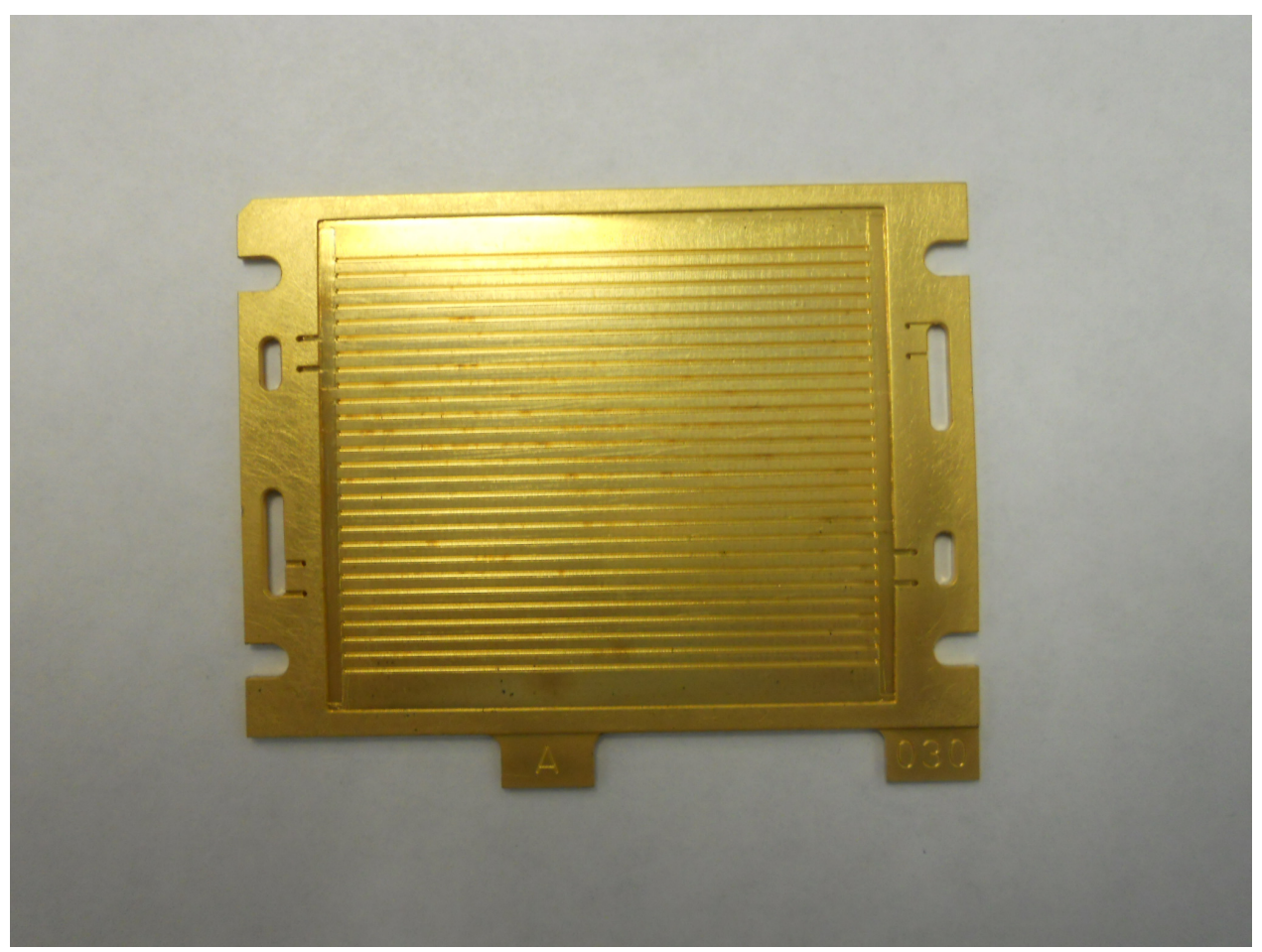

Figure 2.5 Bipolar plate 


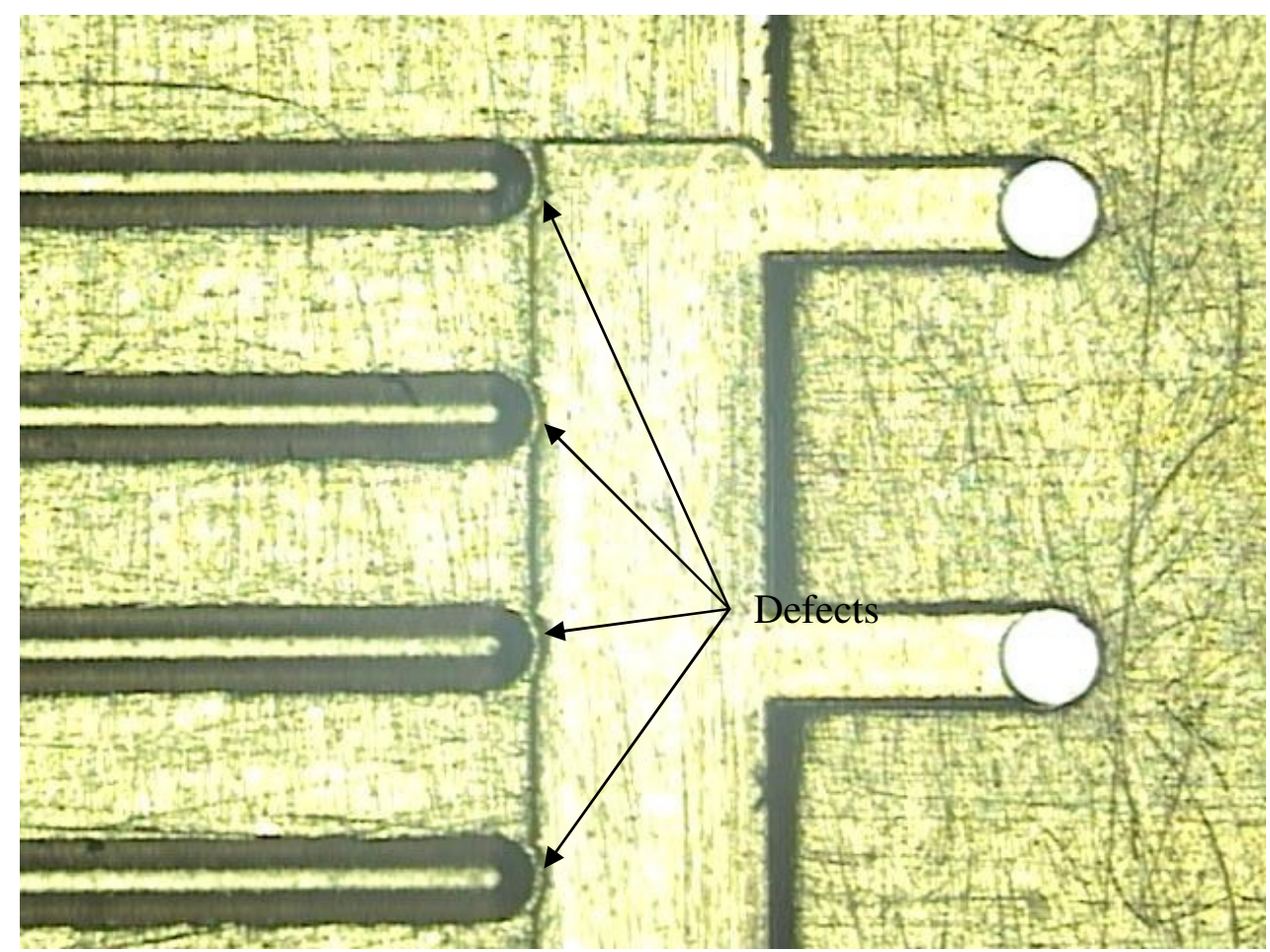

Figure 2.6 Defects on BPP

\subsection{Membrane Electrode Assembly Defect}

One of failure modes we have found in fuel cell stack is low open circuit voltage. The cell components (MEA and BPP) of fuel cells with low OCV were carefully inspected. The anode and cathode gas diffusion layers (GDL) were peeled off from MEAs (Figure 2.7 and 2.8). A defect on membrane was found. The membrane was smaller than the size it should be. When gas diffusion electrodes (GDE) were pressed onto the membrane, the anode GDE contacted the cathode GDE, and formed an electrical short. This kind of membrane defect is not detected until the MEA is built into a stack. The materials for electrodes and labor time for stack assembly and test were wasted. This membrane defect should be detected if an in-line inspection were performed during MEA manufacturing. The incident highlights the importance of in-line inspection in manufacturing of fuel cell components. 


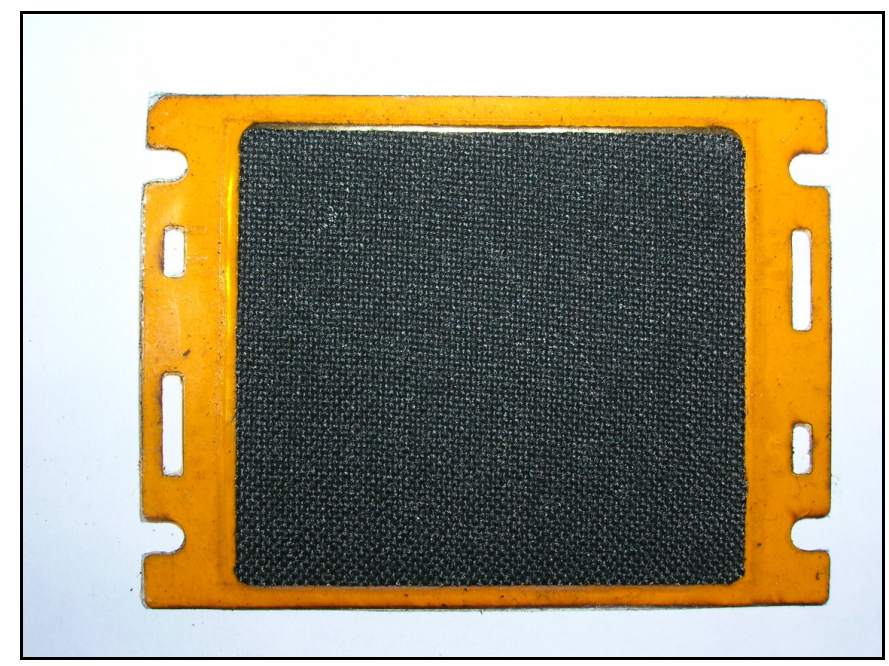

Figure 2.7 Membrane electrode assembly

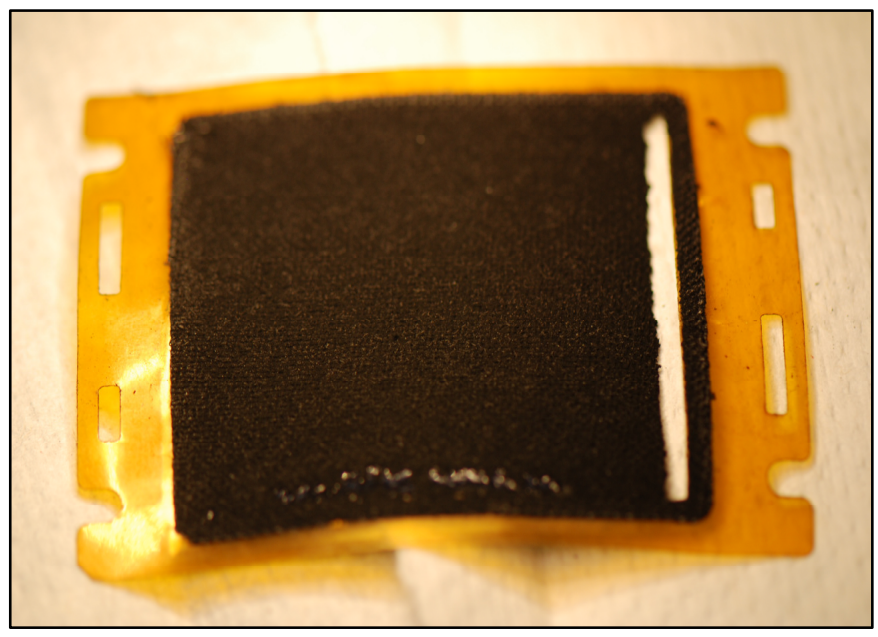

Figure 2.8 Defect in MEA

\subsection{Fuel Cell Break-In}

Fuel cell break-in is very time-consuming. It usually takes $16-24$ hours. This long break-in time limits the throughput of fuel cell stack production. To increase production capacity, more capitals need to be invested in facility and equipment. Materials such as fuel and compressed air are consumed during the long break-in. To lower manufacturing cost, short break-in processes need to be developed. A variety of procedures were investigated to see if the break-in process 
can be accelerated: (1) potential scan from $0-1.0 \mathrm{~V},(2)$ step change of potential from $0-1.0 \mathrm{~V}$, (3) cycling nitrogen and air at the cathode, (4) load cycling between OCV and 0.6 V, (5)

electrochemical hydrogen pump. At UltraCell, a process combined MEA pretreatment and proprietary break-in protocol has been developed to reduce fuel cell stack break-in time to 4 hours or less.

\section{FUEL CELL STACK MECHANICAL CHARACTERIZATION}

\subsection{Dynamic Mechanical Analysis}

In Dynamic Mechanical Analysis (DMA) we wished to examine various dynamic mechanical tests and begin to understand which would be most useful in a fuel cell assembly line. We also wished to qualitatively understand the basic mechanical properties of each component. The objective is to identify whether a component-level DMA signature can be used to predict assembly failure modes and ultimately serve as an incoming material screening method.

Data were taken on a Perkin-Elmer DMA7e. The DMA appears to have very stable mechanical components and is capable of less than $10 \mu \mathrm{m}$ resolution. This is less than the dimensional changes resulting from a 3 degree temperature change. The instrument is more than adequate to obtain quality data. All tests were conducted in a compression mode using a $1 \mathrm{~mm}$ diameter flat tip "disk" pressed into the sample placed on a polished "anvil". The instrument is capable of up to $8000 \mathrm{mN}$ of applied force and for a $1 \mathrm{~mm}$ probe this corresponds to $10.2 \mathrm{MPa}$ or $1480 \mathrm{PSI}$. The following tests were used for experiments:

(1) Static Stress Scan (SSS) - This sweeps the applied force from 0 to $8000 \mathrm{mN}$ (or other desired limits) and records the change in probe position. This is the basic measurement which gives the compressive modulus.

(2) Creep and Recovery (CR) - Force is "instantaneously" applied from $10 \mathrm{mN}$ to 250, 500 or $1000 \mathrm{mN}$, held for some variable time and released. This cycle is repeated. 
(3) Frequency Scan (FS) - At an applied static stress the dynamic stress is oscillated at some constant amplitude but the frequency is varied from 0 to $51 \mathrm{~Hz}$.

(4) Dynamic Temperature Scan (DTS) - Temperature is ramped from $25^{\circ} \mathrm{C}$ to $250{ }^{\circ} \mathrm{C}$ at 5 ${ }^{\circ} \mathrm{C} / \mathrm{min}$ at a constant static stress $(250$ to $500 \mathrm{mN}$ ) and a constant dynamic stress (10\% of static stress) and at a constant frequency of $1 \mathrm{~Hz}$.

\subsection{Gasket A}

The SSS and CR experiments for Gasket A are shown Figure 3.1 and 3.2. In the SSS experiment, Gasket A shows two mechanical behaviors both approximately linear. The initial drop in thickness with applied pressure is probably due either to the roughness present on used Gasket A or from the bonding layer between the two Gasket A sheets. At higher stresses, linear behavior is observed from 120 to 400 PSI. The slope of this line is the Young's modulus in compression.

The CR experiment used $10 \mathrm{mN}$ and $8000 \mathrm{mN}$ as the limiting forces. Application of $8000 \mathrm{mN}$ gives about a $25 \%$ change in film thickness. More importantly the response is very rapid and occurs over a few seconds. Repeated CR cycles show a small decrease in the compressed thickness while the recovered thickness was a bit erratic. In summary Gasket A does not compress or deform readily and does not creep significantly. As will be seen it is probably the least compliant material in the stack except for the end plates. 


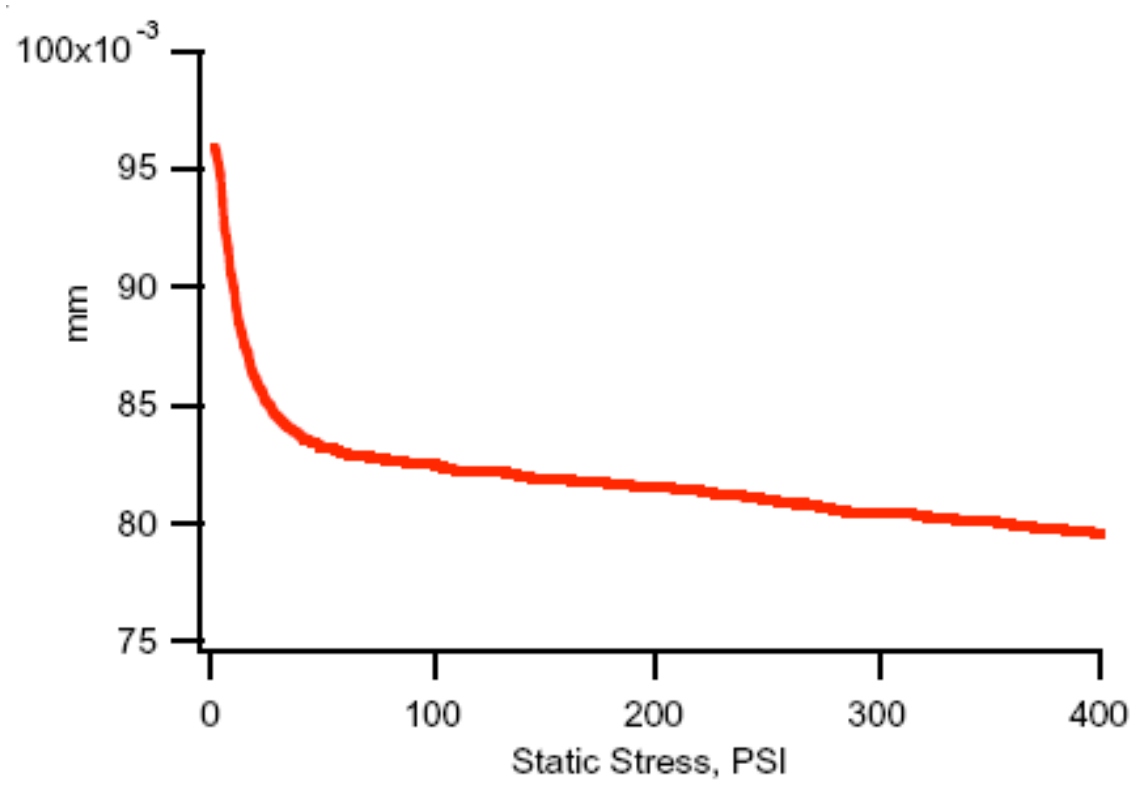

Figure 3.1 Static stress scan test of Gasket A

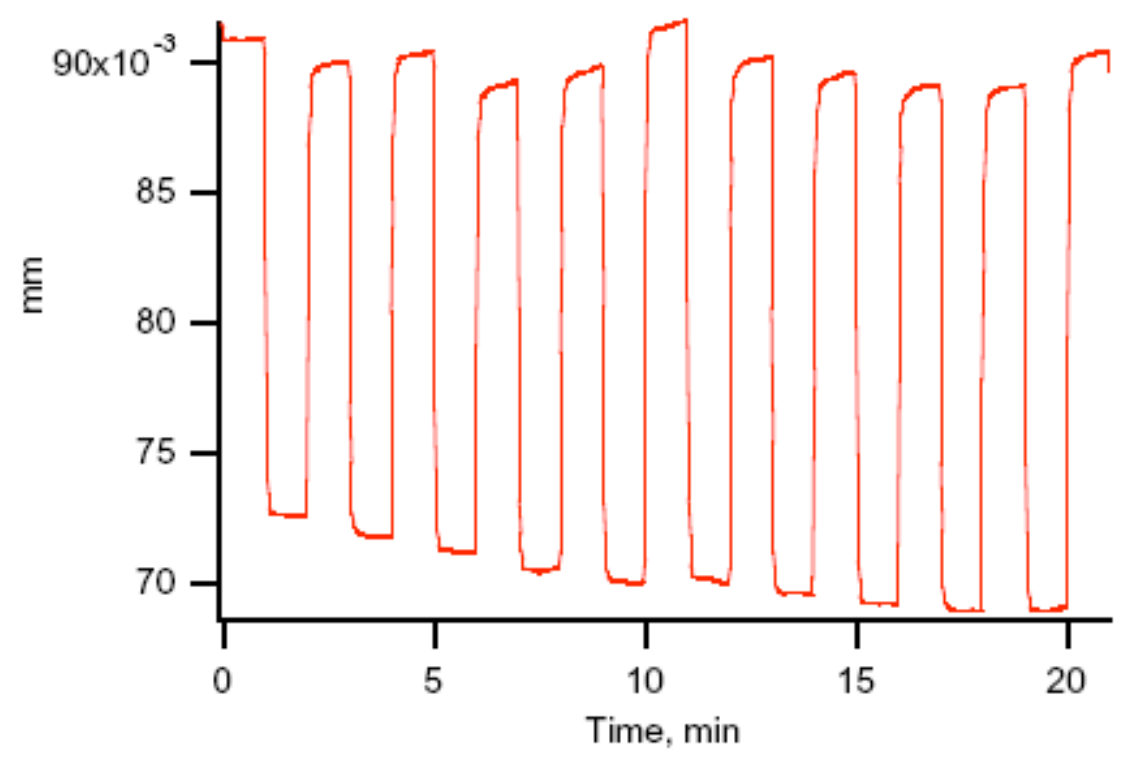

Figure 3.2 Creep and recovery test of Gasket A

\subsection{Gasket B}


The Gasket B material is similar in behavior to the membrane in that both show non-linear stress strain curves with large deceases in compressed height and very long time constants in the CR experiments (Figure 3.3 and 3.4). Actually the gasket material shows extensive creep even after 10 minutes. Note that application of about 40 PSI results in a change in thickness of $150 \mu \mathrm{m}$ from the original assembled height. Most of this change occurs in less than 1 minute but about $25 \mu \mathrm{m}$ change occurs at times up to 10 minutes. These experiments should have been run longer but one can see that significant changes in height could occur at times up to 30 minutes.

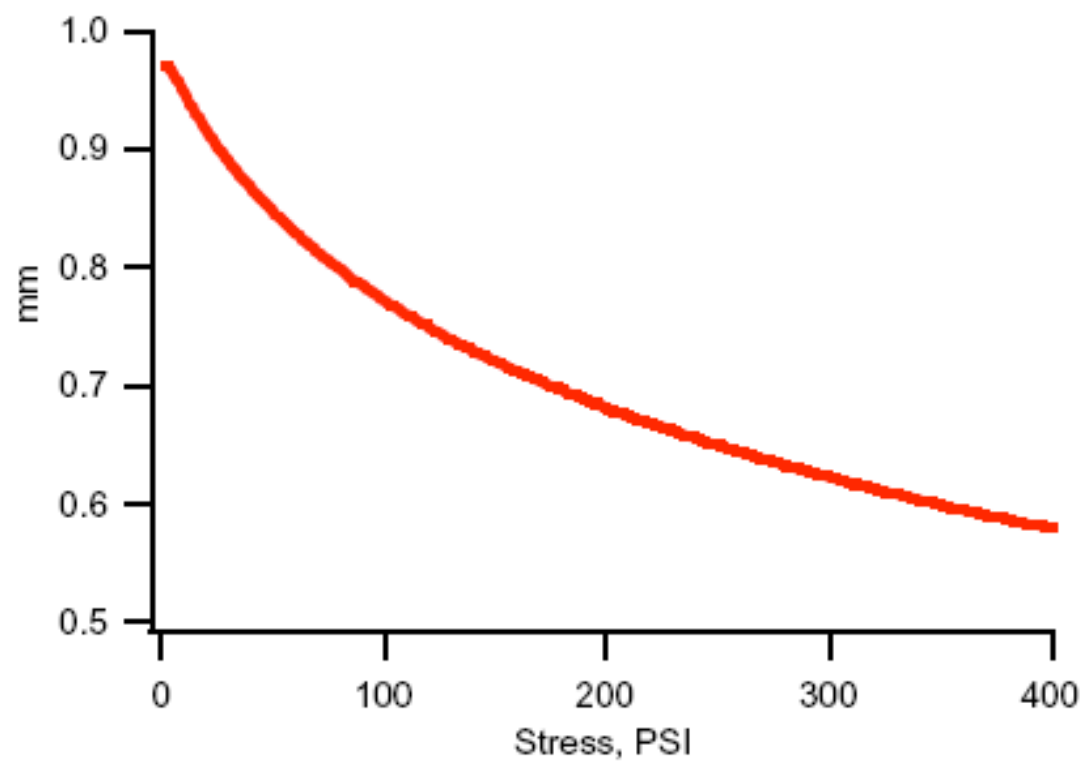

Figure 3.3 Static stress scan test of Gasket B 


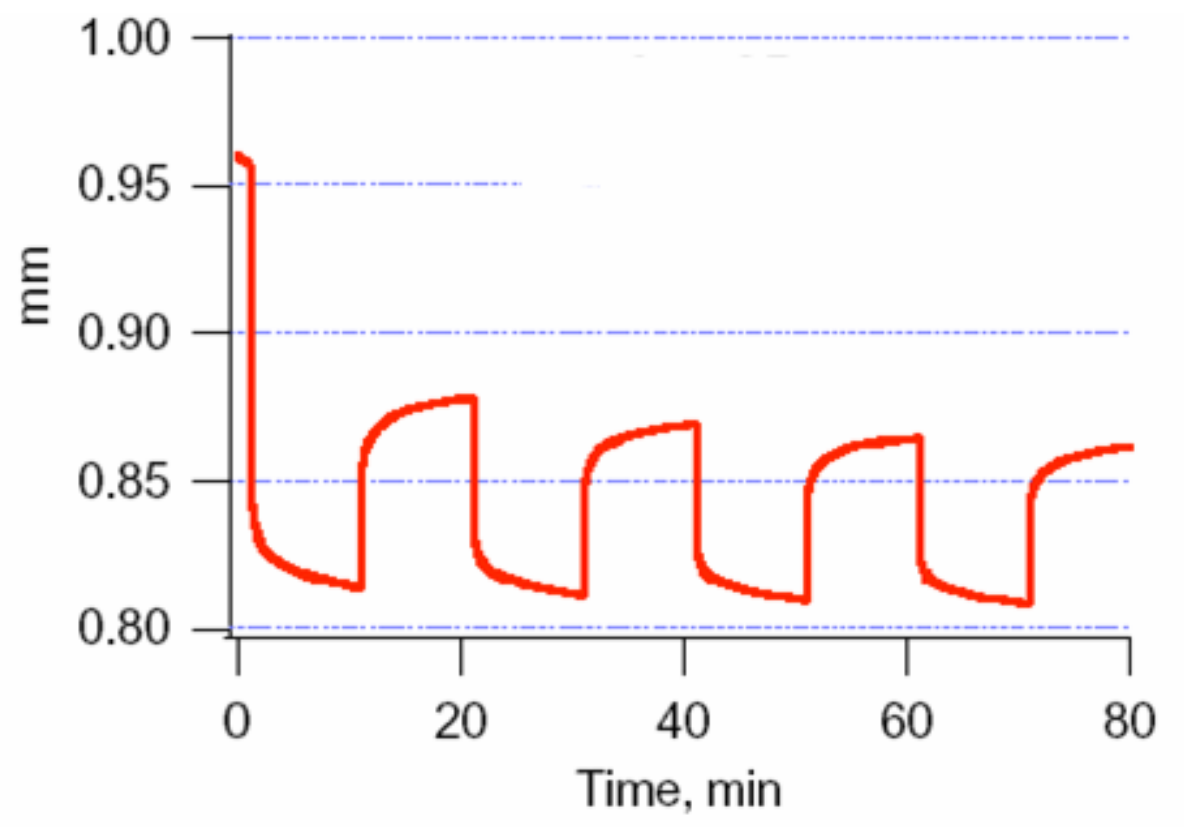

Figure 3.4 Creep and recovery test of Gasket B

\subsection{Gasket C}

Gasket C materials from two different suppliers were evaluated. Gasket material 2 performed better than gasket 1 in fuel cell stacks. Mechanical analysis was performed to investigate the cause of difference. They are about the same thickness within the measurement error and variation in sample thickness at about $50 \mathrm{um}$. The static stress scan for the two gasket materials is shown in Figure 3.5. The gasket 1 showed a slightly rapid compression at the start of the compression curve, which was attributed to bumps or divots or bend in the sample. The static stress scans show no appreciable difference in mechanical properties. The slope of the curve at higher forces might be slightly greater for the Gasket 2 indicating it would be slightly more compliant.

The dynamic temperature scan of the same gasket materials was conducted (Figure 3.6). In this case six layers of gaskets were used to improve the sensitivity. Again, there was no significant difference between two materials. However both showed a transition in amplitude and phase angle centered around $100{ }^{\circ} \mathrm{C}$. While it is not possible to differentiate very similar materials with DTS, it should be easy to distinguish between this and materials with a different glass 
transition temperature.

The creep and recovery profiles for two gasket materials are shown in Figure 3.7 and 3.8. There was substantial difference at the low temperature up to about $60{ }^{\circ} \mathrm{C}$. At higher temperature, the curves are similar although offset from each other. In these experiments, there was no significant difference except for the low temperature behavior, which was attributed to bumps or divots or bend in the sample. Visually, the gasket 1 had more flaws than the gasket 2 . We suspect that the difference of performance of the gaskets is due to the smoothness and uniformity of the films and not in the mechanical properties.

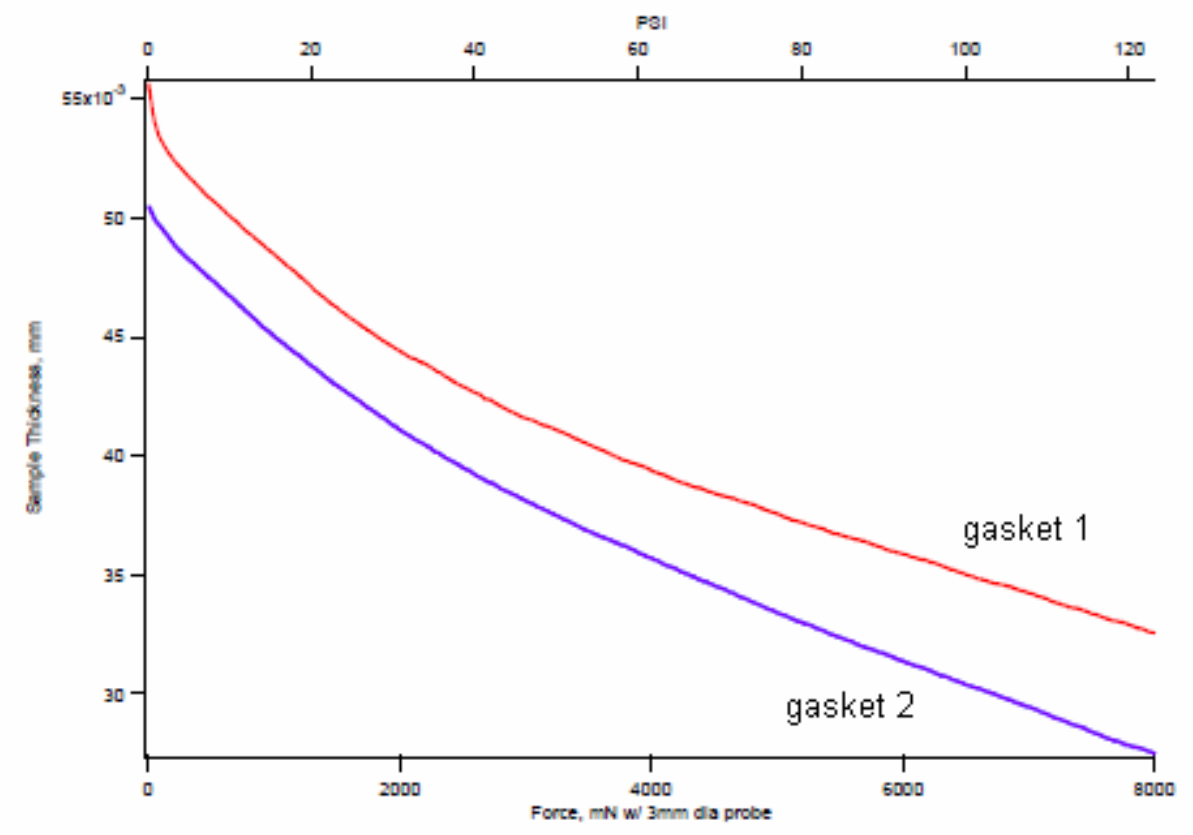

Figure 3.5 Static stress scans of two gasket materials 


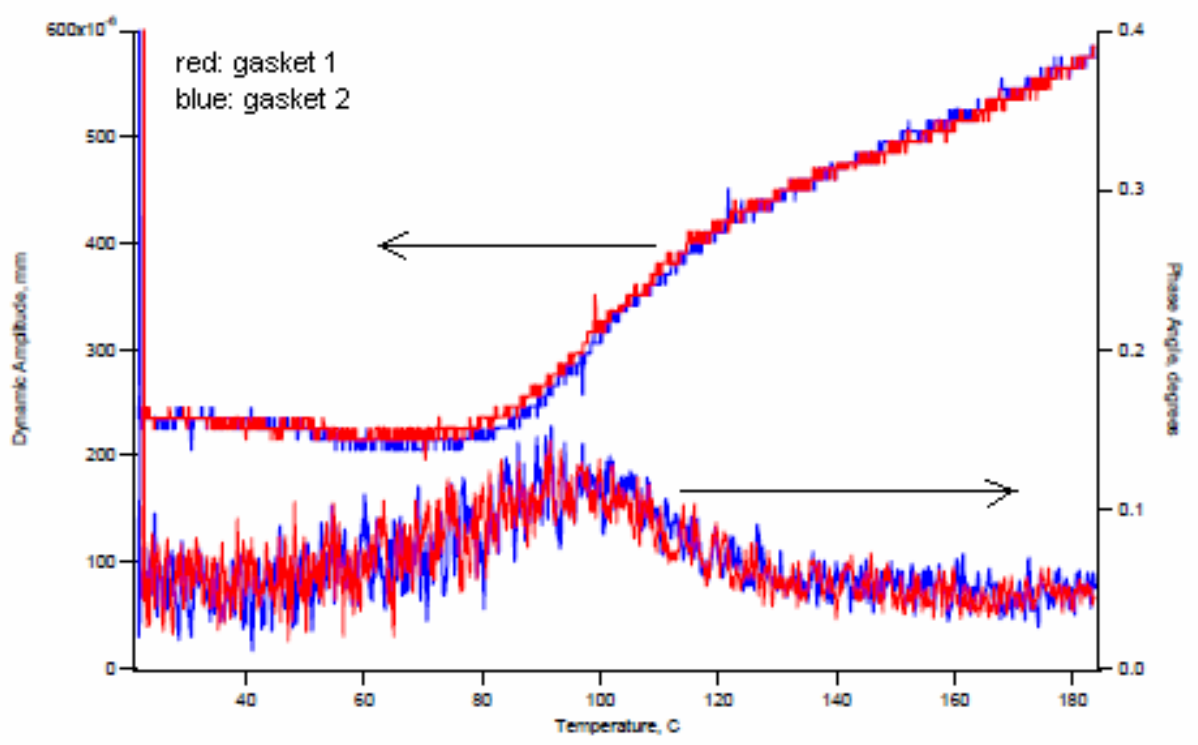

Figure 3.6 Dynamic temperature scans of two gasket materials

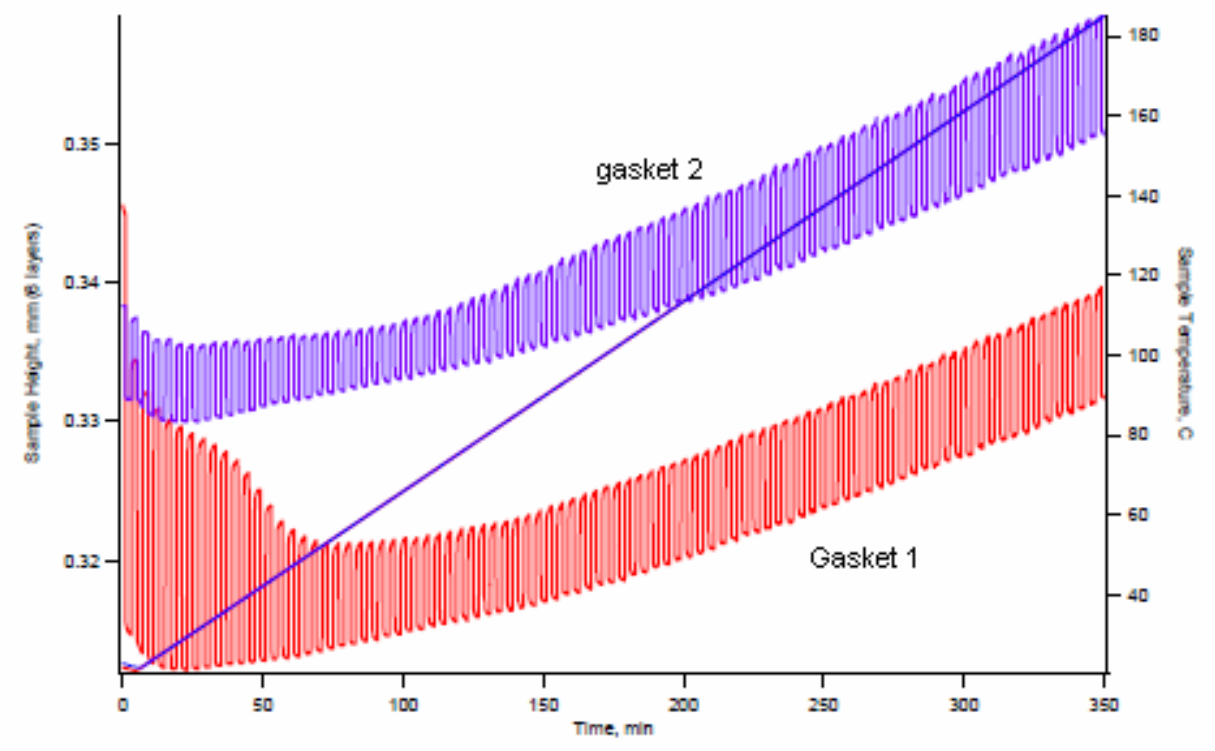

Figure 3.7 Creep and recovery scans of two gasket materials 


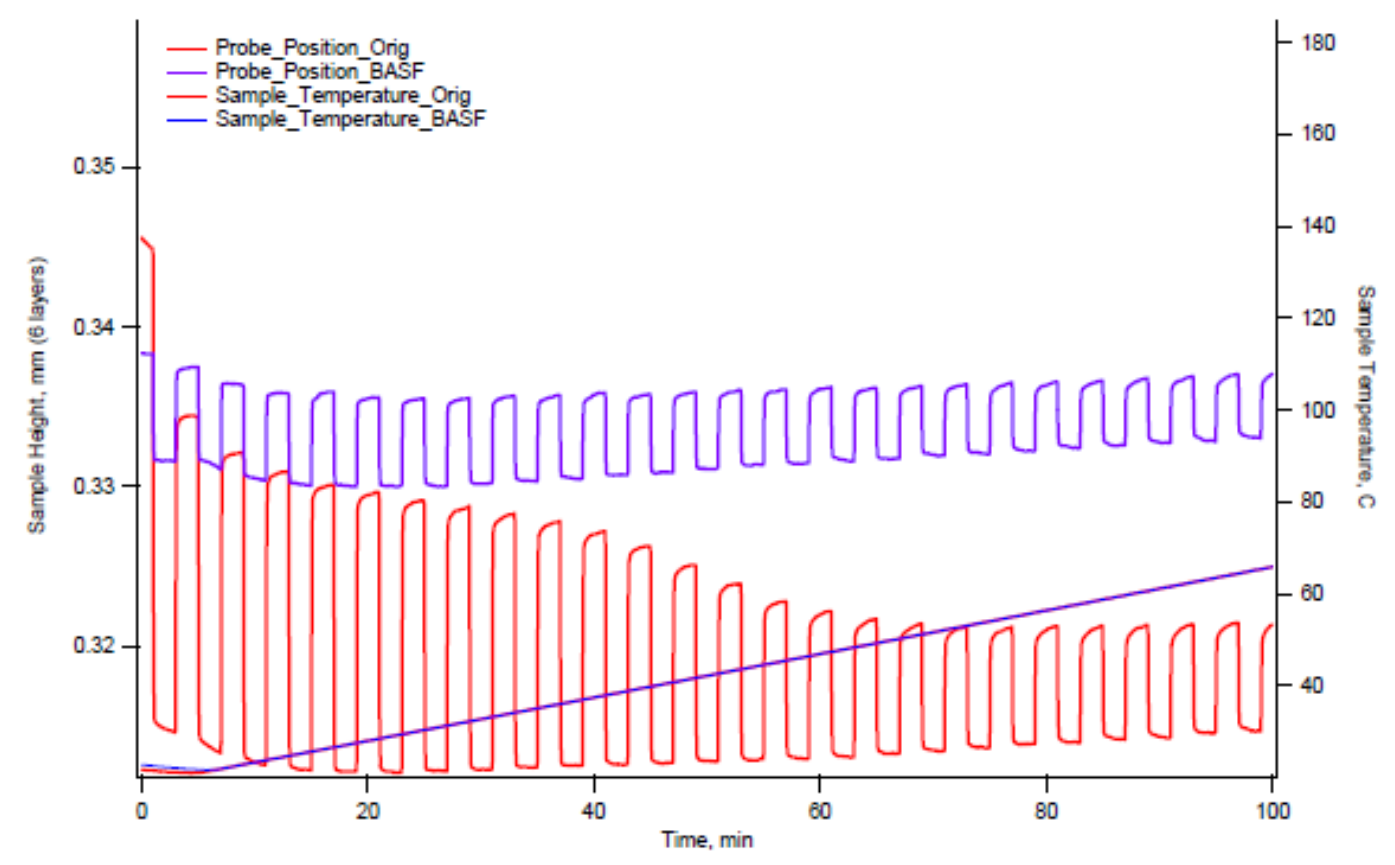

Figure 3.8 Detail of Creep and recovery scans at low temperatures

\subsection{Membrane}

First the SSS shows a gradually curved stress strain curve with no definitive linear region (Figure 3.9). Note that at 400 PSI, the membrane thickness has decreased to almost half its original value. The $\mathrm{CR}$ experiments (10 $\mathrm{mN}$ to $500 \mathrm{mN}$ ) show quite prolonged creep (Figure 3.10). Each cycle was extended for 6 minutes and yet the sample still showed continual creep. Further it did not recover to the original value and the recovered value slowly decreased. In summary the membrane is quite compliant and shows extensive propensity to creep. 


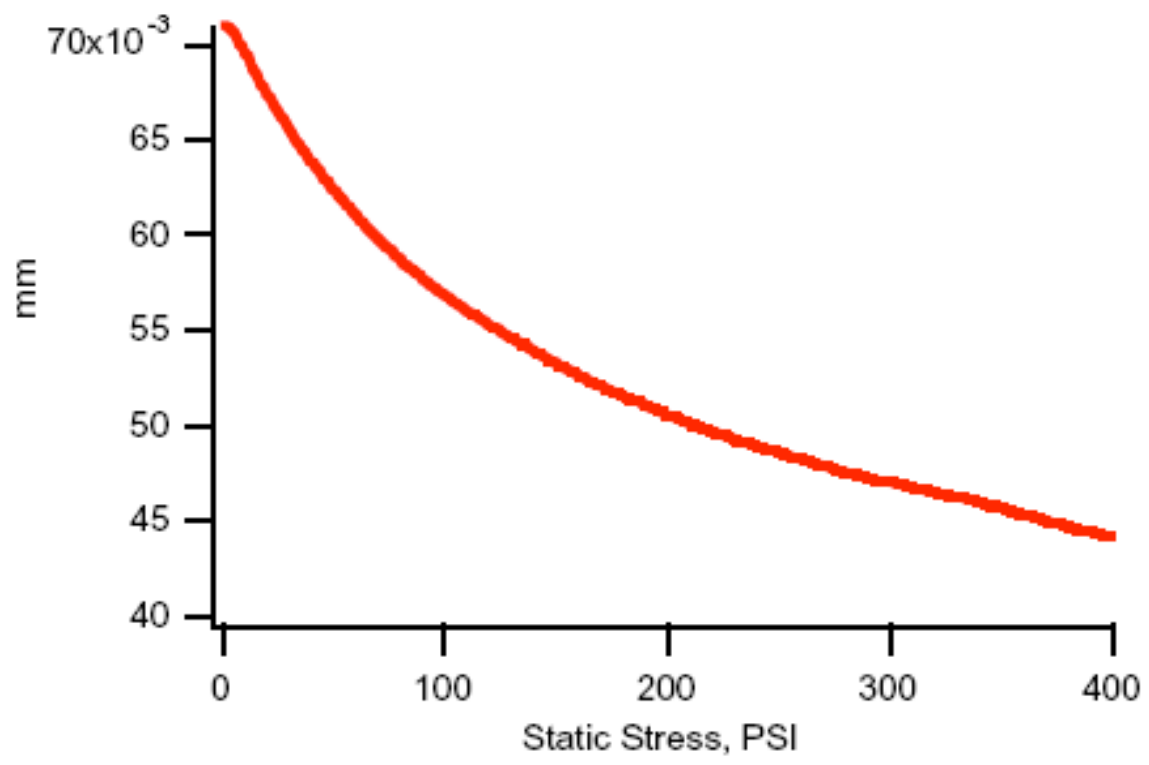

Figure 3.9 Static stress scan test of membrane

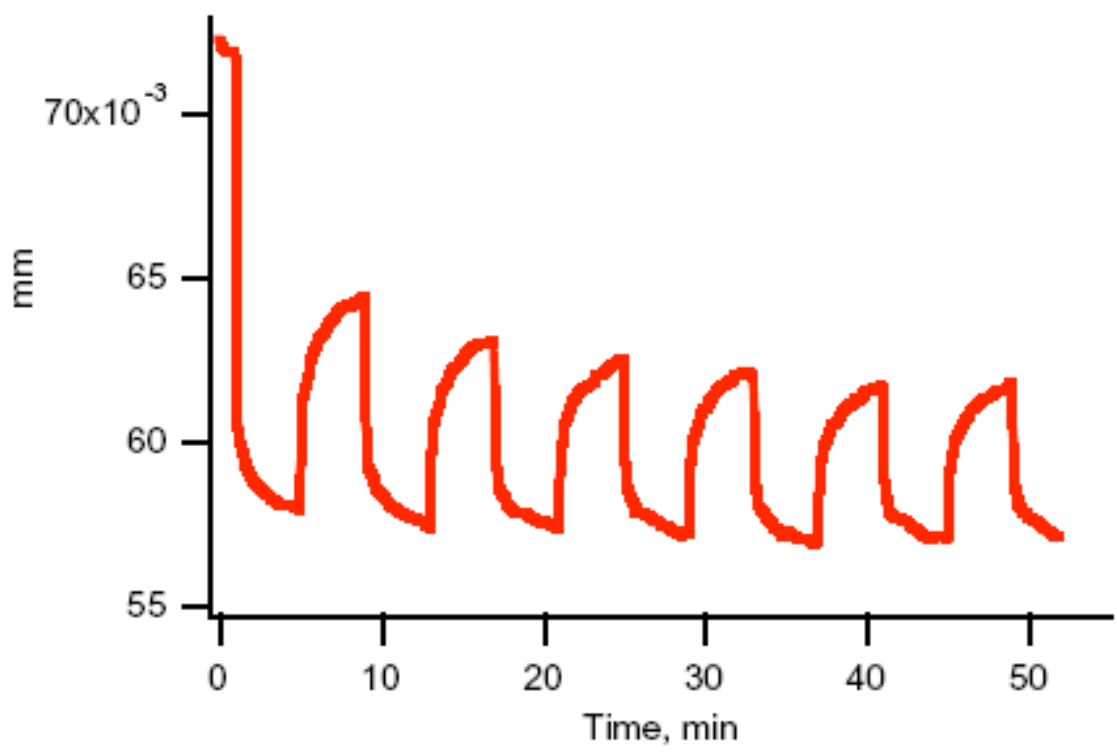

Figure 3.10 Creep and recovery test of membrane

\subsection{Gas Diffusion Electrode}


The average pressure applied to a cell during assembly is roughly about 100 PSI but is undoubtedly not uniformly distributed and some components will see higher and lower pressures. The pressure of 100 PSI corresponds to about $500 \mathrm{mN}$ with this particular probe.

The static stress scans were done with microporous layer (MPL) facing up and MPL facing down (Figure 3.11). This made no detectable difference. However the cathode appeared to compress somewhat more readily than the anode, with an initial steep decline in thickness compared to the anode and compressed to a thinner thickness. The difference indicates different carbon clothes are used for each electrode or alternatively this may be due to variation of properties within a single carbon cloth composition used for both the anode and cathode.

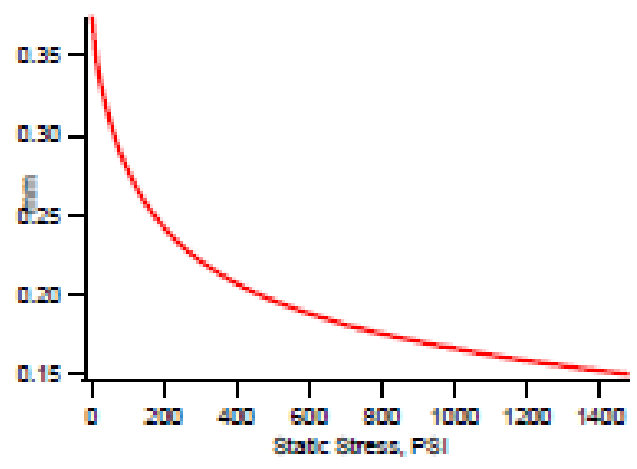

(a)

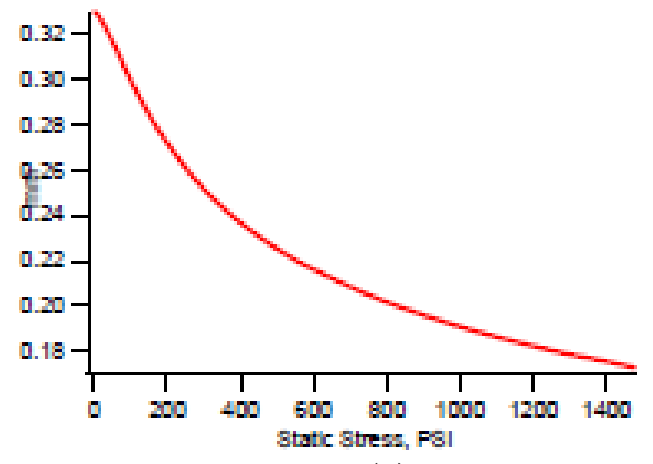

(c)

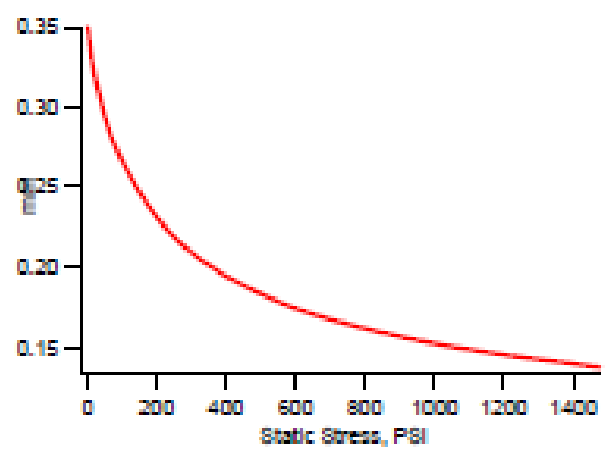

(b)

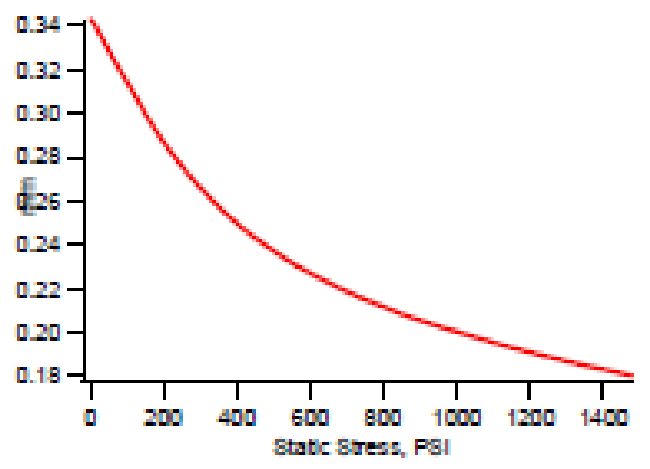

(d)

Figure 3.11 Static stress scan of electrode (a) cathode with MPL up, (b) cathode with MPL down, (c) anode with MPL up, and (4) anode with MPL down 
The creep and recover results are shown in Figure 3.12 and 3.13. These were run with 250, 500 and $1000 \mathrm{mN}$ applied pressure. Only at $250 \mathrm{mN}$ was any significant creep observed otherwise the sample rapidly compressed to a near fixed thickness and only partially recovered upon release of the pressure. While the compressed and released heights continued to decline with repeated cycles, the difference remained constant. However the difference increased with applied pressure. This indicates that a portion of the GDE easily crushes (presumably resulting in fiber fracture) while another portion remains elastic. Consistent with the static strain experiments, the anode appeared to crush less but was also less elastic.

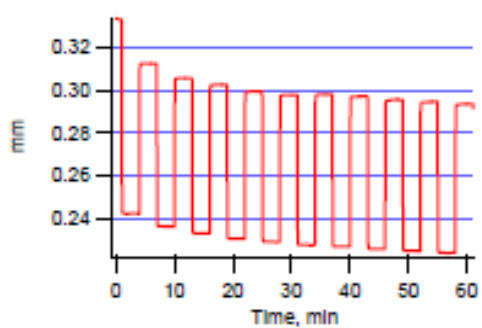

(a)

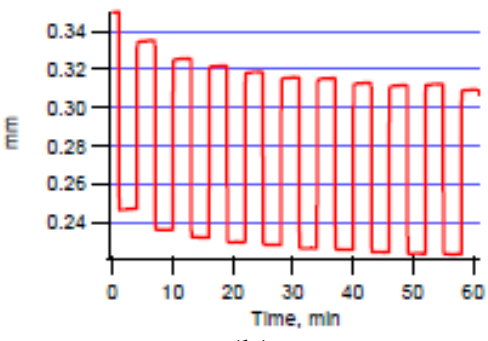

(b)

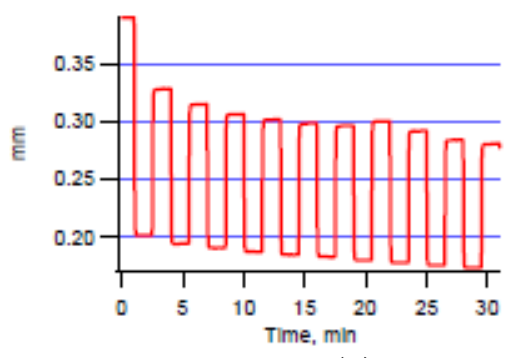

(c)

Figure 3.12 Cathode GDE CR (a) $250 \mathrm{mN}$, (b) $500 \mathrm{mN}$, and (c) $1000 \mathrm{mN}$

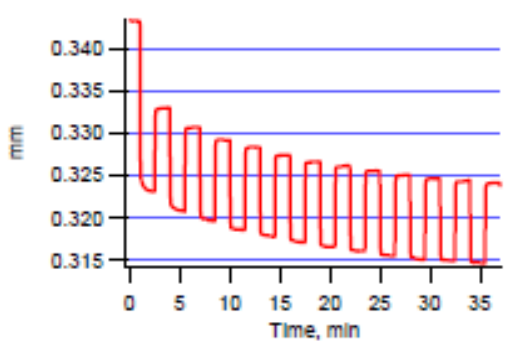

(a)

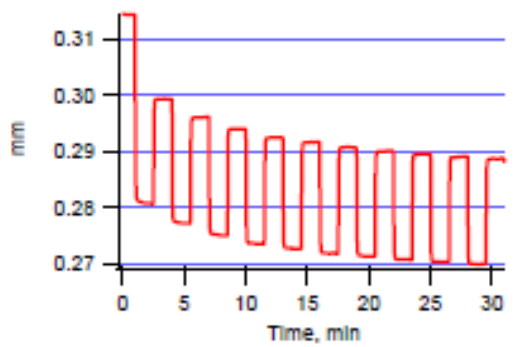

(b)

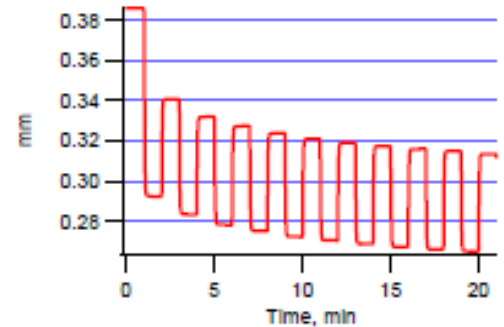

(c)

Figure 3.13 Anode GDE CR (a) $250 \mathrm{mN}$, (b) $500 \mathrm{mN}$, and (c) $1000 \mathrm{mN}$

The results of dynamic mechanical analysis of fuel cell stack components are summarized as follows:

(1) The anode and cathode GDEs exhibited significant, irreversible "crush" with the cathode being more easily crushed. 
(2) Frequency Scan experiments on Gasket A and Gasket C material did not give good results. The materials are probably too thin to dynamically measure thickness variations.

(3) DTS experiments on the Gasket B gaskets showed a significant softening of the material at about $140{ }^{\circ} \mathrm{C}$. This suggests the gaskets undergo significant relaxation at cell operating and compress more easily than at room temperatures. As the gaskets are comparatively thick these components may well contribute to irregular compression and stack height.

(4) DTS experiments on Gasket A and Gasket C materials were not as informative as the above experiments on the Gasket B. This was probably due to the very thin sample thickness. The Gasket $\mathrm{C}$ appears to soften at near $100{ }^{\circ} \mathrm{C}$ while the Gasket A becomes more rigid to dynamic stresses with increasing temperature.

(5) Gasket C does not exhibit significant compression or undergo significant creep or crush. Gasket $\mathrm{C}$ does become softer at about $100{ }^{\circ} \mathrm{C}$ but it may on the whole be too stiff. A more compliant seal material may be worth a try.

\subsection{Stack}

During fuel cell stack manufacturing, the fasteners are tightened to a specific torque, creating a compressive load on the stack. The appropriate compression should be applied and maintained to prevent gas leak externally and internally, and to reduce electrical contact resistance between bipolar plates and MEA. The compressive force on a fuel cell stack was measured by a calibrated load cell at different torques, and the correlation between load and torque was established. The DMA result shows that the stack height decreases as the compressive force increases and significant irreversible stack compression set occurs if the force goes beyond certain value. The stack height change when it is heated was also investigated. Preliminary result show that the stack expanded slightly under constant compressive load. It was interesting to observe that the stack expansion coincides with the theoretical expansion of a component in the stack. Clearly, the stack height changes can be explained mainly by the thermal expansion of this component. Further experiments will be performed to investigate compression characteristic 
of other components in the stack.

\subsection{Stack Modeling Efforts}

The application of a dynamic force to the stack during assembly is expected to reveal how the various components press against each other. However interpretation of the data requires a theoretical framework that can be used to quantitatively interpret the results. To this goal we have begun using finite element methods to explore how the assembled materials respond. Most efforts in Phase I have focused on getting the physics correct and partially on the individual materials properties and on a crude model of the stack assembly.

The individual materials are modeled as Maxwell Spring-Dashpot assemblies as shown in Figure 3.14. Basically each spring-dashpot pair represents a relaxation mechanism in the material. For example in a creep and relaxation experiment, a sudden force would be applied to the assembly compressing the springs by some constant amount and then held constant. The dashpots would then relax and the assembly would compress further depending upon the time constant of the spring-dashpot pair. In most dynamic mechanical analysis experiments this would be interpreted in terms of the molecular properties of the polymers and metals. Here we are interested in the stack assembly and in using time constants that represent the materials in use. Individual time constants for each material can be obtained from DMA experiments like creep and recovery and/or frequency response.

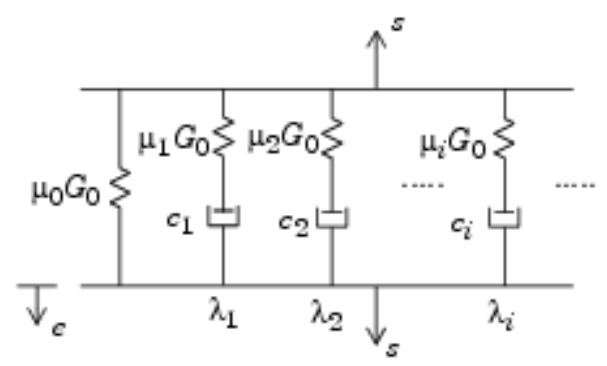

Figure 3.14 Maxwell Spring-Dashpot Assembly 
An initial model of the stack in cross section is shown in Figures 3.15 and 3.16. For the time being, we have ignored the membrane electrode assembly and focused on the edge seals. Dimensions are approximate. The layers are from the top: Metal End Plate/ Gasket B/Bipolar Plate/Gasket C/Gasket A/Gasket C/Bipolar Plate/Gasket B/Metal End Plate (fixed boundary at bottom)

The assembly force is applied to the metal end plate on the top left edge. This is a rough model of how force is applied through the bolts. In this static model we are trying to get dimensions and materials properties approximately correct and validating the model behavior in static compression. The figure shows the original outline of the stack components, a color map of the von Mises stresses and an exaggerated (x100) displacement of the components. The stress map shows where compression forces are most concentrated. Note that a slight bending of the metal end plate occurs and that this causes non-uniform distribution of forces in the polymeric materials. Also it appears the Gasket B takes up most of the assembly force but that the gasket C also exhibits considerable stress.

This model needs substantial improvement before it is useful. First the materials properties in particular the Young's modulus of elasticity (E) are approximate and were garnered from a quick search of web data bases. We need to use more accurate values from in-house DMA experiments. Second, the model does not use spring-dashpots and each material is currently just a spring whose constant is determined by the value of E. Third the MEA is missing. And fourth it is a 2D cross section of one edge of the cell. However, most of these issues are not difficult to resolve and the model should represent the cell mechanical properties relatively well. 


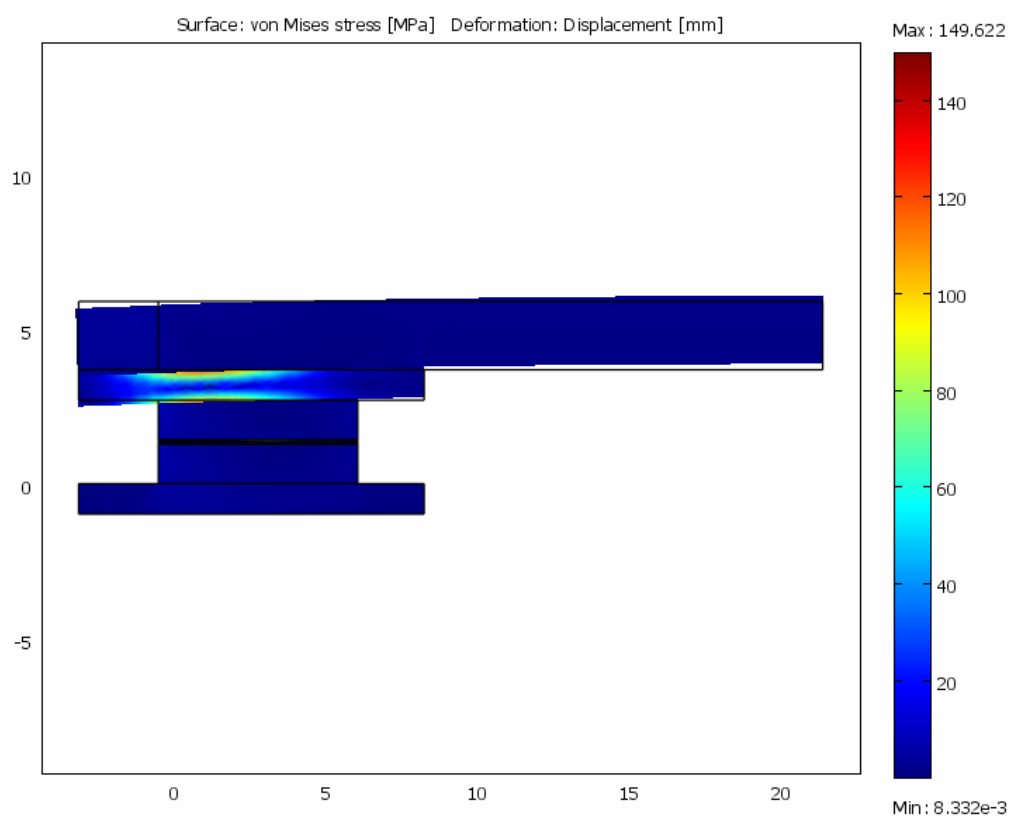

Figure 3.15 Model of stack assembly, half-stack in cross section

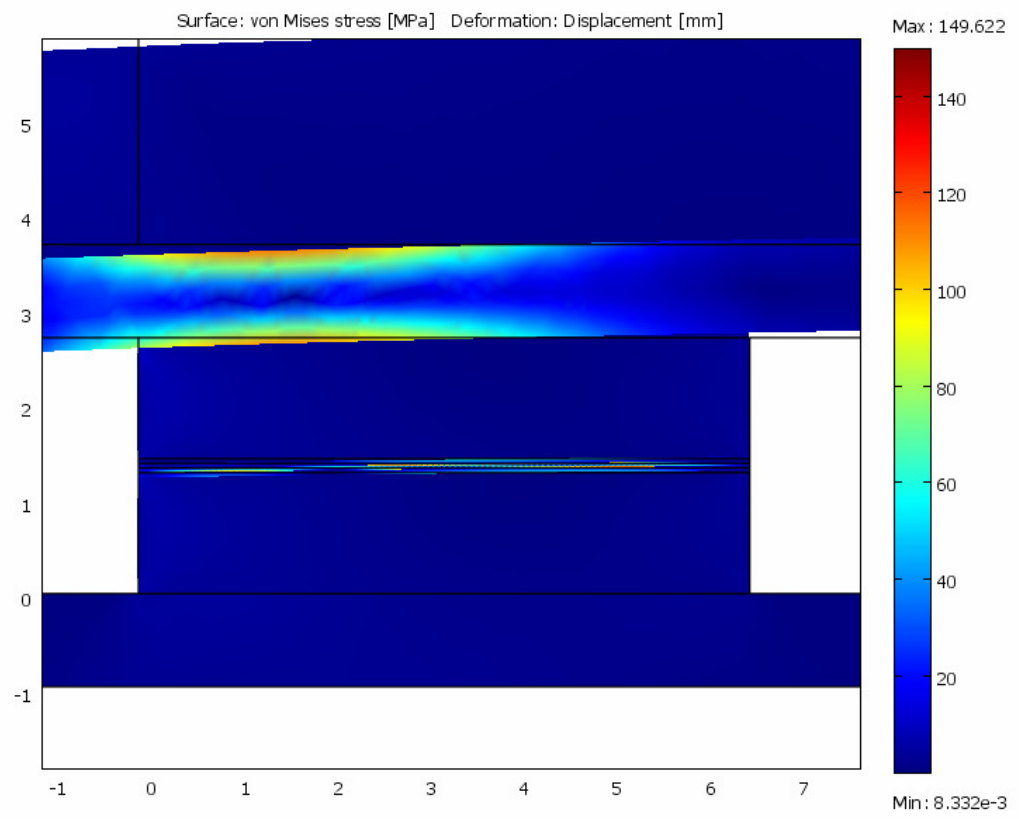

Figure 3.16 Detail of stresses on gasket B 
The biggest modeling issue is modeling the dashpot-sprint pair and below we describe how that is done. It is not trivial and our initial results are meant to demonstrate physical reality in a single material.

A model has been established to simulate the interaction between two or more materials with different dynamic properties. Both materials were described as having identical materials properties (Young's modulus, Poisson ratio, and one spring dashpot pair with a time constant of 10 seconds) except that the bottom material had a glass transition temperature $(\mathrm{Tg})$ of $100{ }^{\circ} \mathrm{C}$ and the top material one of $150{ }^{\circ} \mathrm{C}$. These values were chosen because the gasket materials have a similar spread in Tg values.

The model uses the Williams-Landel-Ferry model to describe how the time constant varies with temperature. Shown in Figure 3.17 is a plot of the time constant multiplier as a function of temperature. The main result is that except for a fairly narrow region around the Tg value the time constant becomes either very large or very small. Thus we expect the material to not show time dependence except near the Tg. At lower temperatures the material viscosity (dashpot part of the model) is extremely high and does not contribute to the compression of the material. At higher temperatures the viscosity is very low and the dashpot collapses instantaneously.

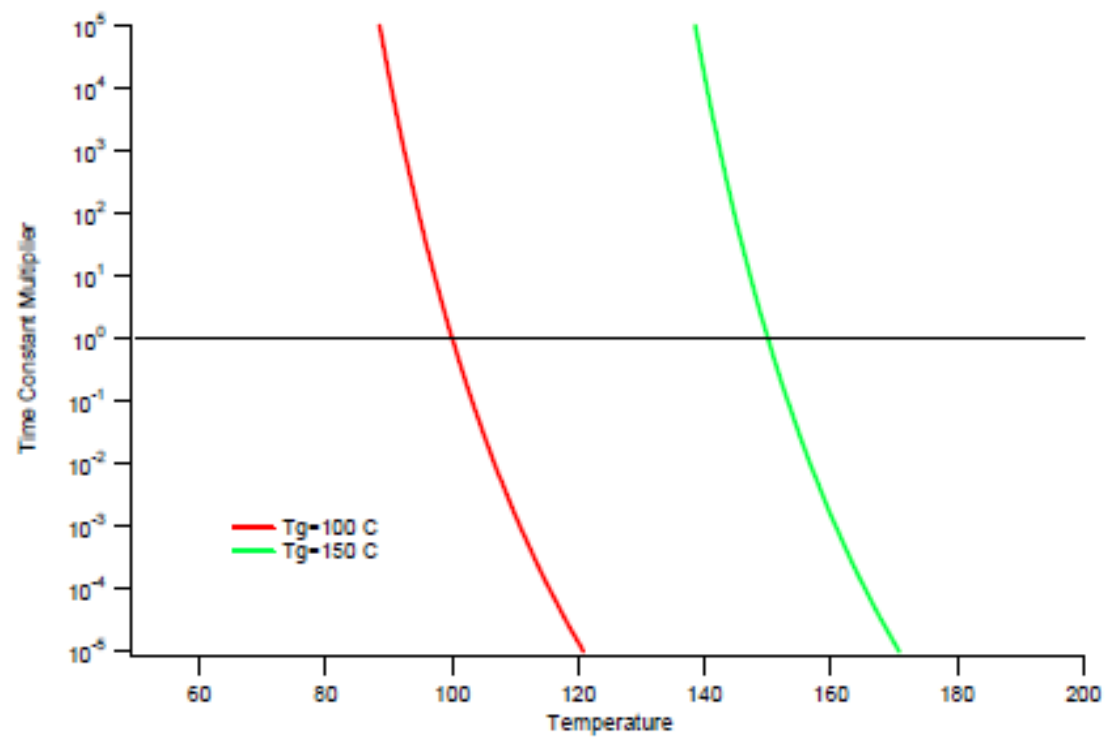

Figure 3.17 Time constant multiplier as a function of temperature 
The results for the creep and recovery of two materials (glass transition temperature $\mathrm{T}_{\mathrm{g}} 100$ and $150{ }^{\circ} \mathrm{C}$ ) stack on top of each other are shown in Figure 3.18. Note that the $4^{\text {th }}$ and $6^{\text {th }}$ profiles show time dependence and these correspond to 100 and $150{ }^{\circ} \mathrm{C}$ respectively. The other temperatures show essentially square profile as expected.

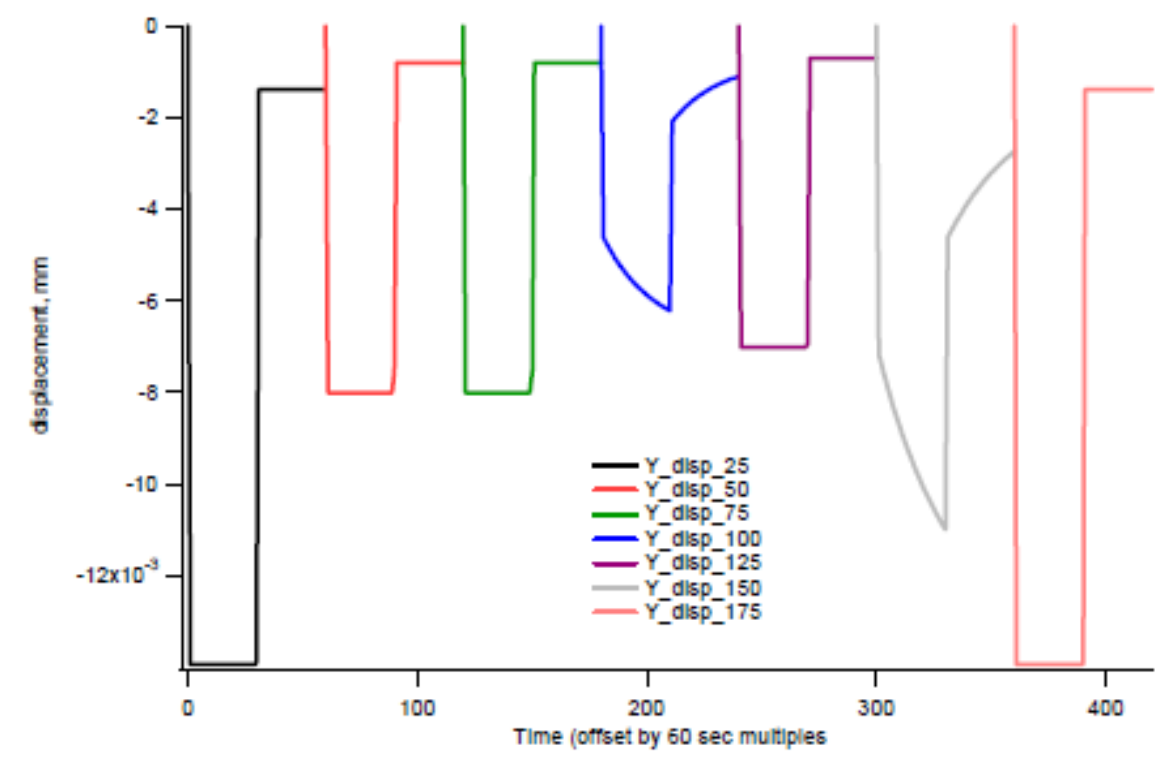

Figure 3.18 Creep and recovery profiles for a two-material assembly at various temperatures.

The dynamic temperature scan results for two-material assembly with $\mathrm{Tg}$ of 50 and $75^{\circ} \mathrm{C}$ was shown in Figure 3.19. The red line is the applied oscillating force with $1 \mathrm{~Hz}$ frequency with a base pressure of $250 \mathrm{mN}$ and an oscillation of $25 \mathrm{mN}$. The green curve is the height response. Figures 3.20 and 3.21 show the stresses in the two materials at 100 and $150{ }^{\circ} \mathrm{C}$ respectively. Note that the bottom materials $\left(\mathrm{Tg}=100{ }^{\circ} \mathrm{C}\right)$ is fully relaxed at both temperatures while the top material $\left(\mathrm{Tg}=150{ }^{\circ} \mathrm{C}\right)$ is not relaxed at $100{ }^{\circ} \mathrm{C}$ but does relax at $150{ }^{\circ} \mathrm{C}$. The relevance to stack assembly is that as the stack heats up the gasket materials will relax at different temperatures and we will be able to see that in the dynamic response. This work can be extended to more realistic geometries, more than 2 materials and also include more than one Maxwell spring/dashpot model for the dynamic properties. 


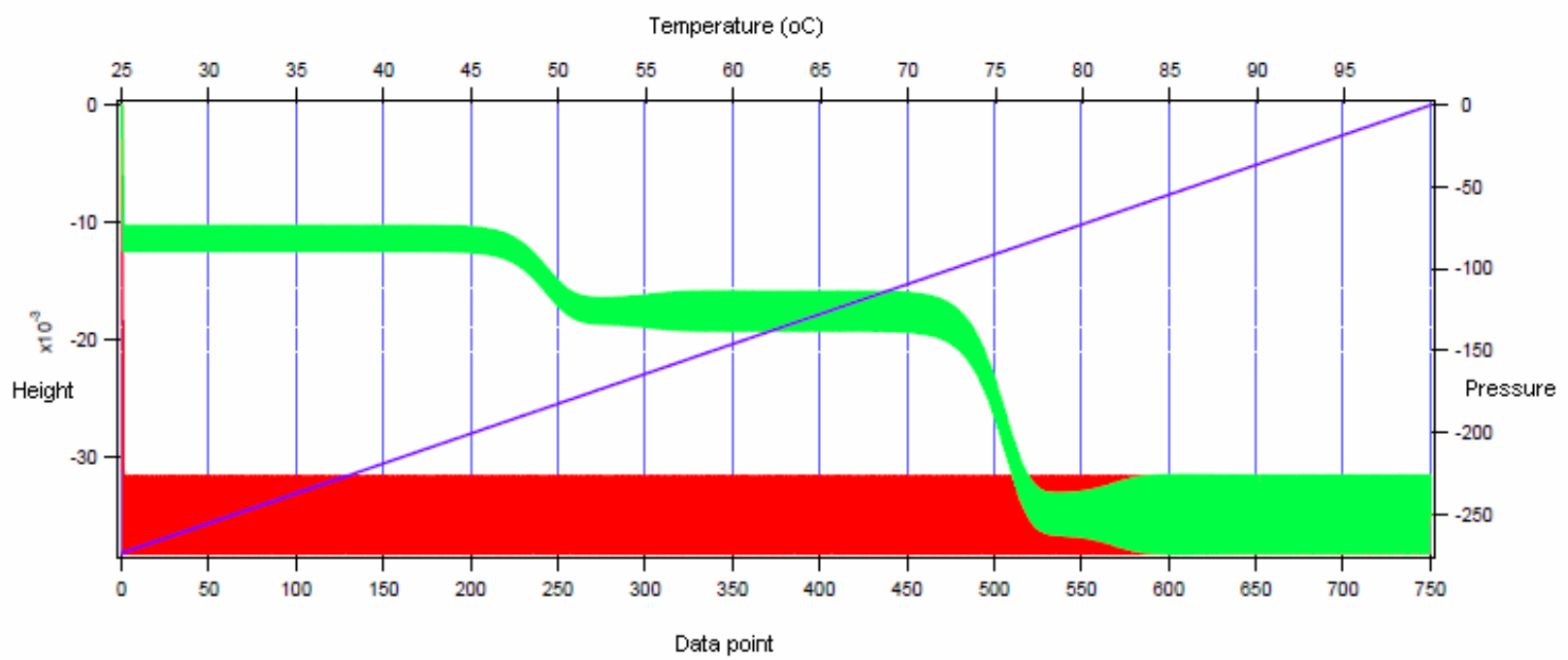

Figure 3.19. Dynamic temperature scan results of a two-material assembly

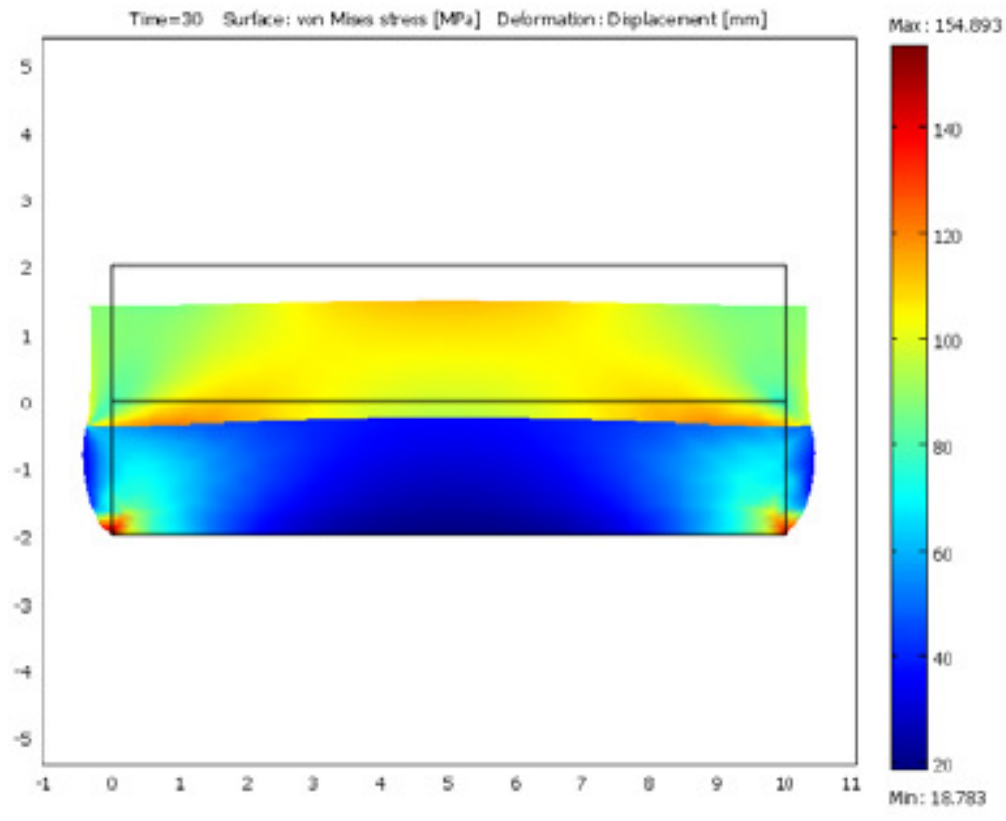

Figure 3.20 Stresses in materials at $100{ }^{\circ} \mathrm{C}$ 


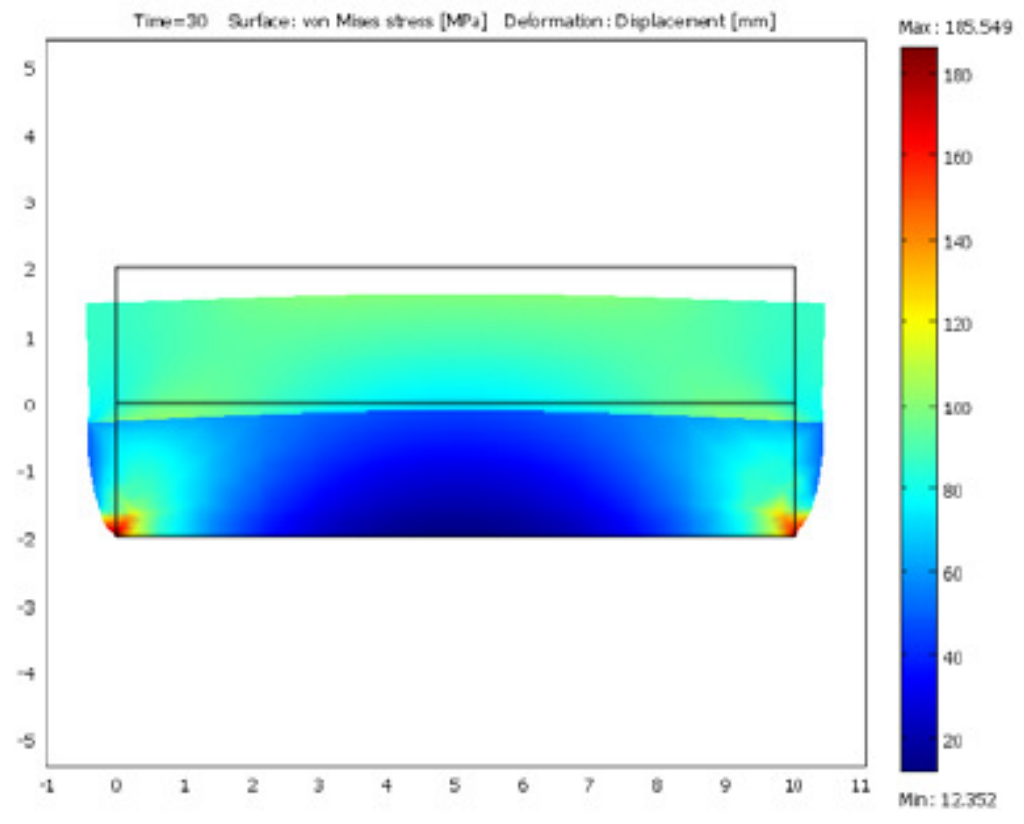

Figure 3.21 Stresses in materials at $150{ }^{\circ} \mathrm{C}$

\subsection{Flexo-Tiltometer}

In this project, the "Flexo-Tiltometer" is a test hardware used for measuring changes in stack deflection and/or pressure and parallelism against calibrated limits. This test hardware will measure the dimensional changes of the fuel cell stack during break-in to ensure that the stack does not change state outside allowable deflection/force and end-plate tilt limits. Extensive testing will be conducted in order to correlate dimensional changes into a simple leak-indication test. In the Flexo - Tiltometer test, the oscillation compressive force and stack height will be measured at various temperatures. The experimental data are expected to be similar to that in Figure 3.22 with more noises. A methodology was developed to extract from synthetic data (and in the future will be applied to real data) the phase and magnitude parameters that are typically reported in dynamic mechanical analysis. The results are shown in Figure 3.23. Note that sloping backgrounds and noise do not significantly affect the signal. The methodology will be implemented in the SQCS and applied to real experimental data. We can see individual components in the presence of many components with highly varied mechanical properties. 


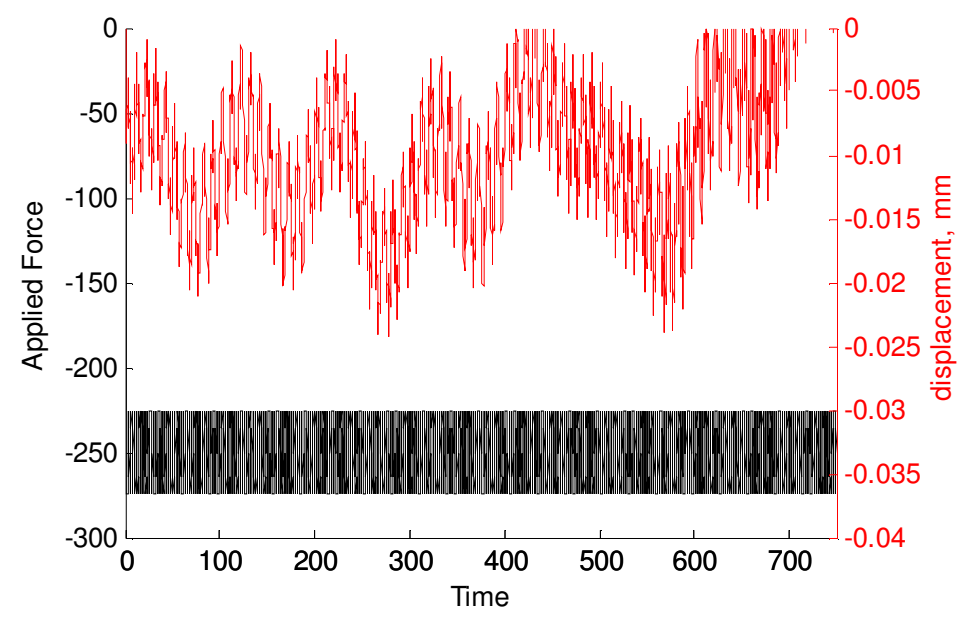

Figure 3.22 Synthetic data of dynamic temperature scan

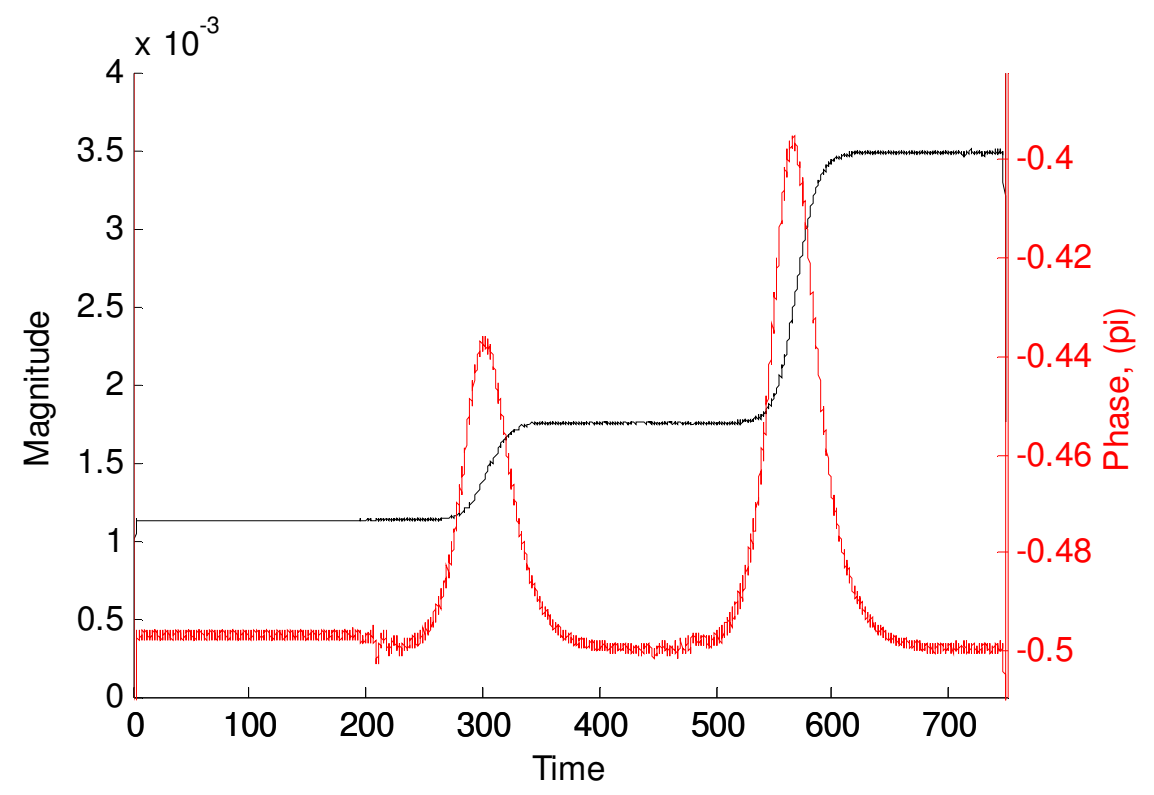

Figure 3.23 Magnitude and phase extracted from synthetic data in Figure 3.22

\section{Leak Test Method Development}


Four leak-test methods were developed during Phase I of the project. They are crossover current test, current interrupt test, OCV decay test, and pressure decay test.

\subsection{Crossover current test}

This test can be performed on fuel cell stacks at many stages during manufacturing. It can be used at stack compression, break-in, and performance test. This test is valuable since it can pinpoint crossover location and can speed diagnosis and remediation of stacks.

The test involves supplying nitrogen and hydrogen to the fuel cell stack cathode and anode, respectively. The anode pressure is slightly higher than the cathode. Any crossover leak will result in hydrogen migrate from the anode side to the cathode side. A voltage is supplied across each individual cell in the fuel cell stack. The hydrogen present in the cathode side will be oxidized and result in a current (Figure 4.1).

We also investigated the parameters that affect the crossover current test, for example, the voltage and nitrogen flow rate. The crossover current increases from $0 \mathrm{~V}$, and starts to level off at $0.15 \mathrm{~V}$ (Figure 4.2). The nitrogen flow at the cathode side can affect the current. High flow of nitrogen can result in low current (Figure 4.3). Nitrogen flow rate need to be optimized to obtain best sensitivity.

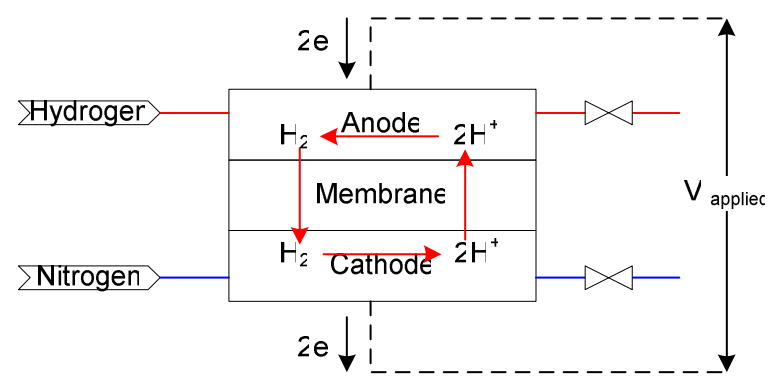

Figure 4.1 Schematic of crossover current test 


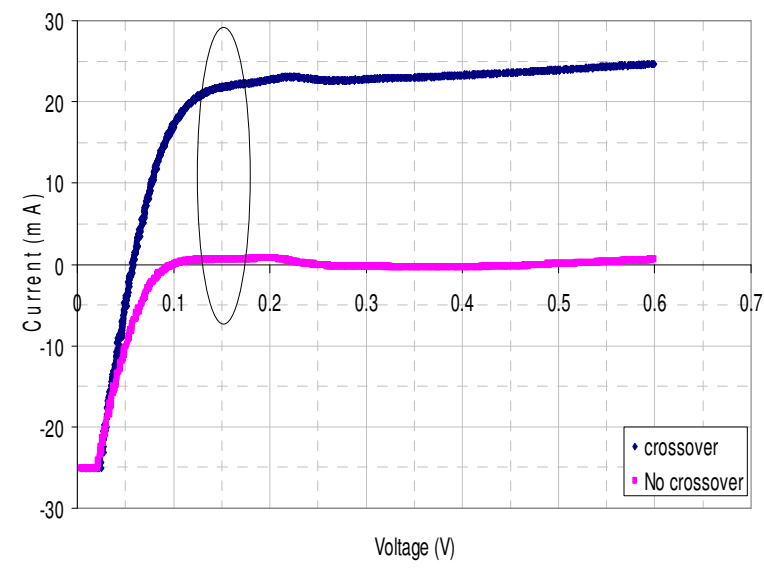

Figure 4.2 Effect of voltage on crossover current measurement

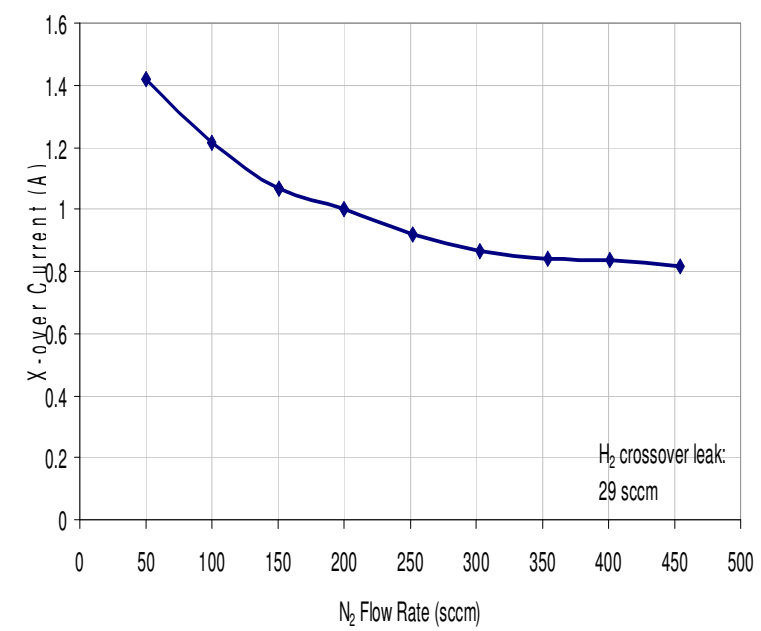

Figure 4.3 Effect of nitrogen flow on the crossover current test

The crossover current test was applied to the test to fuel cell stacks. This test can easily identify the crossover location in a fuel cell stack. An example of the test is shown in Figure 4.4. The result clearly indicates that fuel cell number 1 and 5 have crossover leak. The results correlate very well with other tests, for example, membrane electrode assembly (MEA) leak check. The crossover current test has proved to be a very useful diagnostic tool for fuel cell stack. It was used at UltraCell Ohio manufacturing facility. 


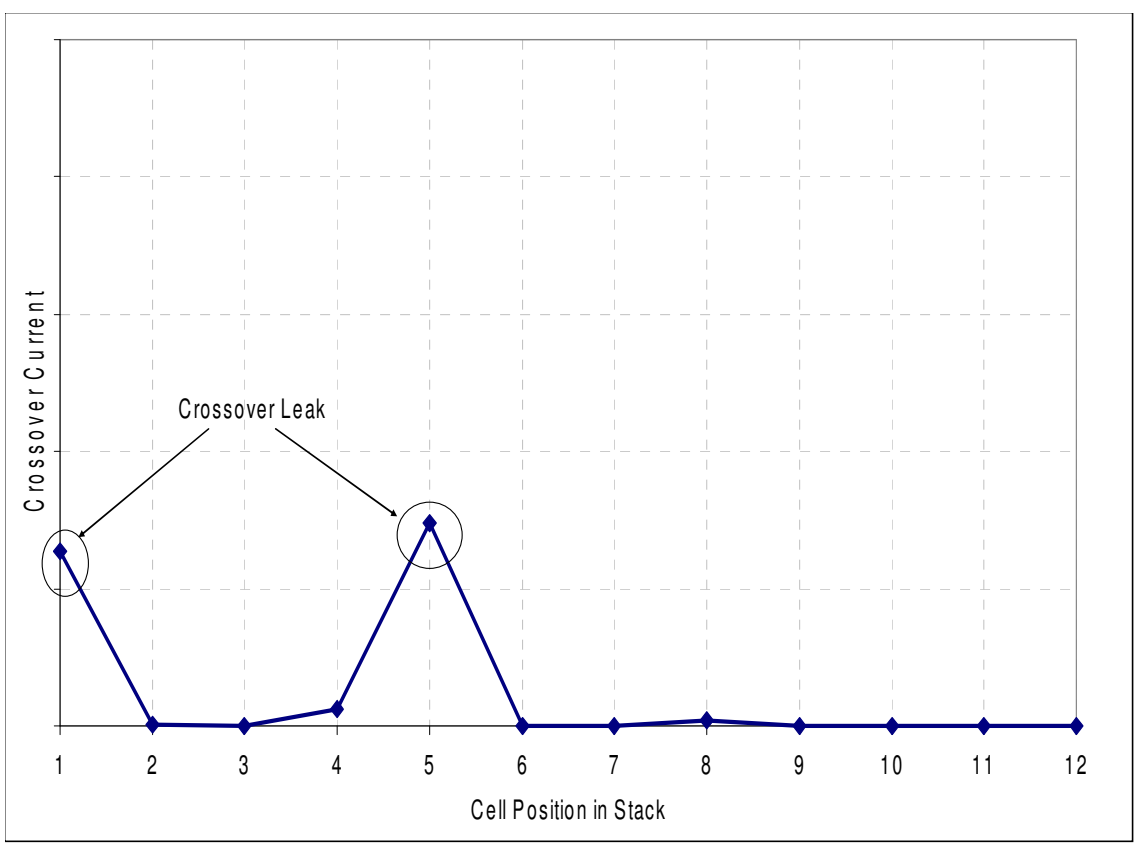

Figure 4.4 Crossover current test result for a fuel cell stack

\subsection{Current interrupt test}

Current interrupt can be performed on the stack while the electronic load is on (Figure 4.5). The fuel cell stack is operated at appropriate flow rates and temperatures with a load on. The current is shut off, and the voltage change in the individual cell is monitored. The crossover leak can affect voltage change. When there is crossover in a cell, the cell voltage increases slower than a normal cell (Figure 4.6).

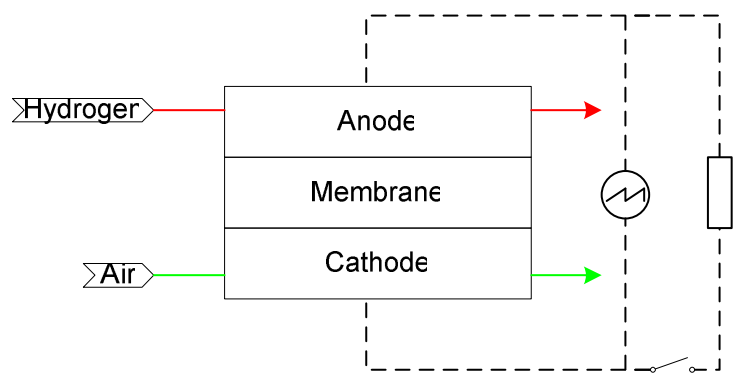

Figure 4.5 Schematics of current interrupt test 


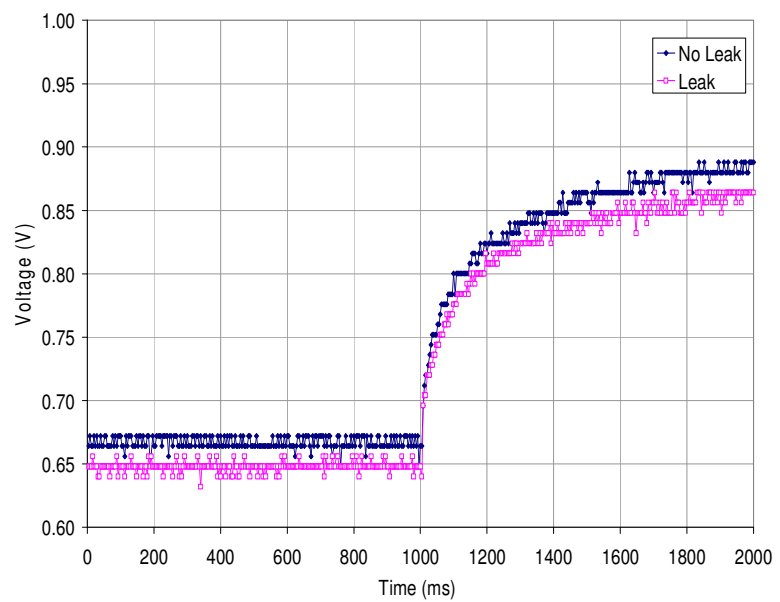

Figure 4.6 Current interrupt test on cells with and without crossover

\subsection{Open circuit voltage decay}

The test can be performed at many stages during the fuel cell stack manufacturing. During the test, hydrogen and air are supplied to the fuel cell anode and cathode respectively. The open circuit voltage of individual cell is monitored (Figure 4.7). One side of the fuel cell is then pressurized. The individual cell with crossover leak shows higher OCV drop than normal cells (Figure 4.8). The test can identify crossover in individual cell and speed the diagnosis and rework of the stack.

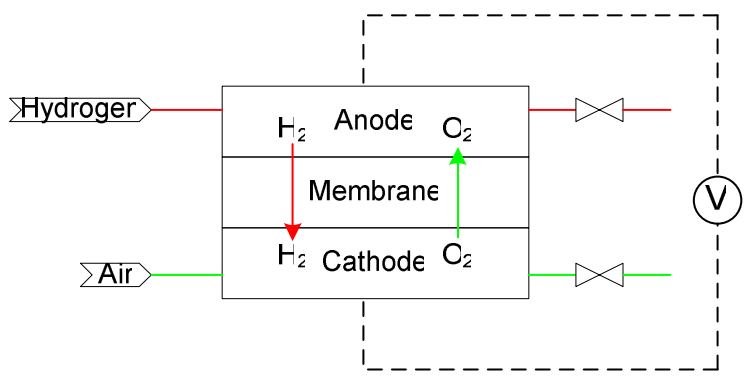

Figure 4.7 Schematics of voltage decay test 


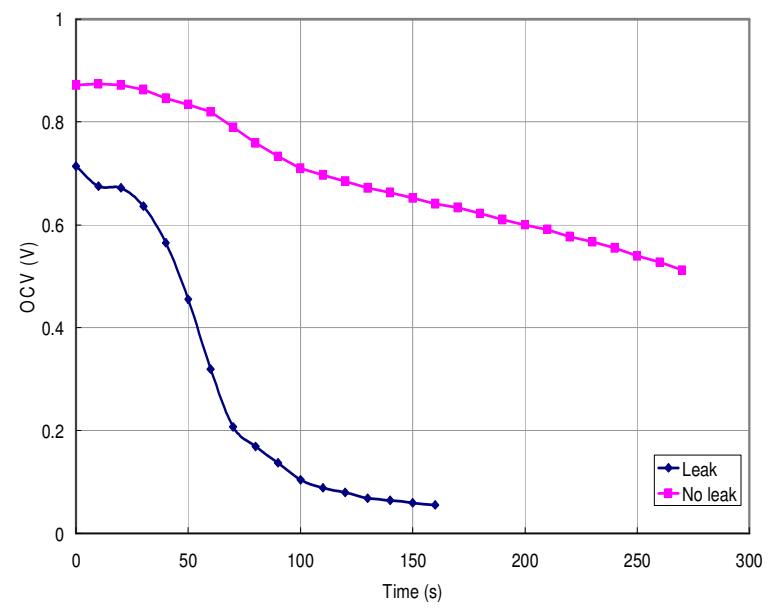

Figure 4.8 Voltage decay test of cells with and without crossover

The open circuit voltage (OCV) decay test was further refined for fuel cell stacks. Fuel cell measured OCV is always lower than the theoretical one. It is affected by fuel crossover, internal short, and parasitic oxidation reactions occurring at the cathode. As a result, OCV changes from cell to cell in a stack. It is difficult to correlate absolute value of OCV with leakage. However, the differential OCV change at different fuel pressures can eliminate the effect of internal short and side reactions, and thus a good indicator of crossover leak. The OCV of normal cells does not change at a small change of fuel pressure. OCVs of cells with crossover leak show a noticeable drop when the fuel is pressurized (Figure 4.9). An example of OCV test result is shown in Figure 4.10. The OCV difference clearly indicates that cell number 9 has crossover leak. 


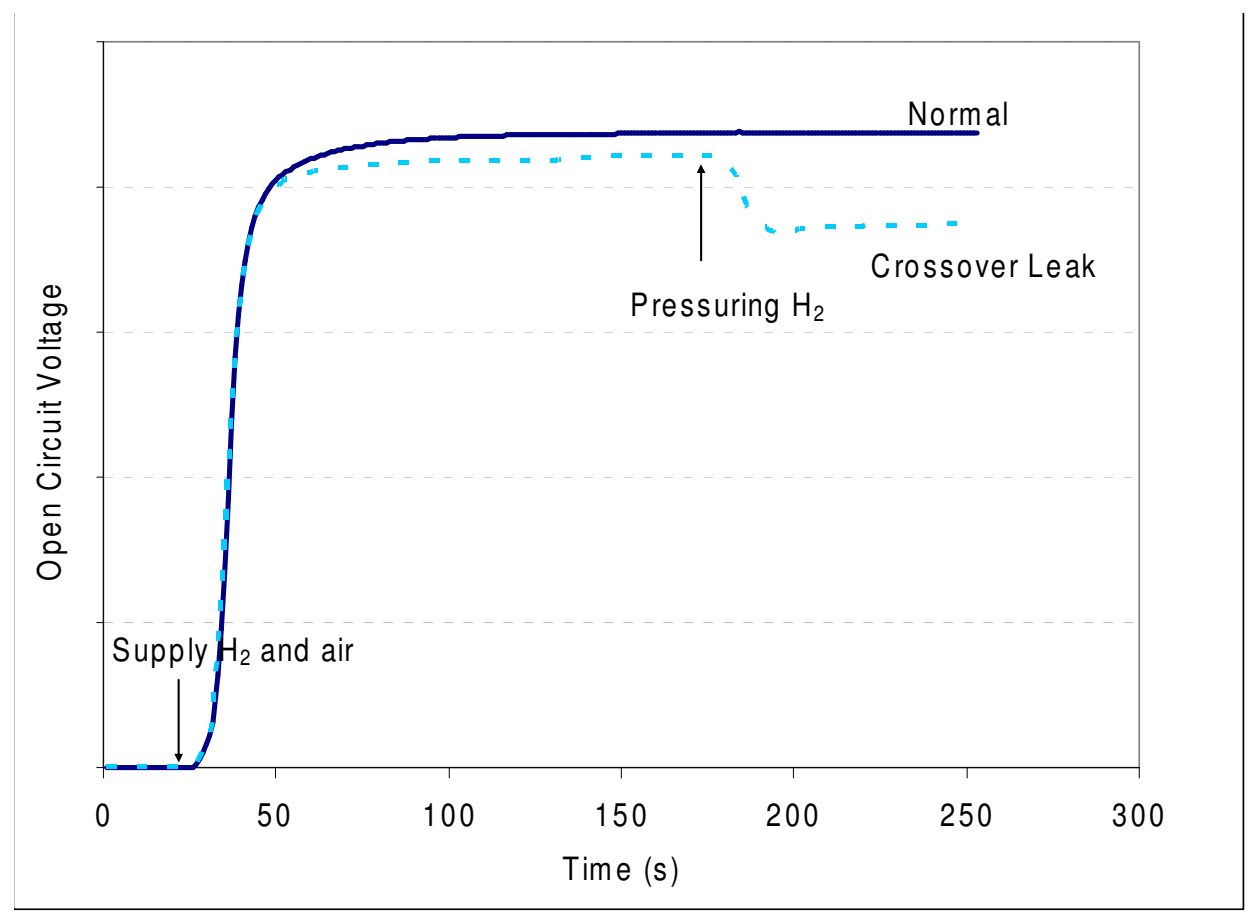

Figure 4.9 OCV decay test of a normal cell and a cell with crossover leak

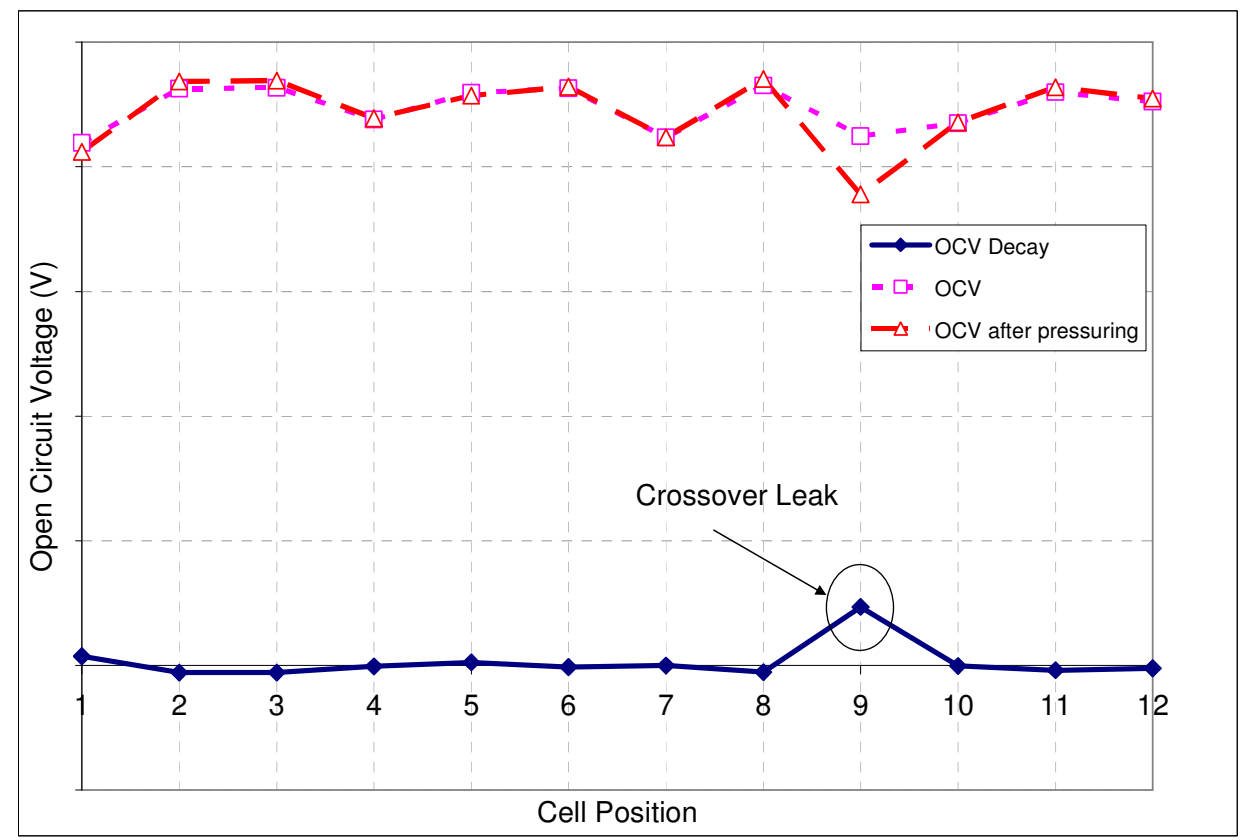

Figure 4.10 OCV decay test result for a fuel cell stack 


\subsection{Pressure decay test}

The pressure decay test for fuel cell stacks was developed. The test was performed on different stacks with different external and internal leak. The results were compared with the acceptable stacks (Figure 4.11). The gas, test duration, initial and final pressures for the external and crossover leak tests were selected.

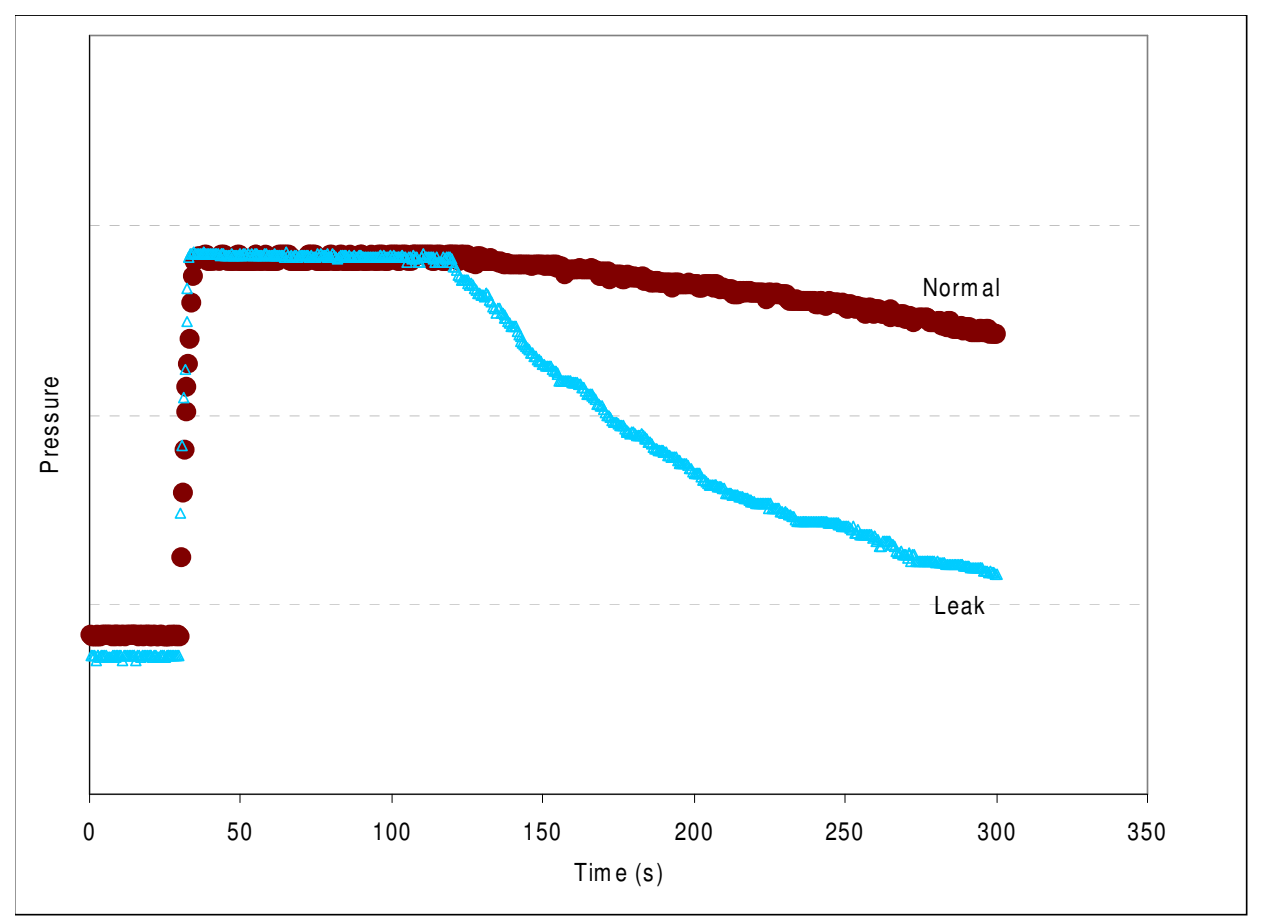

Figure 4.11 Pressure decay test of a normal stack and a stack with internal leak

In summary crossover current, OCV decay, and pressure decay can successfully detect leakage in fuel cell stack with desired sensitivity. These three tests, together with Flexo-Tiltometer, were designed into the stack quality characterization system (SQCS) prototype. The pass/fail criteria of these three tests have been established. The sensitivity of the current interrupt test is too low to detect typical leak in fuel cell stacks. 


\section{Stack Quality Characterization System (SQCS) Prototype Development}

UltraCell, CTS, and PNNL worked together to develop a specification for the SQCS prototype. The specification includes required functions, detail procedures to perform these functions, hardware, software, graphical user interface, gas interface, electrical interface, heating system, and compression stand. The flowchart of the SQCS is shown in Figure 5.1. The fuel cell stack manufacturing process includes assembly, compression, bolting, break-in, performance test, and integration. A variety of leak tests are performed during the stack manufacturing process. The SQCS prototype was designed to automatically perform the all these functions except bolting. 


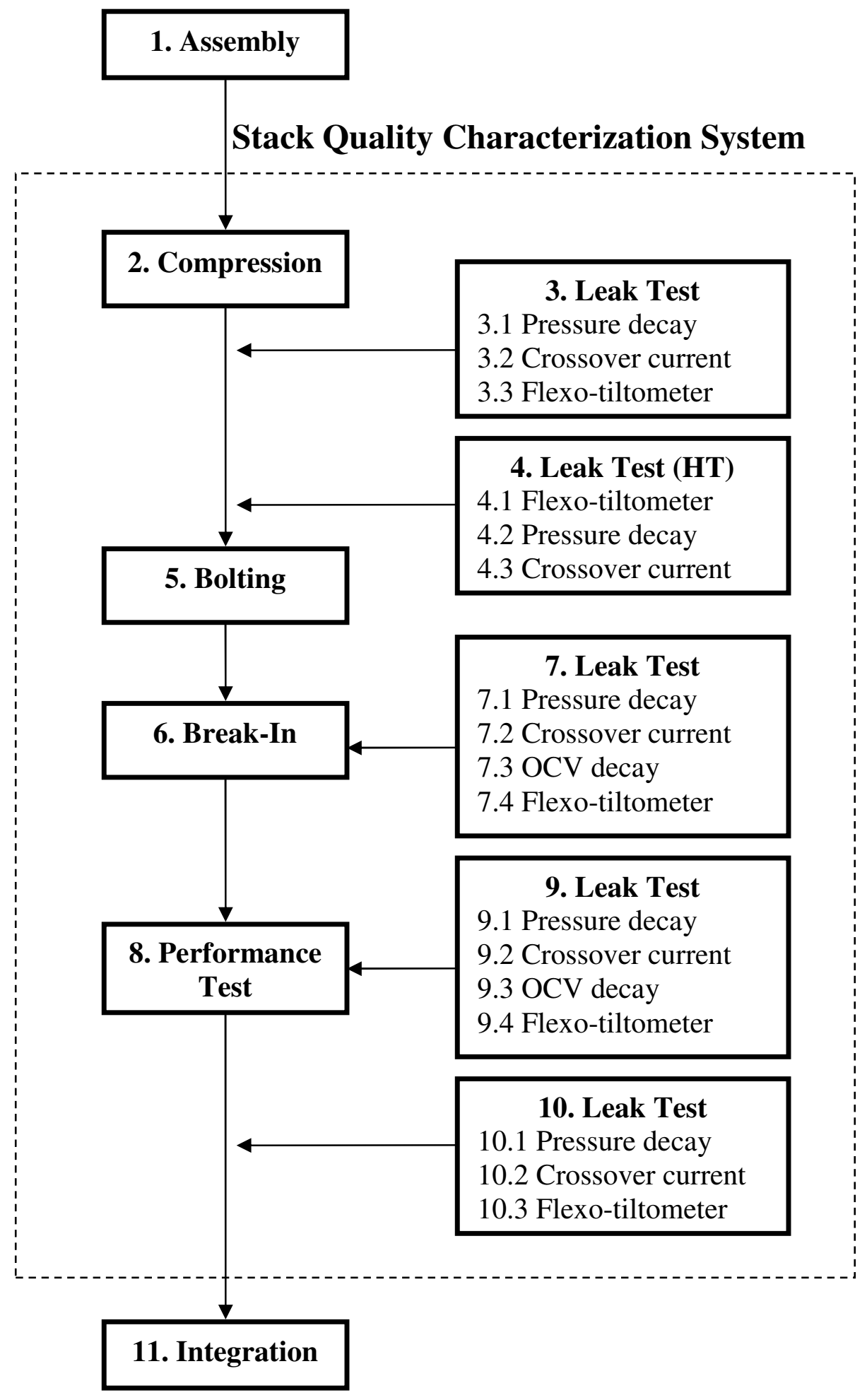

Figure 5.1 Flowchart of SQCS prototype 


\subsection{Leak test procedures}

The procedures for the pressure decay test, crossover current test, OCV decay test, and FlexoTiltometer test are described in the following section.

\subsubsection{Pressure decay (external leak, crossover leaks: anode to cathode and cathode to anode)}

(1) Supply Nitrogen to fuel cell stack anode and cathode inlets.

(2) Close stack anode and cathode outlets.

(3) Adjust Nitrogen pressure to a set point, and wait a certain period of time for the stack pressure to stabilize.

(4) Isolate the stack from Nitrogen source, and monitor the pressure decay in fuel cell stack for a certain period of time. Pass if pressure is above a certain pressure.

(5) Close the cathode inlet, and open the cathode outlet.

(6) Close the anode outlet.

(7) Supply Nitrogen to the anode inlet, adjust the Nitrogen pressure to set point, and wait a certain period of time for the anode side pressure to stabilize.

(8) Insolate the anode side from the Nitrogen source, and monitor the pressure decay on the anode side for a certain period of time. Pass if pressure is above a certain pressure.

(9) Close the anode inlet, and open the anode outlet.

(10) Close the cathode outlet.

(11) Supply Nitrogen to cathode inlet, adjust the Nitrogen pressure to a set point, and wait a certain period of time for the cathode side pressure to stabilize.

(12) Insolate the cathode side from the Nitrogen source, and monitor the pressure decay on the cathode side for a certain period of time. Pass if pressure is above a certain pressure.

\subsubsection{Crossover current}


(1) Supply Hydrogen and Nitrogen to fuel cell stack anode inlet and cathode inlet respectively, and purge for a certain period of time at a certain flow rate.

(2) Short individual cells for a certain period of time.

(3) Close the anode outlet, and adjust Hydrogen pressure to a set point.

(4) Adjust Nitrogen flow at the cathode side to a certain flow rate.

(5) Apply a 0.2 V DC voltage to cell \#1 in the stack. Positive terminal is connected to the cathode side, and negative terminal to the anode side. Wait a certain period of time for the current to stabilize. Record the current. Determine pass/fail. The cell fails if crossover current is greater than a certain current.

(6) Repeat step 4 on cell \#2.

(7) Continue until all cells are tested.

\subsubsection{OCV decay}

(1) Supply Hydrogen and air to fuel cell stack anode and cathode inlets at certain flow rates, respectively. Wait a certain period of time, and measure and record open circuit voltage (OCV) of individual cell in the stack.

(2) Close anode outlet, and adjust Hydrogen pressure to a set point. Wait a certain period of time, measure and record OCV of individual cell in the stack. Pass if OCV is higher than a certain voltage, and the differential OCV before and after pressurization is lower than a certain voltage.

\subsubsection{Flexo-Tiltometer}

(1) Supply Nitrogen to the fuel cell stack anode and cathode at a certain flow rate.

(2) Add dynamic force on top of a constant force (sinusoidal waveform, amplitude $10 \%$ of constant force, frequency $1 \mathrm{~Hz}$ ).

(3) Continue recording compressive force and stack height at a certain time interval. 


\subsection{Over-all SQCS frame}

The over-all frame is shown in Figure 5.2. The test fixture is located at the center of the SQCS system. On the top of the system, there is a fume hood, which is connected to the ventilation system of the facility. A light curtain is installed in the front of the system. This light curtain will suspend the motion of the hydraulic press whenever there is an object crossing the curtain. This feature is to protect the operator from getting injured by the press. An operator can set up parameters, run tests, and obtain test results using the touch-screen monitor and keyboard that are located in the front of the SQCS.

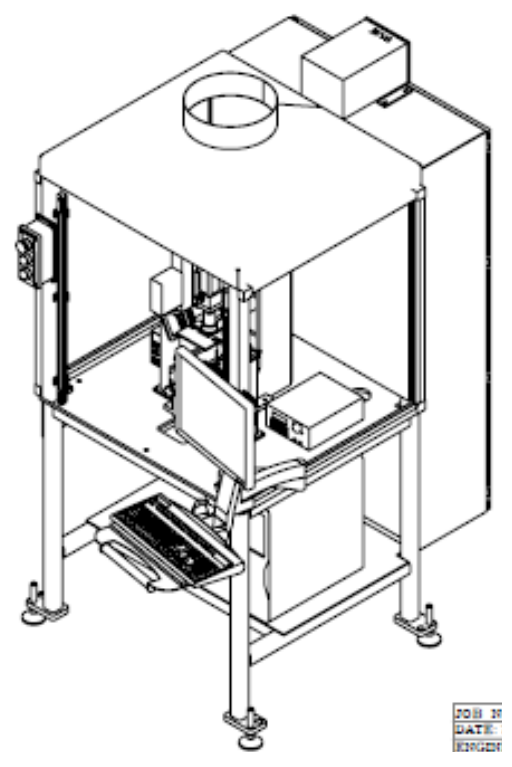




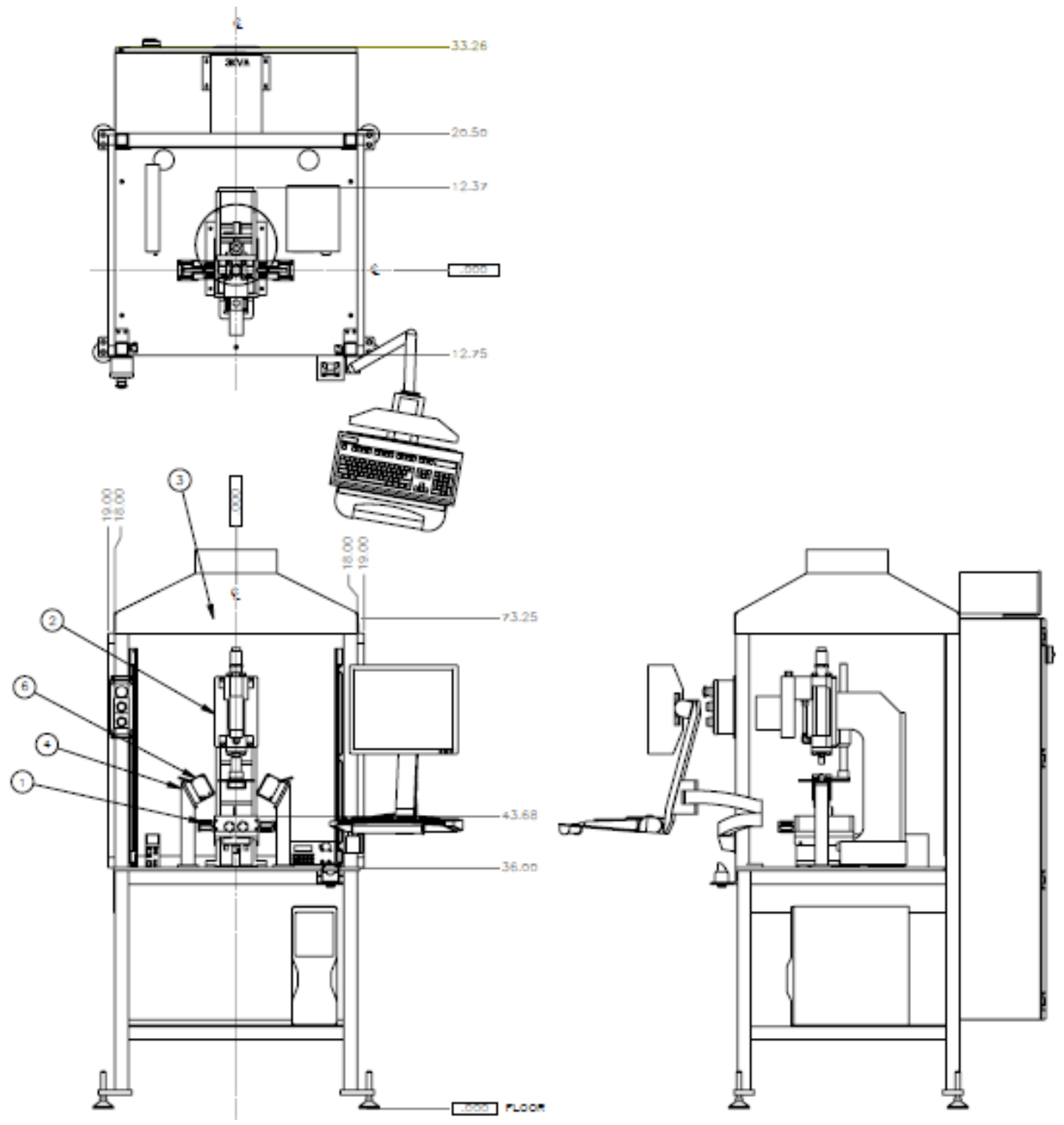

Figure 5.2 SQCS frame

\subsection{Test fixture}

The fuel cell test fixture is shown in Figure 5.3. This fixture is comprised of components which are

- Accurately locate and maintain the fuel cell in position.

- Provide sealing mechanisms to provide leak free connections between the fuel cell and the leak test equipment. 
- Provide a means of accurately applying static and dynamic compression force to the fuel cell stack.

- Provide mounting locations for height sensors to measure fuel cell compression.

- Provide for location and application of an electrical interface to monitor the fuel cell performance.

- Provide for heating/cooling and temperature monitor of the fuel cell assembly.

- Provide a means to torque clamping bolts while the stack is compressed in the fixture.

- Provide change tooling as necessary to support testing of fuel cell stacks with different number of cells.

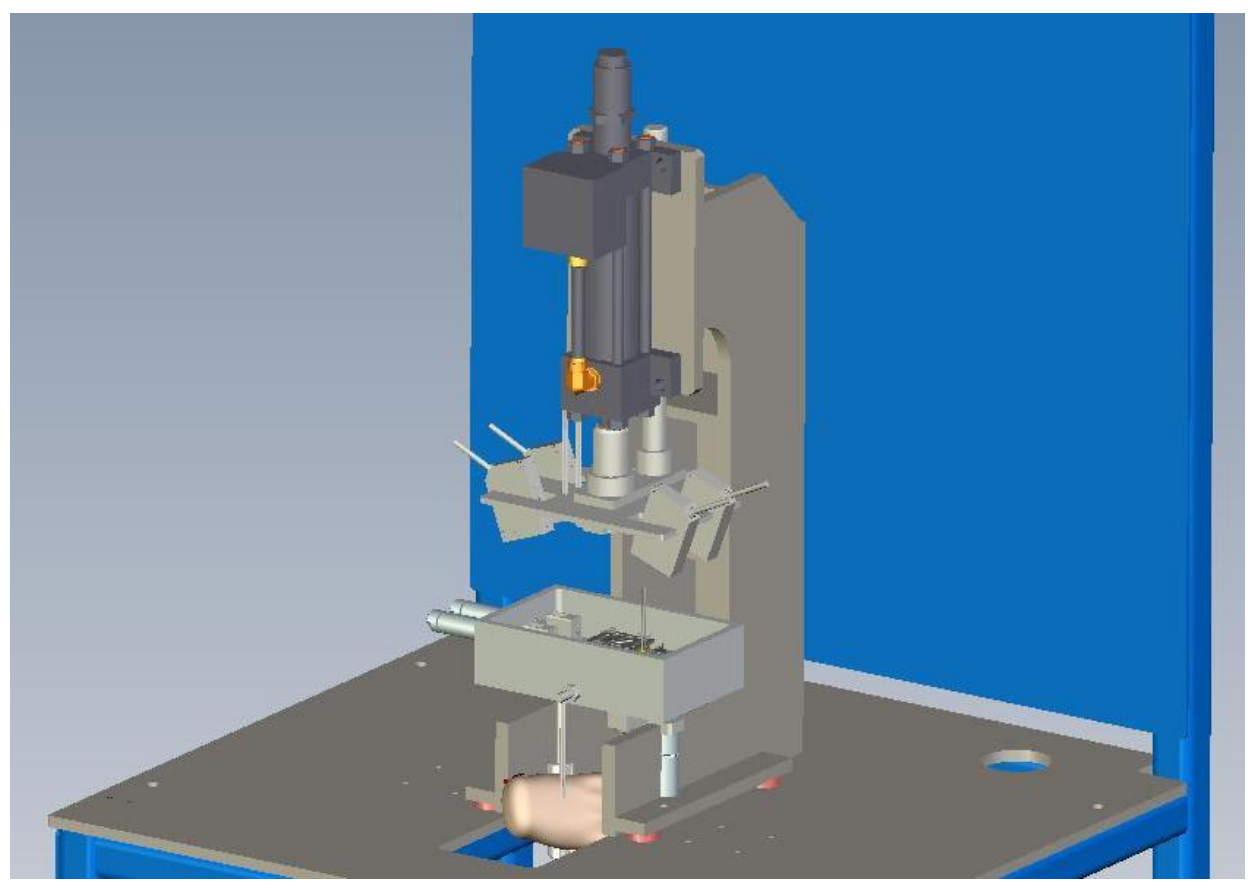




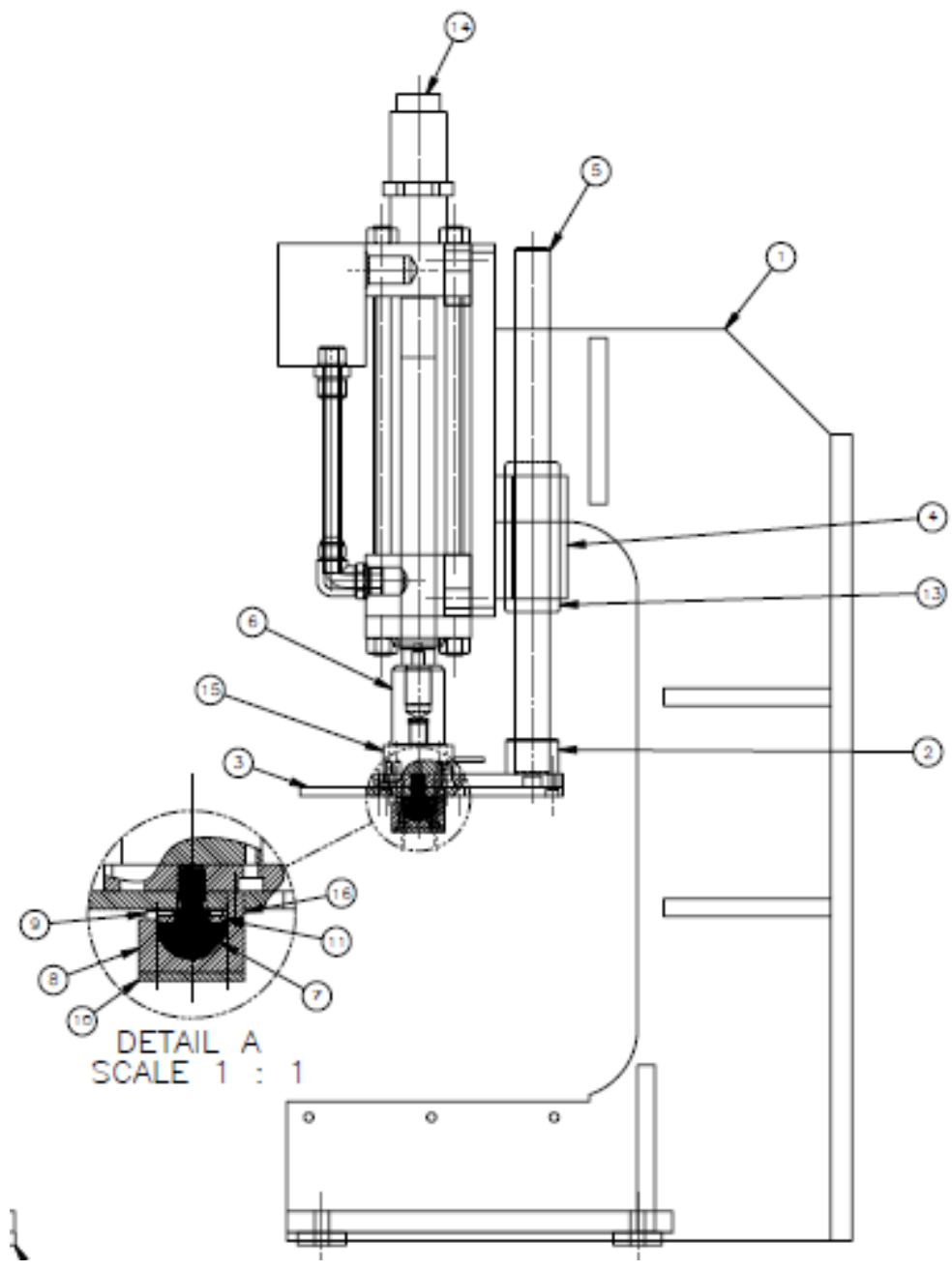




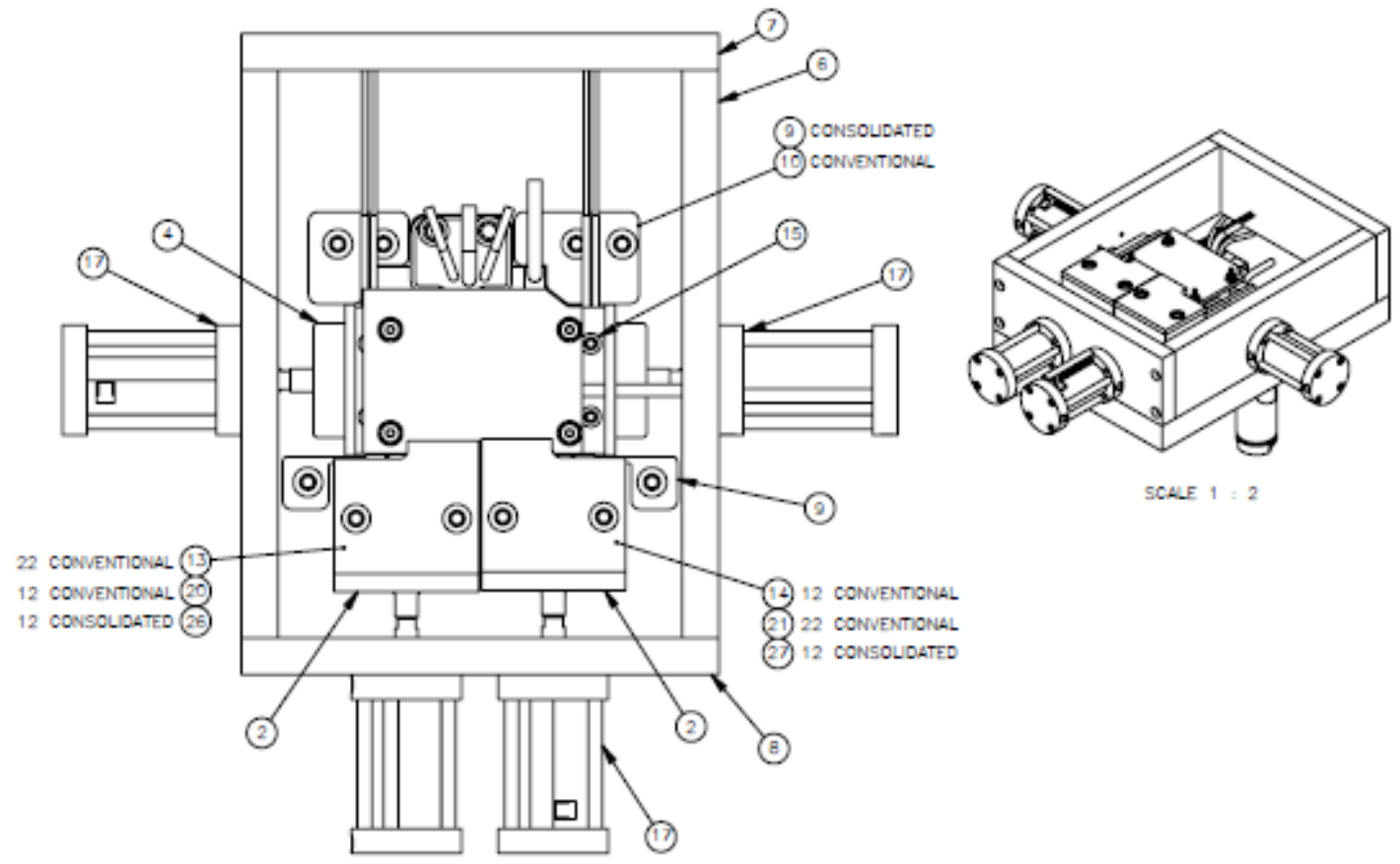

Figure 5.3 Fuel cell test fixture 


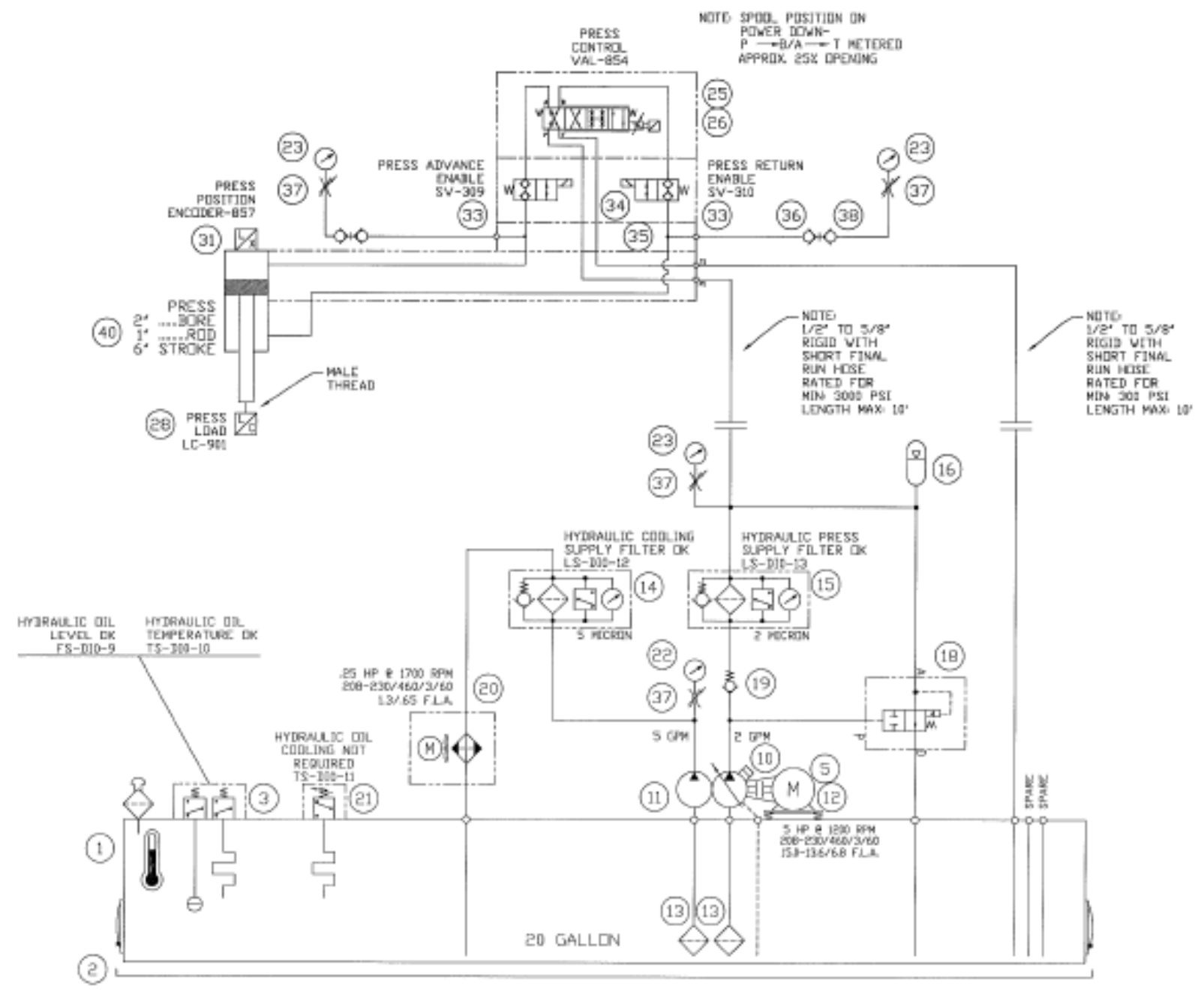

Figure 5.4 Hydraulic design 


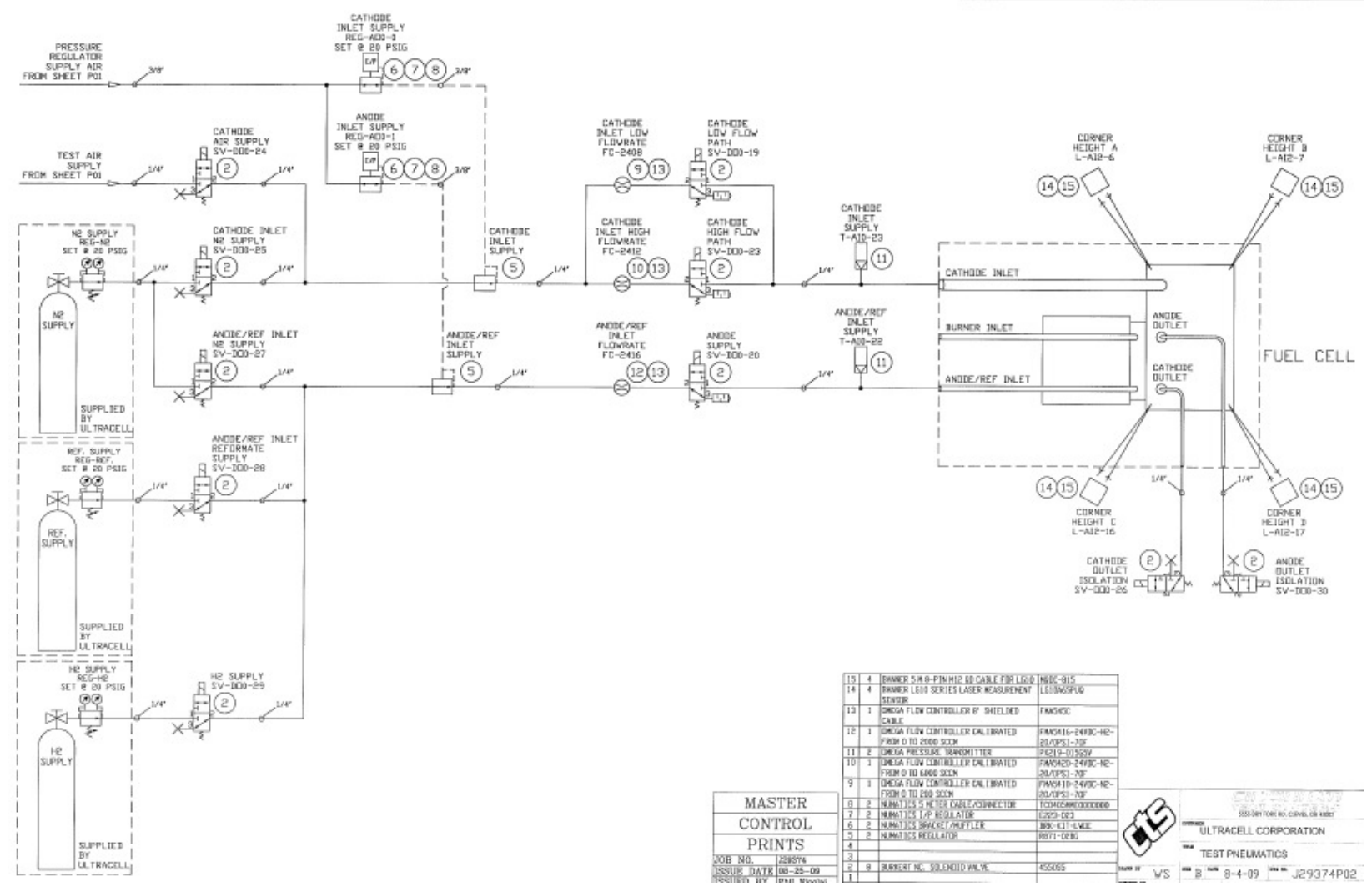

Figure 5.5 Pneumatic design

The hydraulic and pneumatic designs are shown in Figure 5.4 and 5.5. The whole SQCS is shown in Figure 5.6, and the detail of the test fixture is shown in Figure 5.7. 

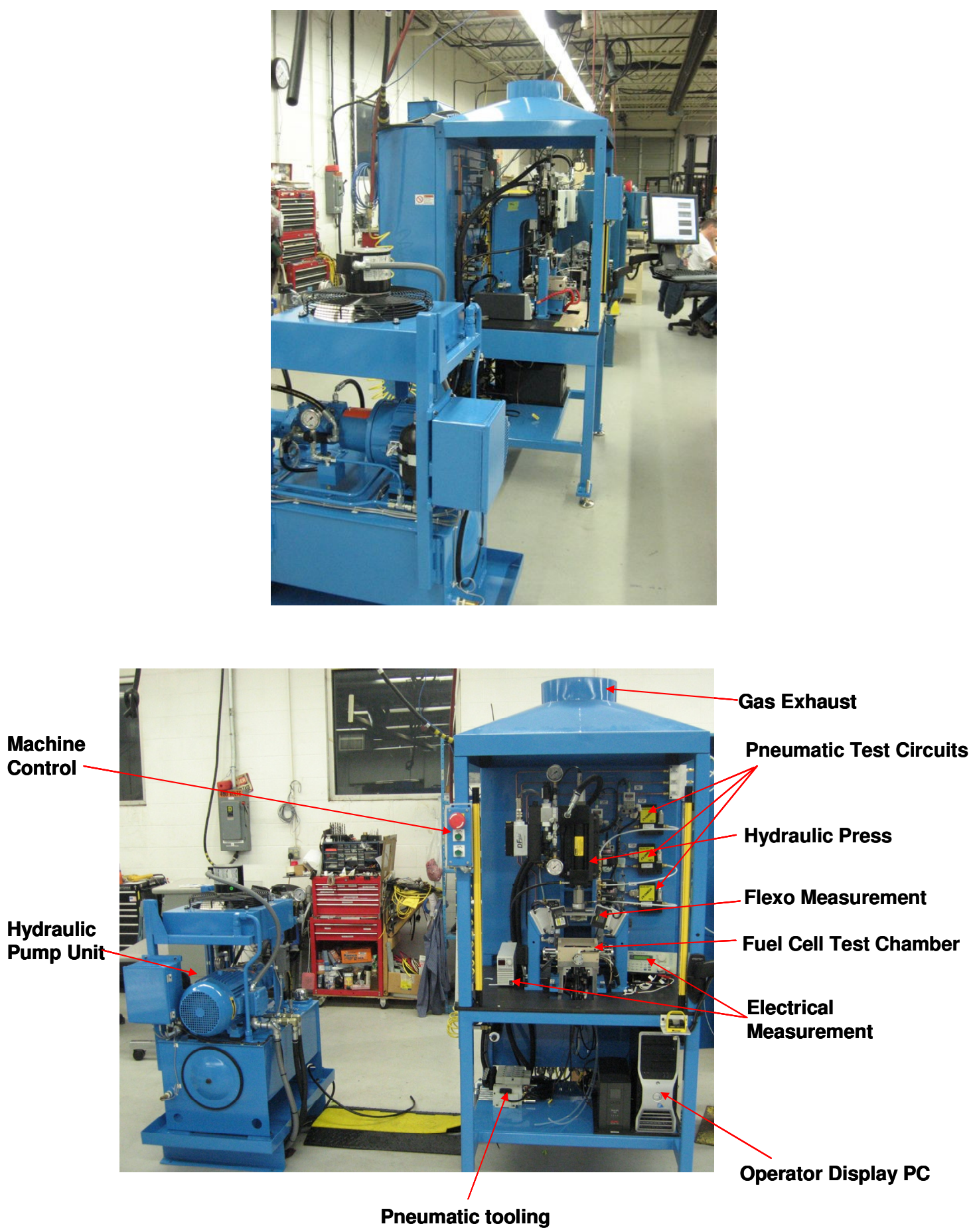

Figure 5.6 SQCS prototype 

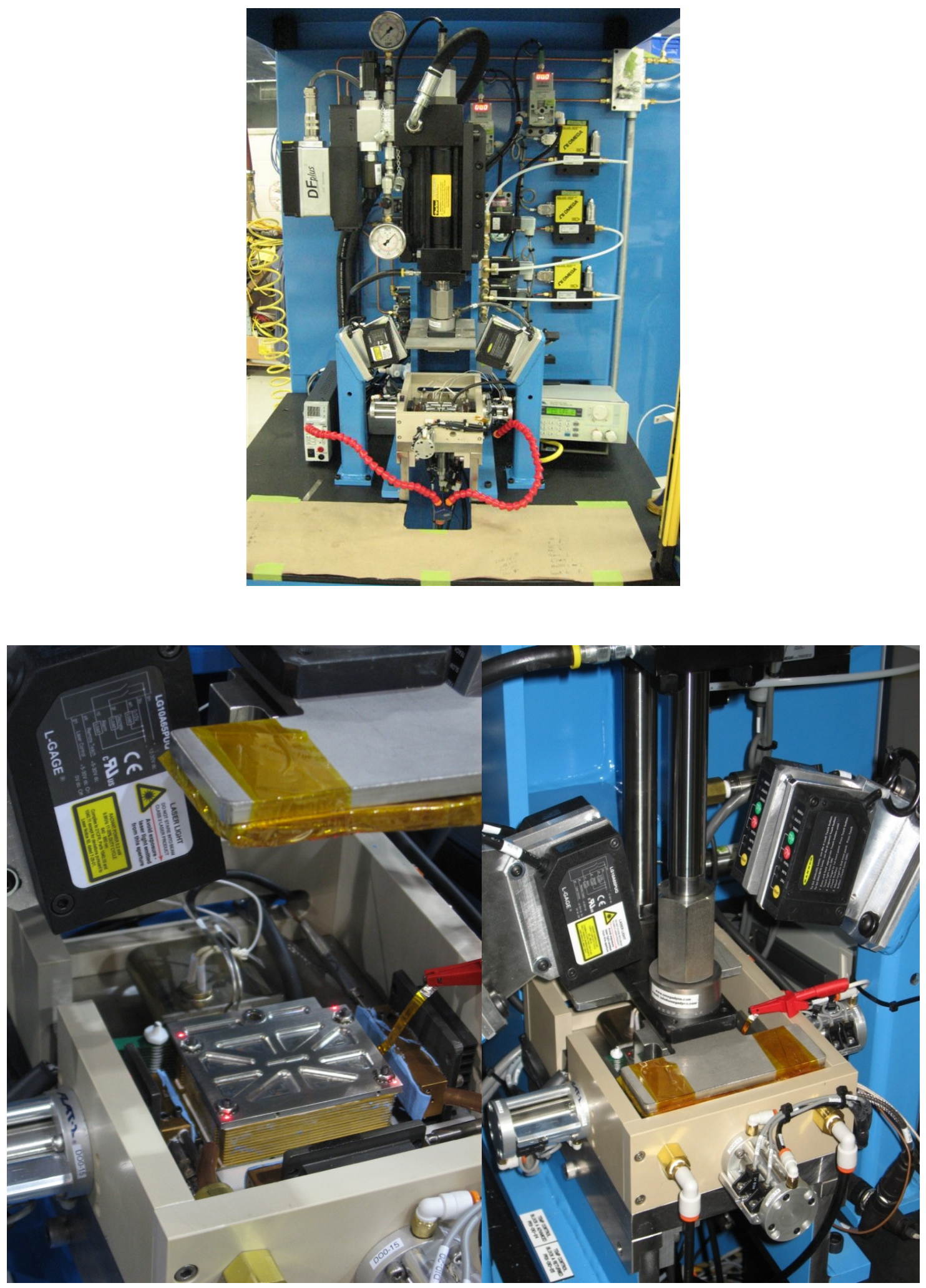

Figure 5.7 SQCS prototype: test fixture 


\subsection{Instrument and software}

A programmable automation controller (PAC), CompactRIO, was chosen to control and acquire data for the leak test suite and prototype. LabView application on PC is used for data display, storage, and analysis. CompactRIO is a low-cost reconfigurable control and acquisition system designed for applications that require high performance and reliability. We have developed graphic user interface for the leak test suite, established software architecture including data communication between human machine interface and CompactRIO. The IO scan structure residing on field-programmable gate array (FPGA) was developed. The main state machine codes were created. Test routines were developed. The routines included sealing and unsealing, pressure decay test, crossover current test, open circuit voltage decay test, Flexo-Tiltometer test, performance test, and fault handling.

The human machine interface (HMI) includes nine major screens:

(1) The main screen will be displayed when the application is started. From this screen the operator can log in, monitor the status of the peripheral devices and change the operating mode (Figure 5.8).

(2) The setup screen is used to enter the parameter files for the tests (Figure 5.9). The files are entered in Excel spreadsheets. The parameters are divided into eight groups: general parameters, break-in parameters, performance parameters, alarms, temperature controller, report, summary, and notes. When the screen is first accessed, the operator can select and load desired parameter file. When changes are made to any parameter, the operator can save the file for future use.

(3) The prototype can be operated manually and automatically. When in manual mode, the operator can manually control hydraulic press, gas, pneumatic, temperature, crossover current, and stack height.

(4) Diagnostic screen displays inputs and outputs. 
(5) Test screen displays test results (Figure 5.10, 5.11, and 5.12).

(6) Notes screen is provided to allow the operator to enter notes that can be referred to in the future.

(7) Faults screen displays a list of faults as they occur.

(8) Calibration screen is used to scale the various input and output functions.

(9) System screen displays human machine interface operation and real-time error, which is used for debug during installation. The user control section is used to perform maintenance on the user database and the user access levels.

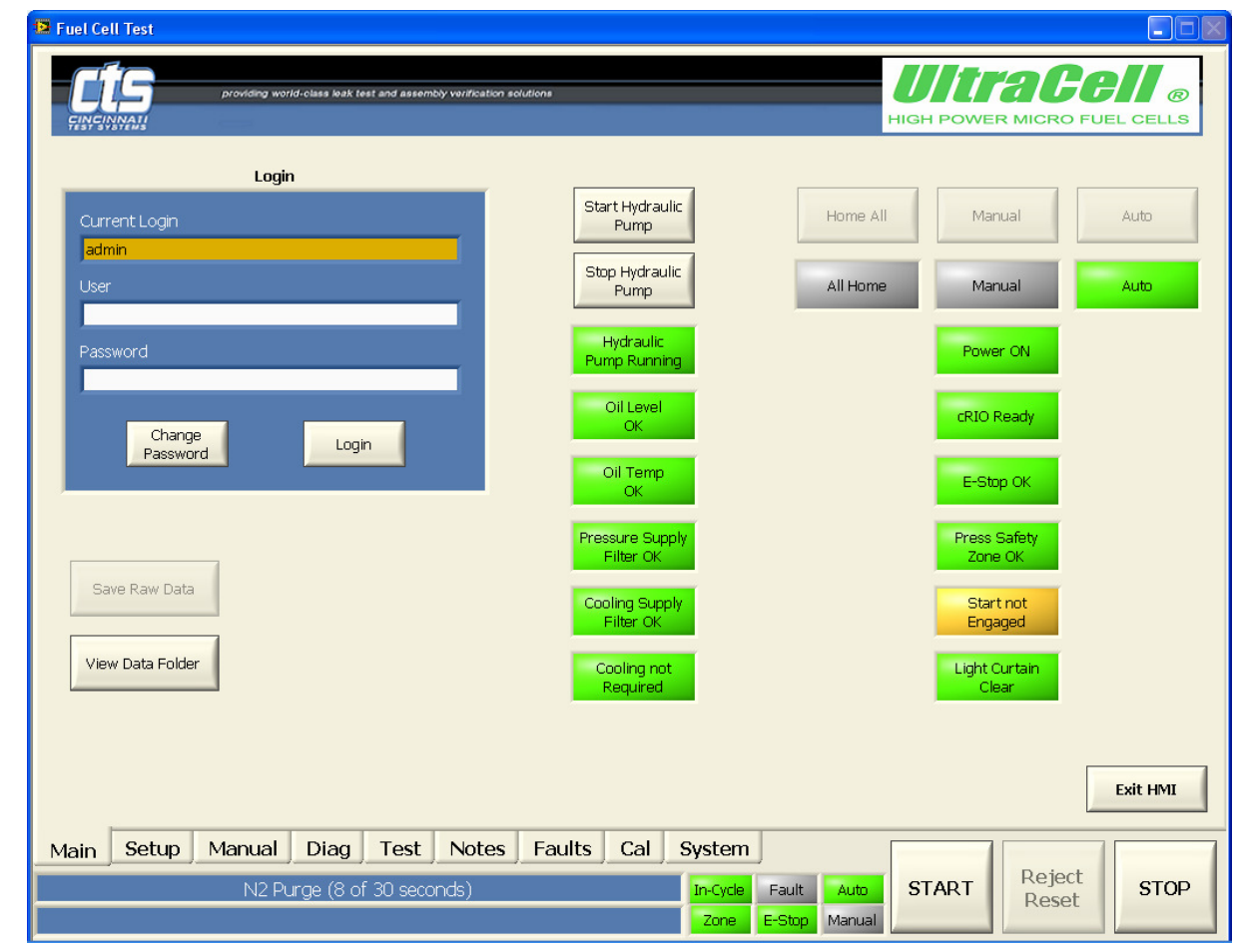

Figure 5.8 Main screen 


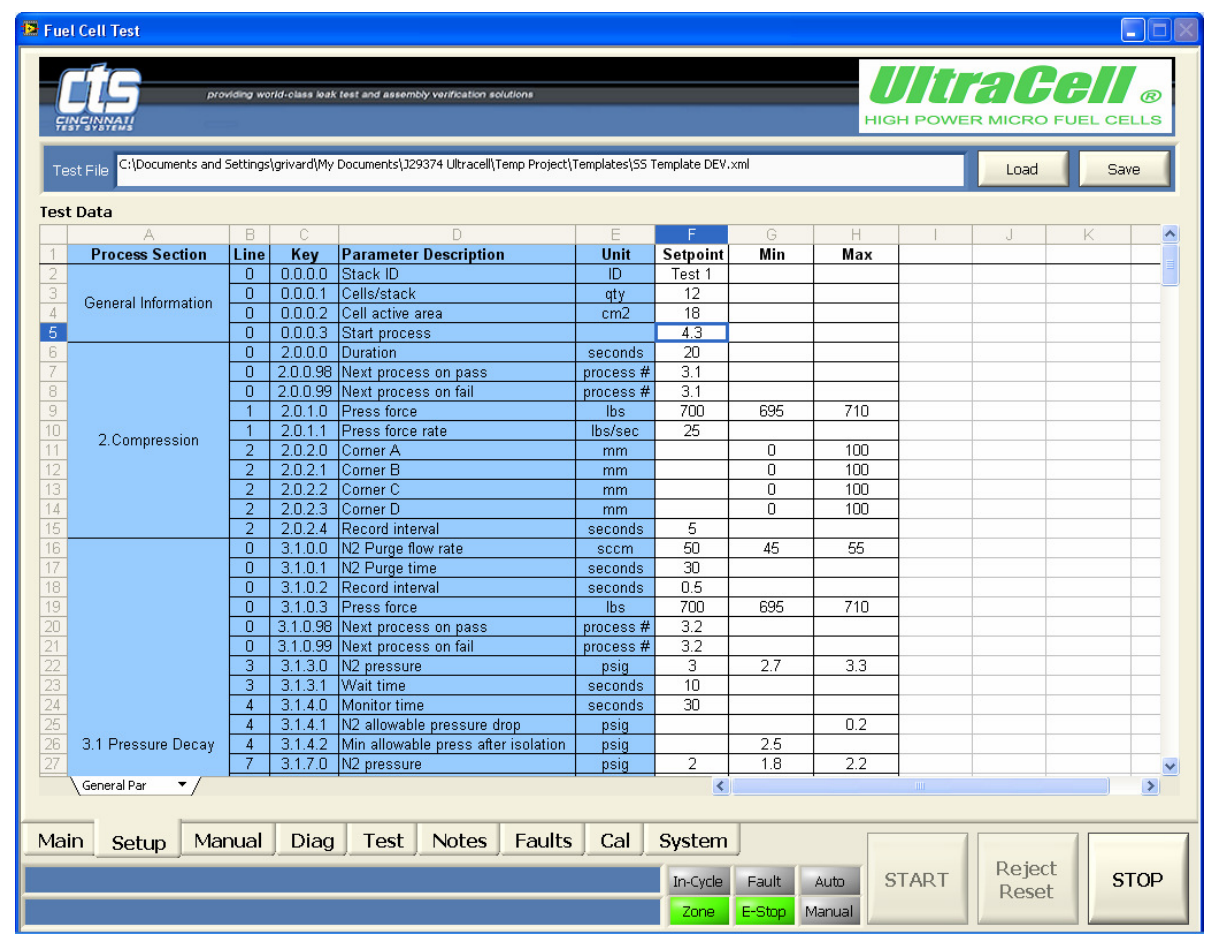

Figure 5.9 Setup screen

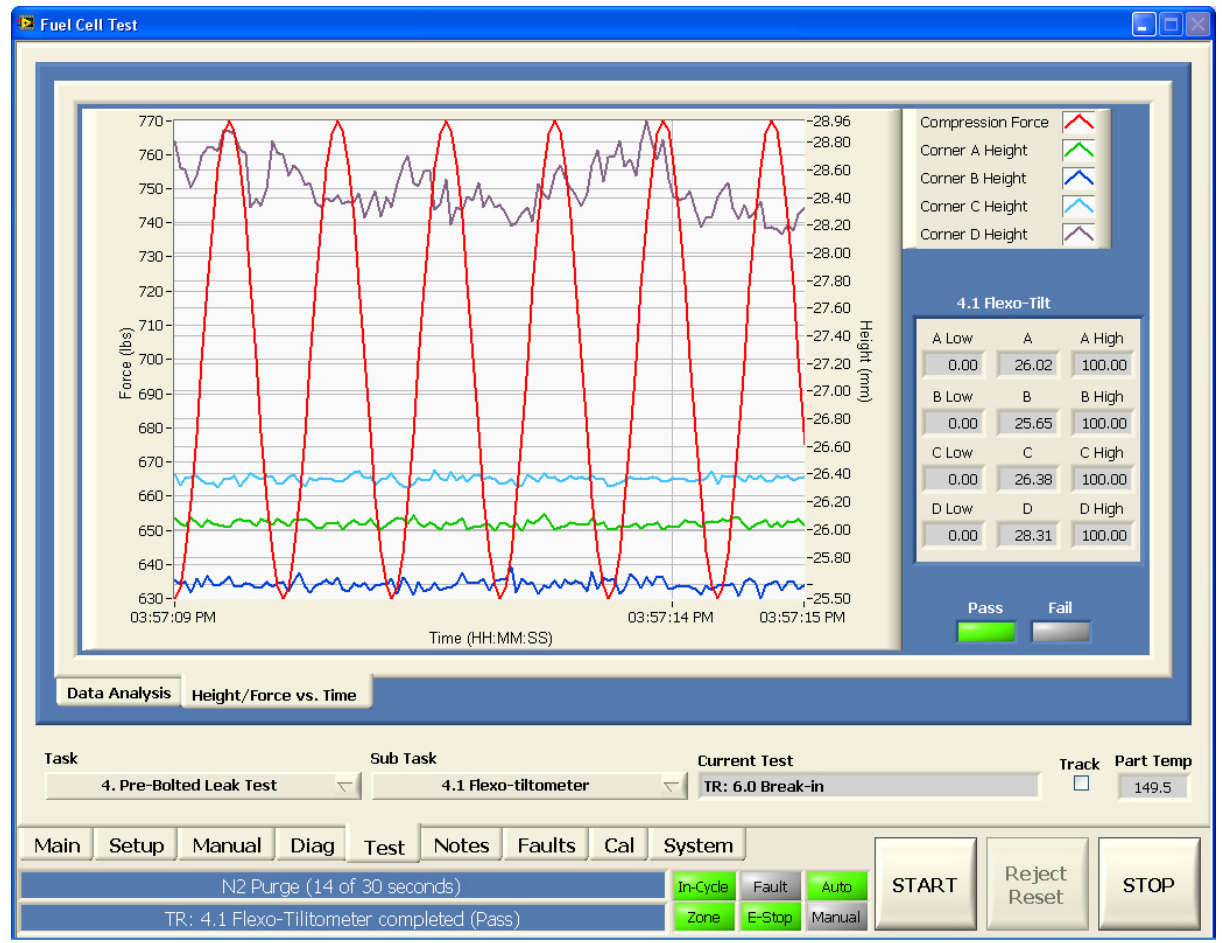

Figure 5.10 Test screen: Flexo-tiltometer test result 


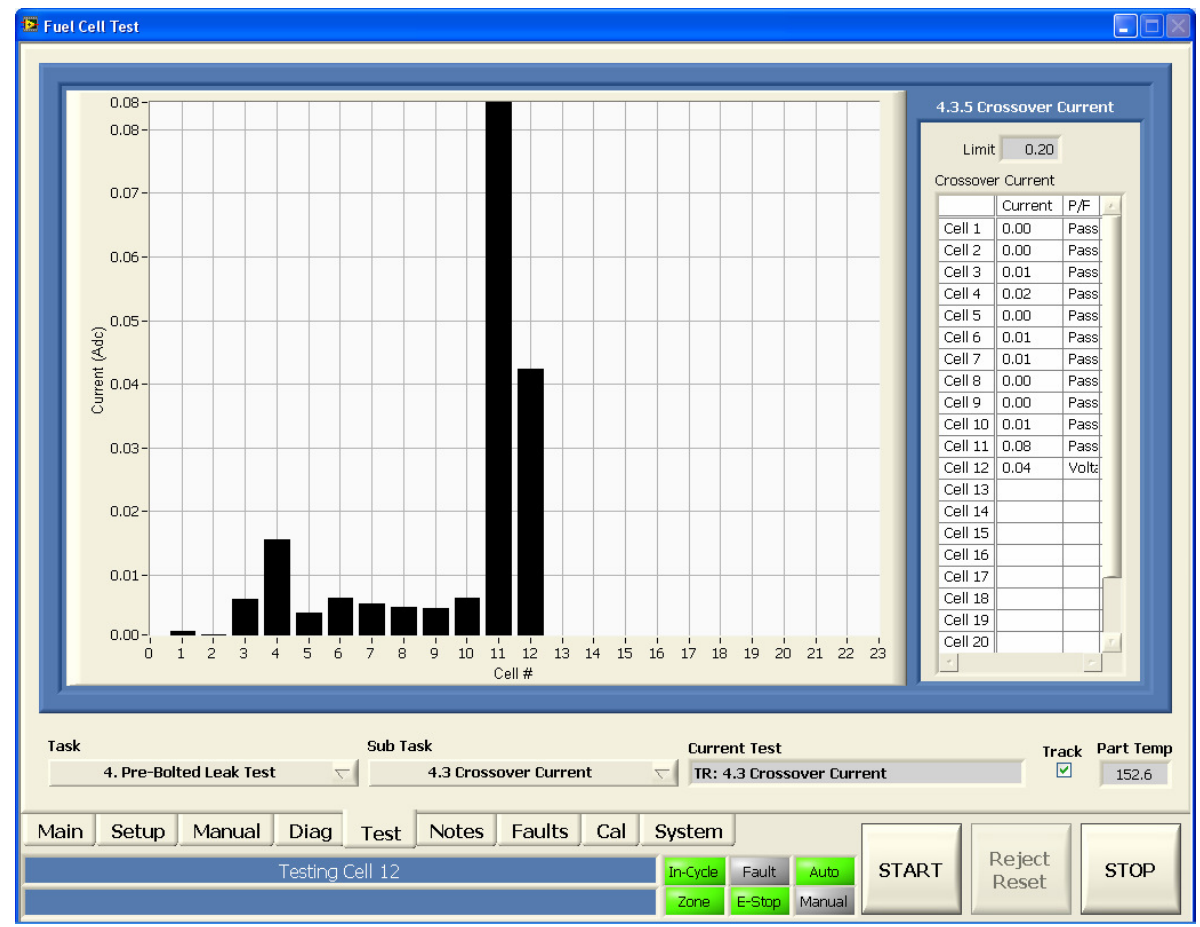

Figure 5.11 Test screen: Crossover current test result

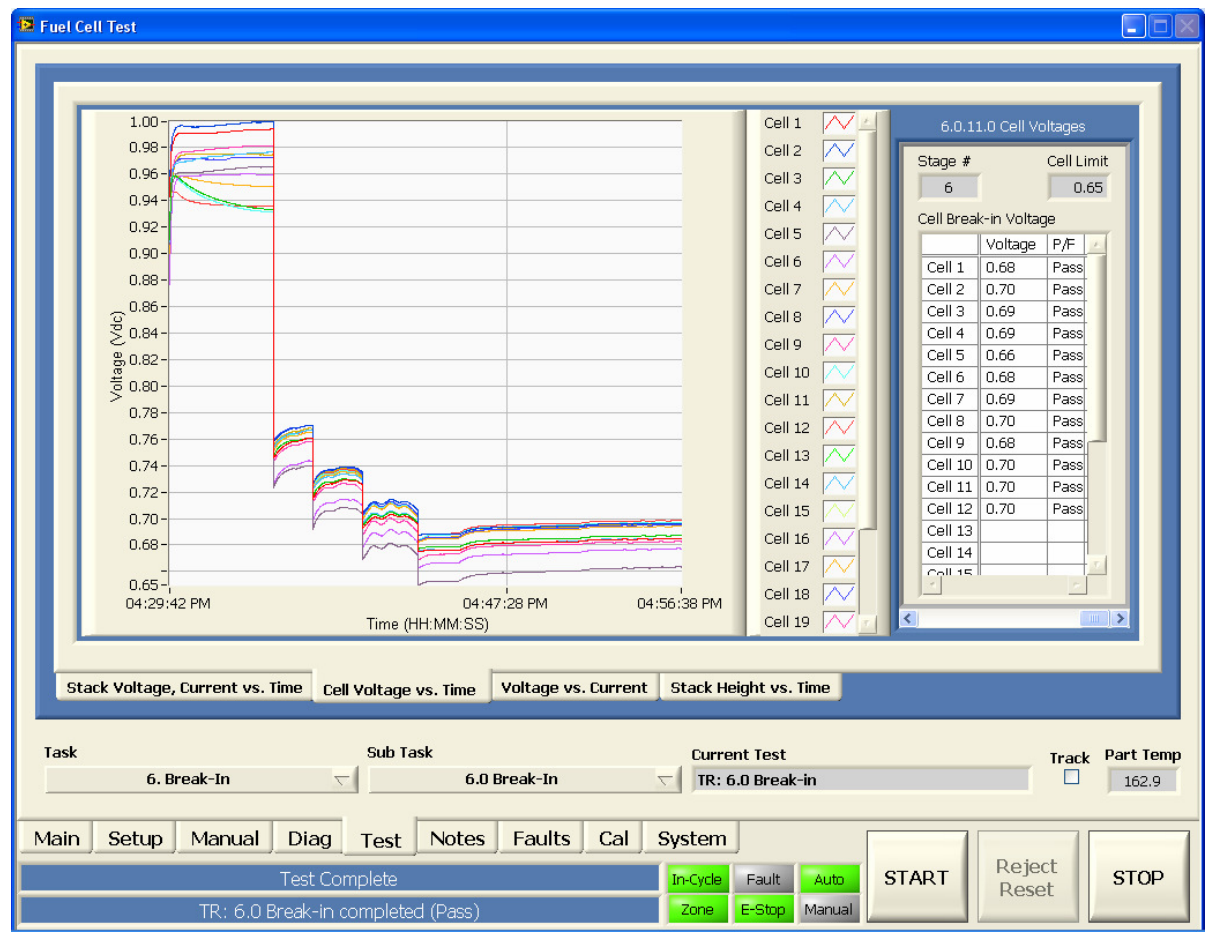

Figure 5.12 Test screen: Break-in test result 


\subsection{Installation}

The SQCS prototype was first installed at UltraCell manufacturing facility in Vandalia, $\mathrm{OH}$. The prototype was tested and evaluated. The results obtained from the prototype were compared with old existing manual test protocols. It was demonstrated that the new instrument can reliably detect individual cell failures. The prototype can performs all manufacturing processes which include inline leak-test, compression, bolting, break-in, and performance test. All these processes except bolting are carried out automatically. The prototype monitors all processes, quickly identifies failures, and provides diagnostic information. Safety features were implemented in the prototype to protect operator. The prototype can be used for both research and manufacturing with simple change in the test protocol. UltraCell personnel at manufacturing facility were trained to operate the prototype. Later, the SQCS was transferred to PNNL for the qualification and development of fuel cell stack dynamic mechanical analysis, which was supposed to be a main focus in Phase II of the project.

\section{Qualification}

The stack quality characterization system was qualified in three steps. The first step is to verify that the SQCS is capable of accurately detecting known leaks in stacks. The second step is to perform durability test on fuel cell stacks made and tested on the SQCS to ensure that the SQCS does not incur any new failure modes. To further validate the SQCS, multiple fuel cell stacks were integrated into fuel cell systems and subjected to a series of acceptance tests.

Twenty-three fuel cell stacks were built and tested on the SQCS. Pressure decay, crossover current, and OCV decay were used to detect leak in stacks. In the Flexo-Tiltometer test, the height changes of a fuel cell stack at four different locations were recorded. The average test times for each leak test are shown in Table 6.1. The total leak test time is 590 seconds. The leak test rate is 6 stack/hour, exceeding the 5 stack/hour target set for Phase I of the project. The leak test results are shown in Table 6.2. This demonstrated that $95 \%$ of leaks can be detected by SQCS. Pressure decay, crossover current and OCV decay tests are based on different mechanisms. These methods characterize fuel cell leaks from different perspectives. The 
sensitivity of these methods is different. Over-all, crossover current and OCV decay is more sensitive than pressure decay. Therefore, some leaks detected by the crossover current and CV decay tests could not be confirmed by the pressure decay test.

Table 6.1 Leak test time

\begin{tabular}{|l|c|}
\hline \multicolumn{1}{|c|}{ Leak Test Process } & $\begin{array}{c}\text { Test Time } \\
(\mathrm{sec})\end{array}$ \\
\hline Pressure decay & 227 \\
Crossover current & 253 \\
OCV decay & 60 \\
Flexo-tiltometer & 50 \\
\hline Total & 590 \\
\hline
\end{tabular}

Table 6.2 Leak Test Results

\begin{tabular}{|l|c|c|}
\hline & YES & NO \\
\hline PD correctly confirms CC or OCV results & 19 & 4 \\
CC correctly detects failure on retest & 15 & 0 \\
OCV correctly detects failure on retest & 15 & 0 \\
CC/OCV correctly detects swap or replacement & 24 & 0 \\
\hline
\end{tabular}

Five stacks were built and tested on the SQCS. These stacks passed the SQCS leak, break-in, and performance tests. Then they were subjected to 30-day life test with one start/stop per day. The stack life test results are shown in Figure 6.1. All stacks completed life test and meet exit criterion, i.e., average cell voltage $0.550 \mathrm{~V}$. One cell in stack 084618-02 failed due to the fuel starvation, and was replaced at $\sim 400 \mathrm{hr}$. However, this type of failure is occasionally observed in stacks, and it was due to the bipolar plate flow field design. The failure should not be attributed the SQCS. Overall, the stack life test demonstrates that the SQCS does not cause new failure modes in stacks. 


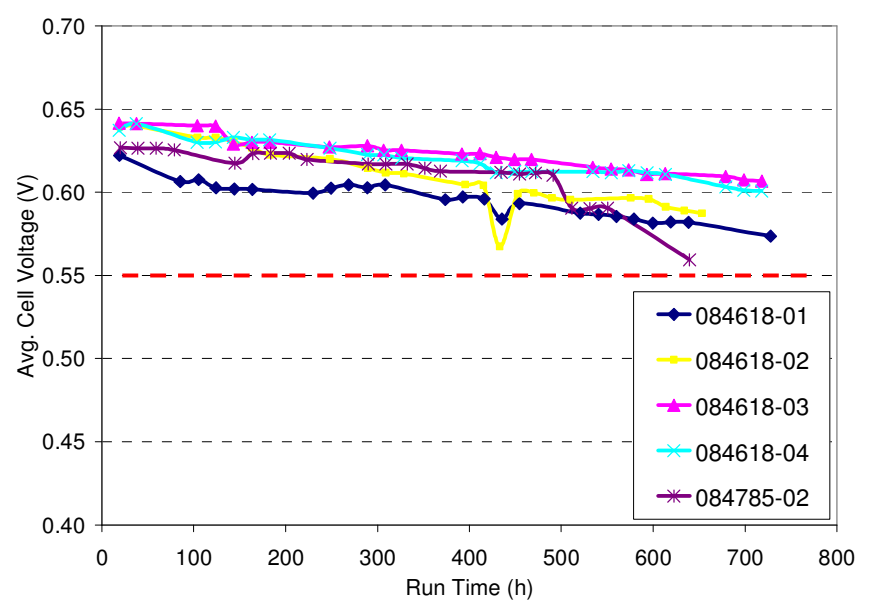

Figure 6.1 Fuel cell stack 30-day life test

Three stacks were built and tested on the SQCS. These stacks passed the SQCS leak, break-in, and performance tests. Then they were integrated into fuel cell systems. The system tests include static/dynamic load (Figure 6.2 and 6.3), cartridge run, $-5{ }^{\circ} \mathrm{C}$ performance, $50{ }^{\circ} \mathrm{C}$ performance, emission, surface temperature, and polarization curve. System 26 and 50 passed all tests. System 45 passed all tests except emission and polarization curve test (Table 6.3). During diagnostics, a stainless steel tube on fuel processor broke off. This indicated there was a bad welding in the fuel line. This might cause fuel leak and result in fuel starvation in fuel cell. Later, an air compressor was found to have a manufacturing defect that caused air leak. The failures in system test are due to the balance of plant component failure and not related to fuel cell stack. The system validation test demonstrates that the SQCS does not cause new failure modes in fuel cell stacks. 


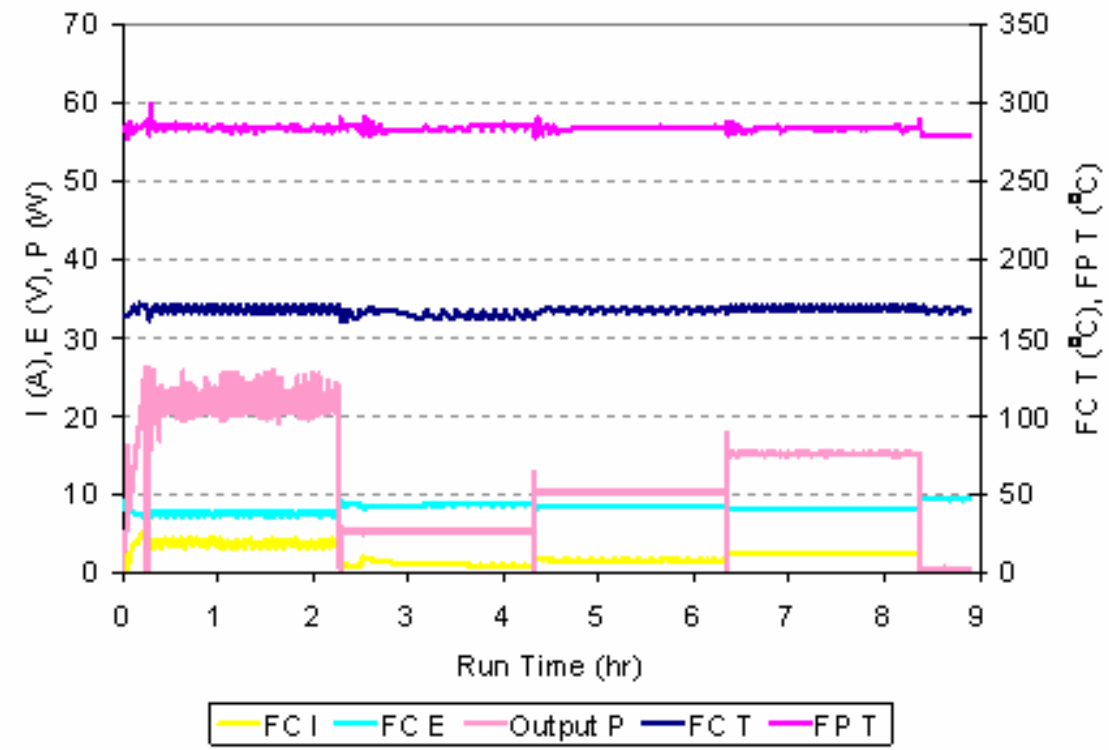

Figure 6.2 Fuel cell system test result at different loads

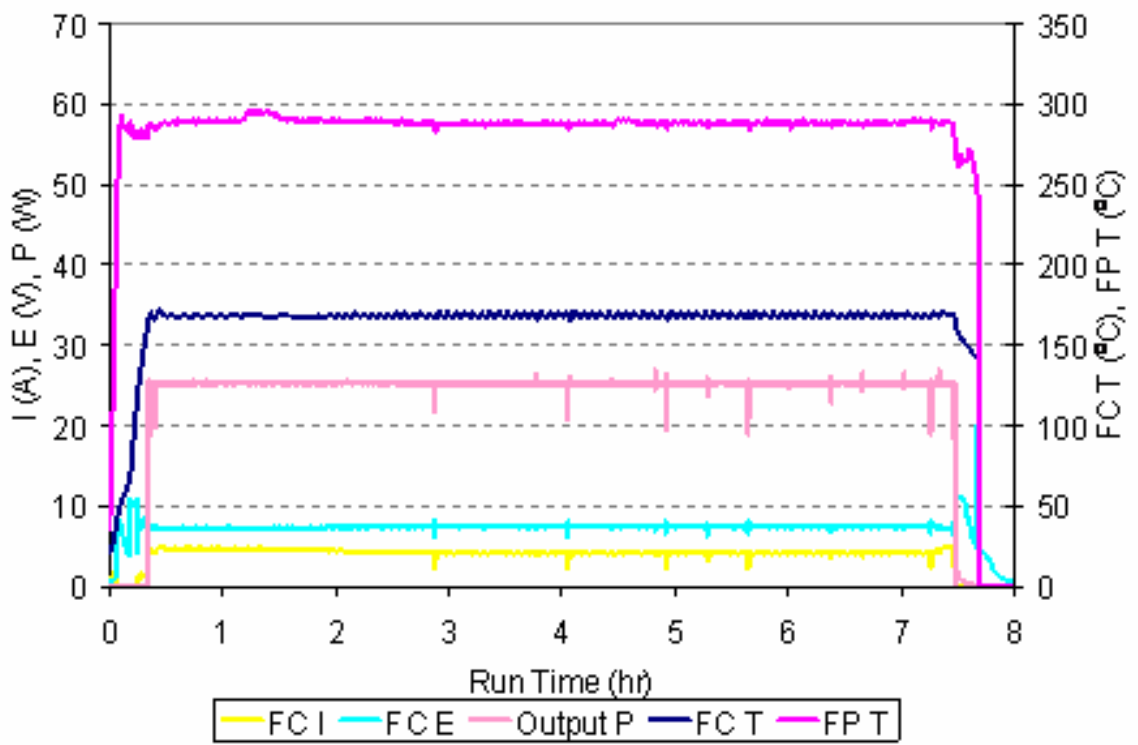

Figure 6.3 Fuel cell system test result at rated power 
Table 6.3 System test results

\begin{tabular}{|c|l|l|l|}
\hline System Tests & 25E1LC0026 & 25ENDY0050 & 25E1LC0045 \\
\hline Static/Dynamic Load & Pass & Pass & Pass \\
\hline Cartridge Run & Pass & Pass & Pass \\
\hline -5C Performance & Pass & Pass & Pass \\
\hline 50C Performance & Pass & Pass & Pass \\
\hline Emission & Pass & Pass & Fail \\
\hline Surface Temperature & Pass & Pass & Pass \\
\hline Polarization Curve & Pass & Pass & Fail \\
\hline
\end{tabular}

